\title{
Mário Issa
}

\section{VARIÁVEIS PROGNÓSTICAS DE EVOLUÇÃO HOSPITALAR E NO LONGO PRAZO DE PACIENTES PORTADORES DE DISSECÇÃO CRÔNICA DE AORTA TIPO A DE STANFORD E ANEURISMA DE AORTA ASCENDENTE, SUBMETIDOS A PROCEDIMENTO CIRÚRGICO.}

\section{VERSÃO CORRIGIDA}

Tese Apresentada ao Instituto Dante Pazzanese de Cardiologia, Entidade Associada à Faculdade de Medicina da Universidade de São Paulo, para obtenção do Título Doutor em Medicina.

Área de Concentração: Medicina / Tecnologia e Intervenção em Cardiologia

Orientador: Prof. Dr. Álvaro Avezum Júnior

\author{
São Paulo
}


Dados Internacionais de Catalogação na Publicação (CIP)

Preparada pela Biblioteca do Instituto Dante Pazzanese de Cardiologia

Creprodução autorizada pelo autor

Issa, Mário

Variáveis prognósticas de evolução hospitalar e no prazo longo de pacientes portadores de dissecção crônica de aorta tipo A de Stanford e aneurisma de aorta ascendente, submetidos a procedimento cirúrgico / Mário Issa.-São Paulo, 2012.

Tese(doutorado)--Instituto Dante Pazzanese de Cardiologia, Universidade de São Paulo.

Área de Concentração: Medicina, Tecnologia e Intervenção em Cardiologia.

Orientador: Prof. Dr. Álvaro Avezum

Descritores: 1. DOENÇAS DA AORTA. 2. ANEURISMA DA AORTA. 3. MORTALIDADE. 4. ANÁLISE MULTIVARIADA. 5. CIRURGIA CARDÍACA. 6. DISSECÇÃO. 7. FATORES DE RISCO. 


\section{DEDICATÓRIA}

Dedico esta tese ao meu pai, Maroun Y. Issa, mesmo tendo nos deixado há quatorze anos, sua marcante presença, seus imutáveis valores e seu carinho nos deixou profundas marcas e inabalável confiança na educação adquirida. Nossa referência.

À minha mãe, Samira Issa, o real e verdadeiro pilar de nossa família, com incansável dedicação, amor e sabedoria. Muitas vezes abdicando de sua própria vida para o bem de toda a família.

À minha irmã Juliana Issa, precocemente requisitada por Deus, mas que ao longo do seu sofrimento durante a enfermidade, jamais teve sua fé abalada. Mesmo acamada, preocupava-se com suas responsabilidades profissionais de advogada, sobretudo com as causas familiares.

À minha esposa, Jaqueline Scholz Issa, cujo apoio incondicional e irrestrito amor em todos os momentos de nossa longa convivência, foi fundamental para meu crescimento.

Aos meus filhos, Mário Scholz Issa e Marcelo Scholz Issa, cujo amor é infinito, minha razão de viver e de enfrentar com coragem qualquer dificuldade ou sacrifício, e sobretudo o dever de dar o exemplo para uma vida íntegra, justa e honesta.

Aos meus irmãos Massoud Issa Sobrinho, Jusiana Issa e Edgar Issa, não apenas pela eterna união e força compartilhada nos momentos mais difíceis, mas também por proporcionar o bem estar e alegria ao longo de nossa caminhada.

Às minhas cunhadas, Fabiana Issa e Milene Issa, que assumiram lugar de grande importância em nossos corações.

Aos meus afilhados, Gustavo N. Issa, Maria Eduarda C. Issa, Jacqueline Scholz Berça e Andressa Scholz Berça tão queridos e amados quanto os filhos. 
Aos meus amigos Antonio Flávio S. de Almeida, Eliana Bittar e Márcia K. Sonoda, parceiros de longa data e de todas as horas. Com incansável disposição para ajudar a quem necessite. 


\section{AGRADECIMENTOS}

Primeiramente, ao meu orientador, Prof. Dr. Álvaro Avezum, médico da mais alta competência, reconhecido mundialmente, respeitado por todos colegas de profissão, sem o qual este estudo jamais teria nascido e concluído desta forma. Seu conhecimento, experiência e dedicação foram imprescindíveis para o desfecho desta tese de doutorado e a gratidão será eterna.

Ao residente da cirurgia cardiovascular, Daniel Dantas, que mesmo com grande carga de trabalho imposta pela especialidade que abraçou, foi fundamental na participação deste trabalho.

À estatística Roberta de Souza, pela sua dedicação e competência em calcular dados e transformar informações médicas em resultados capazes de facilitar e melhorar nossa prática médica.

Aos funcionários do Instituto Dante Pazzanese de Cardiologia, à Secretária da Divisão de Epidemiologia Translacional Simone Batista da Cruz, ao Analista de Sistemas Wellington Cícero de Carvalho e à Chefe do SAME Helena das Dores Alfenas, profissionais cuja boa vontade foi fundamental em todas as fases deste trabalho. 
"O valor das coisas não está no tempo que elas duram, mas na intensidade com que acontecem. Por isso existem momentos inesquecíveis, coisas inexplicáveis e pessoas incomparáveis".

\section{Fernando Pessoa}


SUMÁRIO

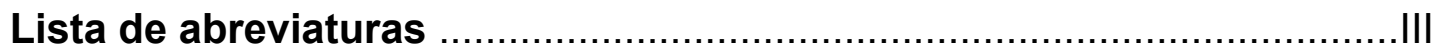

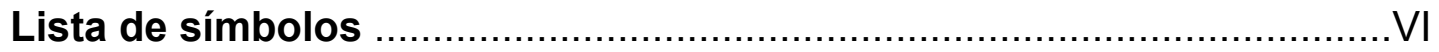

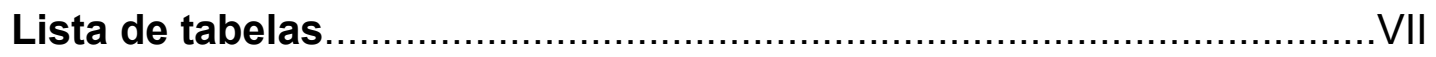

Lista de gráficos ……..................................................................

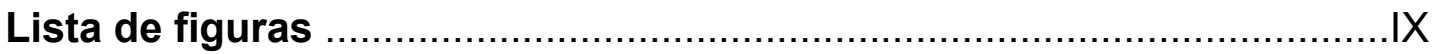

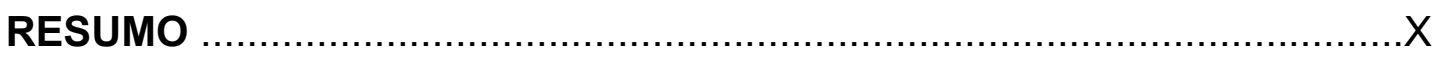

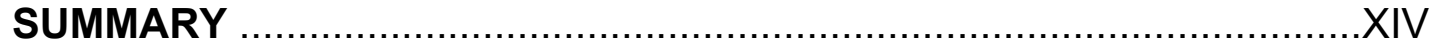

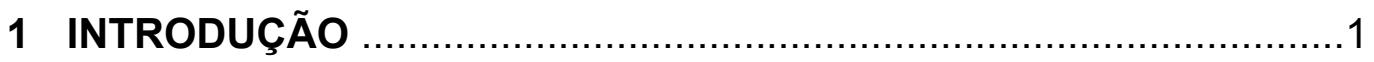

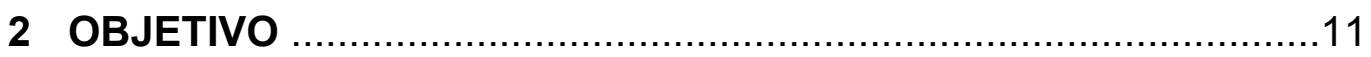

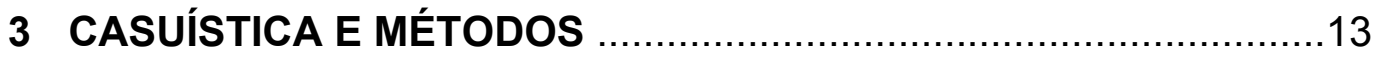

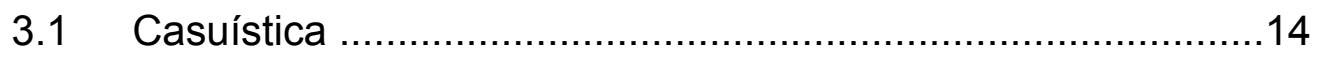

3.1.1 Delineamento da pesquisa........................................14

3.1.2 População do estudo.................................................14

3.1.3 Estratégia de recrutamento.........................................14

3.1.4 Elegibilidade (critérios de inclusão e de exclusão).......14

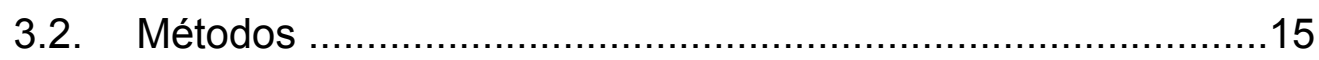

3.2.1 Definições de desfechos clínicos..................................15

3.2.2 Definições dos tipos de cirurgias..................................15

3.2.3 Classificação das dissecções de aorta.........................17

3.2.4 Apresentações clínicas das dissecções de aorta..........18

3.2.5 Variáveis prognósticas avaliadas..................................19

3.2.6 Cálculo de tamanho de amostra...................................20

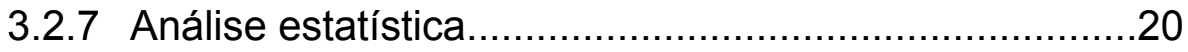

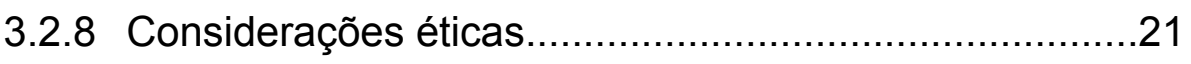

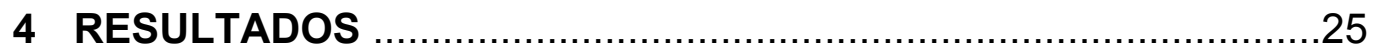

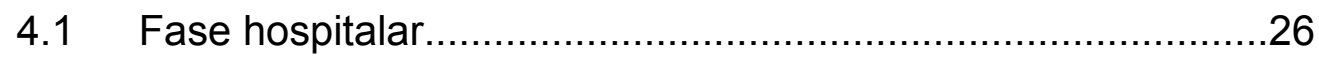




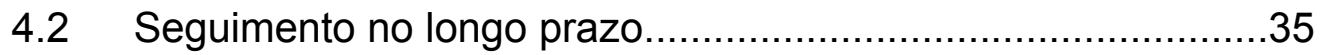

4.3 Análises exploratórias no longo prazo....................................39

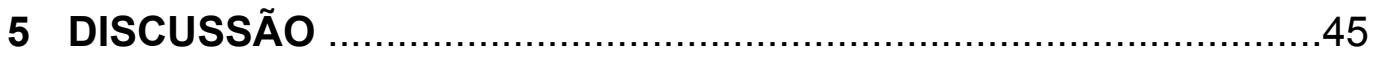

5.1 Variáveis associadas ao óbito hospitalar...............................50

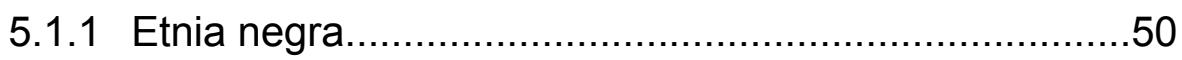

5.1.2 Cirurgia de Revascularização do Miocárdio ................52

5.1.3 Operação de Cabrol ...................................................52

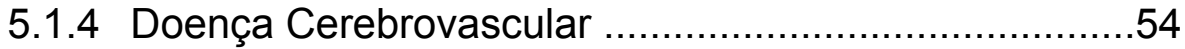

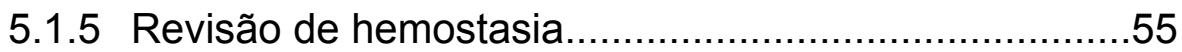

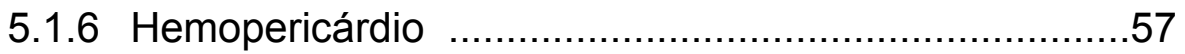

5.1.7 Tempo de circulação extra-corpórea.............................58

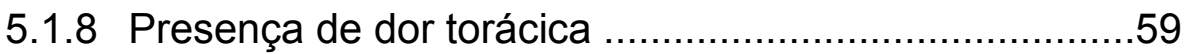

5.2 Variáveis associadas ao desfecho clínico composto................60

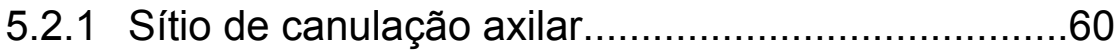

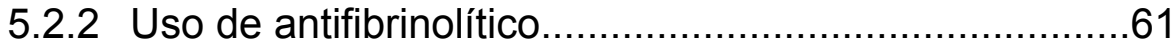

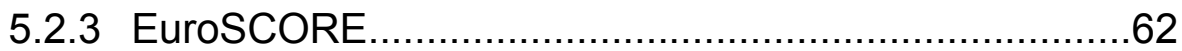

5.2.4 Tempo de circulação extracorpórea ………...............63

5.2.5 Complicação Renal...................................................63

5.2.6 Complicação Pulmonar................................................64

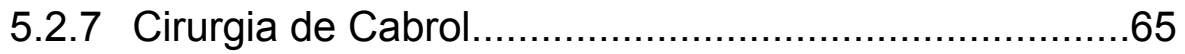

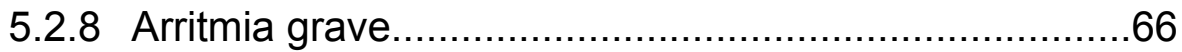

5.3 Variáveis associadas ao óbito no longo prazo........................67

5.3.1 Doença arterial obstrutiva periférica prévia..................67

5.3.2 Uso de estatina na alta hospitalar.................................68

5.3.3 Síndrome de Marfan....................................................69

5.3.4 Acidente Vascular Cerebral Prévio...............................70

5.3.5 Sangramento nas primeiras 24 horas..........................71

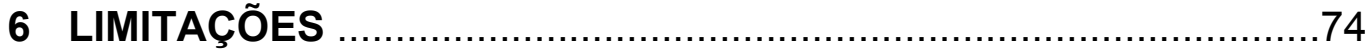

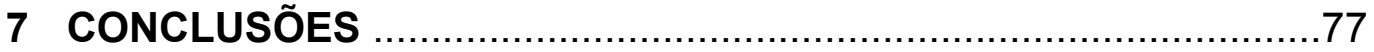

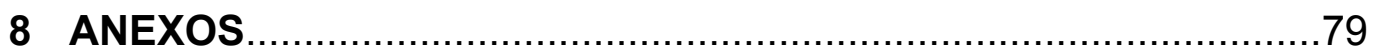

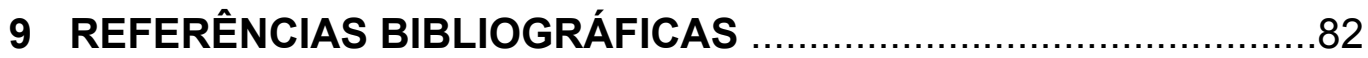




\section{LISTA DE ABREVIATURAS}

EUA : Estados Unidos da América

SIDA : Síndrome da Imunodeficiência Adquirida

IDPC : Instituto Dante Pazzanese de Cardiologia

Rx Tórax : Radiografia de tórax

CEC : Circulação Extra-Corpórea

TC : Tomografia Computadorizada

RNM : Ressonância Nuclear Magnética

Kg : Quilograma

CF : Classe Funcional

DAOP : Doença Arterial Obstrutiva Periférica

AVC : Acidente Vascular Cerebral

IRA : Insuficiência Renal Aguda

IRC : Insuficiência Renal Crônica

HAS : Hipertensão Arterial Sistêmica

PAS : Pressão Arterial Sistólica

PAD : Pressão Arterial Diastólica

FEVE : Fração de Ejeção do Ventrículo Esquerdo

VE: Ventrículo Esquerdo

CIV : Comunicação Interventricular

CoAo : Coarctação da Aorta 
VAo : Valva Aórtica

IAo : Insuficiência Aórtica

EAo : Estenose Aórtica

TBC : Tronco Braquiocefálico

BCP : Broncopneumonia

ITU : Infecção do Trato Urinário

VM : Ventilação Mecânica

TEP : Tromboembolismo Pulmonar

SDRA : Síndrome do Desconforto Respiratório do Adulto

FA : Fibrilação Atrial

FV : Fibrilação Ventricular

TV : Taquicardia Ventricular

BAVT : Bloqueio Atrioventricular Total

TPSV : Taquicardia Supraventricular

MS : Membro Superior

MI : Membro Inferior

FMO: Falência de Múltiplos Órgãos

IC : Insuficiência Cardíaca

UTI : Unidade de Terapia Intensiva

IECA : Inibidores da Enzima Conversora da Angiotensina

BRA : Bloqueadores dos Receptores da Angiotensina

VAB : Valva Aórtica Bicúspide 
MMPs : Metaloproteinases

AAA : Aneurisma de Aorta Abdominal

RC : Razão de Chance

IC: Intervalo de Confiança

IRAD: International Registry of Acute Aortic Dissections (Registro Internacional de Dissecções Agudas de Aorta ) 
LISTA DE SÍMBOLOS

\begin{tabular}{ll}
$>$ & maior \\
$\mathbf{2}$ & menor \\
$\mathbf{S}$ & maior ou igual \\
$\mathbf{\pm}$ & menor ou igual \\
$\mathbf{c m}$ & mais ou menos \\
$\mathbf{m m}$ & centímetro \\
$\mathbf{d l}$ & milímetro \\
$\mathbf{R \$}$ & decilitro \\
$\mathbf{K g}$ & reais \\
$\mathbf{M}$ & quilogramas \\
$\mathbf{N}$ & metro ao quadrado \\
$\mathbf{m g}$ & número \\
& miligramas \\
\hline
\end{tabular}




\section{LISTA DE TABELAS}

Tabela 1. Fatores demográficos e pré-operatórios

Tabela 2. Fatores demográficos e pré-operatórios a óbito hospitalar

Tabela 3. Fatores intra e pós-operatórios e óbito hospitalar

Tabela 4. Fatores pré-operatórios e desfecho clínico composto

Tabela 5. Fatores intra e pós-operatório e desfechos clínicos compostos

Tabela 6. Modelo logístico para óbito hospitalar

Tabela 7. Modelo logístico para óbito hospitalar ajustado para sexo e idade

Tabela 8. Modelo logístico para desfecho clínico composto

Tabela 9. Modelo logístico para desfecho clínico composto ajustado para sexo e idade

Tabela 10. Fatores demográficos e pré-operatórios para óbito tardio

Tabela 11. Fatores intra e pós-operatórios para óbito tardio

Tabela 12. Modelo de Regressão de Cox para óbito tardio

Tabela 13. Modelo de Regressão de Cox ajustado para sexo e idade 


\section{LISTA DE GRÁFICOS}

Gráfico 1. Curva de sobrevida com seguimento médio de 7 anos

Gráfico 2. Curva de sobrevida em pacientes com sangramento aumentado nas primeiras 24 horas

Gráfico 3. Curvas de sobrevida dos pacientes com aneurisma da aorta e dissecção crônica de aorta tipo A de Stanford

Gráfico 4. Curvas de sobrevida dos pacientes com e sem doença arterial obstrutiva periférica

Gráfico 5. Curva de sobrevida de paciente com antecedentes de acidente vascular cerebral

Gráfico 6. Curva de sobrevida no longo prazo de paciente com diagnóstico prévio de Síndrome de Marfan 


\section{LISTA DE FIGURAS}

Figura 1. Classificação anatômica das dissecções da aorta

Figura 2. Precursores de dissecção 
RESUMO 
ISSA, M. Variáveis Prognósticas de Evolução Hospitalar e no Longo Prazo de Pacientes Portadores de Disseção Crônica de Aorta Tipo A de Stanford e Aneurisma de Aorta Ascendente, Submetidos a Procedimento Cirúrgico. São Paulo, 2012. 104 p. Tese (Doutorado) Instituto Dante Pazzanese de Cardiologia, Universidade de São Paulo.

Introdução: Aneurismas e dissecções da aorta constituem as principais doenças da aorta, as quais podem ser submetidas a princípios e técnicas de tratamento cirúrgico em comum. A conduta clínica e cirúrgica continua sendo um desafio nos procedimentos eletivos, bem como em casos de emergência. Informações sobre variáveis prognósticas associadas independentemente com óbito hospitalar e no longo prazo, são escassas, havendo necessidade da identificação destes fatores para a avaliação apropriada sobre o risco cirúrgico desta população.

Objetivos: Primário: identificar variáveis prognósticas associadas independentes ao óbito hospitalar em pacientes submetidos a procedimento cirúrgico para correção de doenças da aorta. Secundários:identificar variáveis prognósticas associadas independentes ao óbito tardio e ao desfecho clínico composto (óbito, sangramento, disfunção ventricular e complicações neurológicas).

Casuística e Métodos: Delineamento transversal com componente longitudinal, com coleta de dados retrospectiva e prospectiva. Pacientes consecutivos, portadores de aneurisma de aorta ascendente ou dissecção crônica de aorta tipo A de Stanford, foram incluídos por meio de revisão de prontuários. Foram incluídos 257 pacientes, cujos critérios de inclusão envolviam aqueles que foram operados por dissecção crônica de aorta tipo $A$ de Stanford e aneurisma de aorta ascendente. Foram excluídos pacientes com dissecção aguda de aorta, de qualquer tipo, e pacientes que tiveram aneurisma de aorta em outro segmento da aorta que não fosse a aorta ascendente. Os desfechos clínicos avaliados foram óbito, sangramento clinicamente relevante, complicações neurológicas e disfunção ventricular, 
fase hospitalar e óbito no longo prazo. As variáveis prognósticas avaliadas incluíram: demografia, fatores pré-operatórios, fatores intra-operatórios e complicações pós-operatórias. O seguimento médio foi de 970 dias. 0 tamanho de amostra foi definido por conveniência aliado a publicações prévias sobre o tópico. Análise univariada foi realizada para selecionar variáveis para serem inseridas no modelo multivariado para identificação das variáveis prognósticas independentemente associados aos desfechos clinicamente relevantes.

Resultados: As seguintes variáveis prognósticas apresentaram associação independente como o risco aumentado de óbito na fase hospitalar (RC; IC95\%; P valor): etnia negra (6.8; 1.54-30.2; 0,04), doença cerebrovascular (10.5; 1.12-98.7; 0,04), hemopericárdio (35.1; 3.73-330.2; 0,002), cirurgia de Cabrol (9.9; 1.47-66.36; 0,019), cirurgia de revascularização miocárdica (4.4 ;1.31-15.06; 0,017), revisão de hemostasia (5.72;1.29-25.29; 0,021) e circulação extra-corpórea [min] $(1.016 ; 1.007-1.026 ; 0,001)$. A presença de dor torácia associou-se independentemente com o risco reduzido de óbito hospitalar $(0.27 ; 0.08-0.94 ; 0,04)$. As seguintes variáveis apresentaram associação independente com o risco aumentado do desfecho clínico composto na fase hospitalar: uso de antifibrinolítico (3.2; 1.65-6.27; 0,0006), complicação renal $(7.4 ; 1.52-36.0 ; 0,013)$, complicação pulmonar $(3.7 ; 1.5$ 8.8; 0,004), EuroScore $(1.23 ; 1.08-1,41 ; 0,003)$ e tempo de CEC [min] (1.01; 1.00-1.02; 0,027). As seguintes variáveis apresentaram associação independente com o risco aumentado de óbito no longo prazo: doença arterial obstrutiva periférica $(7.5 ; 1.47-37.85 ; 0,015)$, acidente vascular cerebral prévio $(7.0 ; 1.46-33.90 ; 0,015)$, uso de estatina na alta hospitalar $(4.9 ; 1.17-21.24 ; 0,029)$ e sangramento aumentado nas primeiras 24 horas $(1.0017 ; 1.0003-1.0032 ; 0,021)$

Conclusão: Etnia negra, doença cerebrovascular, hemopericárcio, cirurgia de Cabrol, revascularização miocárdica cirúrgica associada, revisão de hemostasia e tempo de CEC associaram-se independentemente com risco aumentado de óbito hospitalar. A presença de dor torácica associou-se independentemente com o risco reduzido de óbito hospitalar. Doença arterial 
obstrutiva periférica prévia, acidente vascular cerebral prévio, uso de estatina na alta hospitalar e sangramento aumentado nas primeiras 24 horas associaram-se independentemente com risco aumentado de óbito no prazo longo. Uso de antifibrinolítico, complicação renal, complicação pulmonar, EuroScore e tempo de CEC associaram-se independentemente com o risco aumentado de desfecho clínico composto hospitalar (óbito, sangramento, disfunção ventricular e complicações neurológicas). 
SUMMARY 
ISSA, M. Hospital and long-term prognostic variables in patients with ascendant aortic aneurism or Stanford Type A aortic chronic dissection who underwent surgical procedure. São Paulo, 2012. 104 p. Tese (Doutorado) - Instituto Dante Pazzanese de Cardiologia, Universidade de São Paulo.

Introduction: Both aortic aneurisms and dissections constitute the main aortic diseases, sharing common principles and surgical procedure approaches. Medical and surgical management are seen as a medical challenge concerning elective procedures as well as in emergency cases. Data on prognostic variables independently associated with both hospital and long term death are scarce, leading to a need for appropriate identification of those factors for proper surgical risk evaluation of this population.

Objectives: Primary: to identify prognostic variables independently associated with hospital death in patients who underwent surgical procedures for aortic disease correction. Secondary: to identify prognostic variables independently associated with long term death and with composite clinical endpoint (death, bleeding, ventricular dysfunction and neurological complications).

Methods: Cross-sectional design plus a longitudinal component, with retrospective and prospective data collection. Consecutive patients, diagnosed with ascendant aortic aneurism or type A of Stanford aortic chronic dissection were included by means of hospital chart revision and data extraction. A total of 257 patients were recruited and eligibility criteria included those who underwent surgical procedures due to ascendant aortic aneurism or type A of Stanford aortic chronic dissection. Patients with acute aortic dissection and with aortic aneurism in a different segment location other than ascendant aorta were excluded. Clinical endpoints evaluated were death, clinically relevant bleeding, ventricular dysfunction and neurological complications, during the hospital phase and long-term death. Prognostic variables evaluated included: demography, pre-operative factors, intra- 
operative factors and post-operative complications. Mean follow up was of 970 days. Sample size estimation was defined by a convenience sample along with previous publications. Univariate analysis was conducted to select key variables to be inserted in the multivariate model and to identify the prognostic variables independently associated with clinically relevant endpoints

Results: The following prognostic variables have been identified as independently associated with increased risk of hospital death (OR; $95 \% \mathrm{IC}$; $P$ value): black ethnicity $(6.8 ; 1.54-30.2 ; 0,04)$, cerebrovascular disease (10.5; 1.12-98.7; 0,04), hemopericardium (35.1; 3.73-330.2; 0,002), Cabrol operation $(9.9 ; 1.47-66.36 ; 0,019)$, associated coronary artery bypass graft (4.4; 1.31-15.06; 0,017), reoperation for bleeding $(5.72 ; 1.29-25.29 ; 0,021)$ and cardiopulmonary bypass time (CPB) [min] (1.016; 1.007-1.026; 0,001). Presence of chest pain was independently associated with reduced risk of hospital death $(0.27 ; 0.08-0.94 ; 0,04)$. The following variables were independently associated with increased risk of composite clinical endpoint during hospital phase: antifibrinolitic use (3.2; 1.65-6.27; 0,0006), renal failure $(7.4 ; 1.52-36.0 ; 0,013)$, respiratory failure $(3.7 ; 1.5-8.8 ; 0,004)$, EuroScore $(1.23 ; 1.08-1,41 ; 0,003)$ and cardiopulmonary bypass time (CPB) [min] (1.01; $1.00-1.02 ; 0,027)$. The following variables were independently associated with increased risk of long term death: peripheral obstructive arterial disease (7.5;1.47-37.85;0,015), previous stroke (7.0;1.46-33.90;0,015), at discharge statin use $(4.9 ; 1.17-21.24 ; 0,029)$ and first 24-hour increased bleeding $(1.0017 ; 1.0003-1.0032 ; 0,021)$.

Conclusion: Black ethnicity, cerebrovascular disease, hemopericadium, Cabrol operation, associated coronary artery bypass graft, reoperation for bleeding, and cardiopulmonary bypass time were associated with increased risk of hospital death. Presence of chest pain was associated with reduced risk of hospital death. Peripheral obstructive arterial disease, previous stroke, at discharge statin use and first 24-hour increased bleeding were associated with increase risk of long-term death. 
Use of antifibrinolitic, renal failure, respiratory failure, EuroScore and cardiopulmonary bypass time were associated with increased risk of hospital composite clinical endpoint (death, bleeding, ventricular dysfunction and neurological complications). 
1 INTRODUÇÃO 
primeiro relato de aneurisma de aorta ascendente foi feito em 1757. Sua descrição foi relacionada com a Síndrome da Veia Cava Superior, em estudo publicado por William Hunter ${ }^{1}$ sobre um portador de sífilis que desenvolvera aneurisma sifilítico da aorta ascendente.

Em 1761 um anatomista italiano, Giovanni Battista Morgagni ${ }^{2}$ descreveu; os achados de um paciente com tamponamento cardíaco secundário à ruptura da aorta e René-Théophile-Hyacinthe Laennec ${ }^{3}$, inventor do estetoscópio, utilizou em 1826, o termo aneurisma dissecante de aorta pela primeira vez.

Nos EUA, aproximadamente 15 mil pessoas ao ano são diagnosticadas como portadoras de aneurisma da aorta torácica. Adicionalmente, mais de 47 mil indivíduos por ano morrem vítimas de doenças da aorta; mais do que câncer de mama, SIDA, homicídios ou acidentes automobilísticos, fazendo da doença aórtica uma epidemia silenciosa ${ }^{4}$.

Aneurismas e dissecções constituem as principais doenças da aorta, os quais podem ser submetidos a princípios e técnicas de tratamento cirúrgico em comum. O manuseio cirúrgico continua sendo um desafio nos procedimentos eletivos, bem como em casos de emergência. A decisão quanto à cirurgia é baseada no equilíbrio entre o risco cirúrgico e a chance de ruptura da aorta, podendo ser particularmente difícil em casos eletivos. Por outro lado, entre pacientes com ruptura de aorta torácica, a mortalidade é extremamente elevada, situando-se acima de $94 \%$,

Quando a ruptura é avaliada como potencialmente iminente, como na dissecção aguda da aorta proximal, o resultado do tratamento cirúrgico, em termos de mortalidade, não melhorou substancialmente nas últimas décadas, apesar dos progressos do tratamento clínico e cirúrgico, segundo o IRAD, o índice de mortalidade se manteve em aproximadamente $25 \%$.

A prevalência e a incidência dos aneurismas e dissecções da aorta, o resultado do tratamento cirúrgico e resultados a longo prazo, 
independentemente do manuseio inicial afetam a carga imposta aos cuidados médicos e ao sistema de saúde. O nível de conhecimento da incidência e dos resultados são fundamentais para resultados clínicos satisfatórios e também para otimizar a alocação de recursos, orientando a conduta médica no seguimento de médio e longo prazo.

Entretanto, o conhecimento atual é em grande parte baseado em estudos com tamanho de amostra insuficientes para conclusões sólidas e robustas, não-contemporâneos, abrangendo 3 décadas ou mesmo em período antes da utilização sistemática da tomografia computadorizada e ecocardiograma, métodos relativamente acurados para averiguação da doença $^{9,10}$.

Outras doenças como aterosclerose e aortites, podem acometer a aorta. Enquanto em algumas, a camada atingida é a íntima, como na aterosclerose, em outras, como nos aneurismas e dissecções ${ }^{11}$, a camada média é atingida.

Em 1987 a incidência de doenças da aorta torácica na Suécia era de 10,7 por 100.000/ano em homens, elevando-se para 16,3 por 100.000/ano em 2002 (aumento relativo de 52\%). Comparativamente, em mulheres a incidência era de 7,1 por 100.000/ano em 1987 e 9,1 por 100.000/ano em 2002 (aumento relativo de 28\%). A idade média no momento do diagnóstico diminuiu de 73 anos no período de 1987-1990, para 71 anos no período de $1999-2002^{12}$.

Com o aumento da longevidade da população e a maior facilidade na realização do diagnóstico, taxas maiores de prevalência e incidência estarão elevadas em comparação com as taxas atuais

O diagnóstico de doença da aorta, é muitas vezes subestimado. Muitos diagnósticos inapropriados atribuem a causa do óbito a outras doenças como infarto agudo do miocárdio, arritmias cardíacas, embolia pulmonar e isquemia mesentérica.

O número de óbitos devido à dissecção ou ruptura da aorta torácica é duas vezes maior do que os atribuídos à ruptura da aorta abdominal ${ }^{4}$. 
Os aneurismas de aorta constituem um sério risco à saúde pois, podem romper ou dissecar, causando risco imediato à vida. Quando detectado a tempo, pode ser reparado cirurgicamente ou por meio de outros métodos menos invasivos.

Os aneurismas são dilatações segmentares saculares ou fusiformes dos vasos, envolvendo suas três camadas. Uma artéria é considerada patologicamente dilatada quando, o seu diâmetro excede aquele considerado normal para a idade e superfície corporal.

É possível calcular o diâmetro normal aproximado, esperado na aorta ascendente e descendente, com base na idade, pela fórmula de Hannuksela 13.

Aorta Ascendente : $\mathrm{D}=31+0,16 \mathrm{x}$ idade

Aorta Descendente : $D=21+0,16 \times$ idade

$\mathrm{D}=$ Diâmetro $(\mathrm{mm})$

Nos segmentos descendente da aorta torácica e da aorta abdominal, a causa mais comum dos aneurismas é a inflamação. Assim, os casos de aterosclerose que evoluem com aneurismas, são aqueles com inflamação mais exuberante. Junto com a inflamação, em geral ocorre a destruição do tecido elástico e fibrose (deposição cicatricial de colágeno). Na aorta ascendente, a grande maioria dos doentes não tem inflamação, mas a camada elástica também apresenta alterações. As características histopatológicas desses aneurismas são semelhantes às das dissecções e muitos aneurismas podem evoluir para dissecções.Por isso, muitos estudos analisam em conjunto essas duas doenças, às vezes com o nome "doenças dilatativas da aorta ascendente". Contudo, ainda que existam muitos fatores em comum, deve haver diferenças que justifiquem a manifestação de uma ou outra doença ${ }^{11}$.

As dissecções da aorta consistem na delaminação de sua parede no sentido longitudinal ao longo da túnica média, em quase todos os casos no 
seu terço externo, criando uma falsa luz, paralela à luz verdadeira. A aorta torna-se dilatada sem que suas três camadas sejam comprometidas.

Existem vários tipos de classifcações de dissecção de aorta. A anatômica e a temporal são as mais utilizadas, pois têm relevância clínica na conduta a ser tomada.

A classificação temporal é dividida em aguda, até duas semanas do início dos sintomas, e crônica, após duas semanas do início dos sintomas.

As classificações anatômicas de De Bakey e Stanford são amplamente aceitas e usadas ${ }^{14,15,16,17,18}$.

As dissecções estão associadas, muitas vezes, com hipertensão arterial sistêmica, presente em 80 \% dos casos, em várias séries. A hipertensão arterial crônica afeta a composição da parede arterial, causando espessamento da íntima, fibrose, calcificação e deposição extracelular de ácidos graxos. Em paralelo, a matriz extracelular sofre degradação acelerada, apoptose e elastólise com hialinização do colágeno. Ambos os mecanismos podem, eventualmente, levar ao rompimento da íntima, na maioria das vezes nas bordas das placas, como visto na placa coronária. $O$ espessamento da íntima aumenta, o que compromete ainda mais o fornecimento de nutrientes e oxigênio para a parede arterial. A fibrose na adventícia pode obstruir os vasos que alimentam a parede arterial, bem como pequenas vasa vasorum intramural. Ambos resultam em necrose das células musculares lisas e fibrose das estruturas elásticas da parede do vaso, o que leva à rigidez e vulnerabilidade às forças pulsáteis, criando um substrato para aneurismas e dissecções ${ }^{19,20}$.

$\mathrm{Na}$ sua etiopatogenia, dois fatores estão presentes: anormalidade vascular e alteração pressórica. Duas teorias são aceitas: a primeira onde a lesão primária delas é a laceração da íntima, levando à dissecção intramedial; de acordo com a segunda teoria, ocorre a ruptura dos vasa vasorum aórticos causando hemorragia intramedial, e provocando a 
dissecção. Estas alterações explicam o hematoma intramural, considerado lesão pré-dissecção.

Alterações histopatológicas dos aneurismas da aorta foram descritas por Erdheim em 1929²1, como a fragmentação difusa das fibras elásticas, aparente diminuição da população de células musculares lisas e acúmulo de material mucóide. Provém deste autor a denominação inadequada e amplamente utilizada, "necrose cística da média". A diminuição das células musculares lisas pode ocorrer devido à necrose ou apoptose, mas também pode ser aparente, decorrente não da diminuição das células, mas do aumento do espaço extracelular pelo acúmulo de mucóide.

A meia-vida dos componentes da matriz extracelular é longa. Sua degradação depende da ação de enzimas que os têm como substrato, , como as metaloproteinases (colagenases e gelatinases), as serinoproteinases ( elastase leucocitária, plasmina e outras ) e as "ADAMS" e "ADAMTS" (a disintegrin and metalloproteinase with a thrombospondin type 1 motif), que são tipos especiais de metaloproteinases com domínio de desintegrinas, com conteúdo rico em cisteína. Essas enzimas catalisam preferencialmente, mas não exclusivamente, uma determinada classe de moléculas; agem até mesmo em elementos que não são da matriz ${ }^{22,23,24}$.

Os principais produtores dessas enzimas são as células inflamatórias. Mas as próprias células conjuntivas que fabricam a matriz, como os fibroblastos e células musculares lisas, também as secretam ${ }^{25}$.

Os componentes extracelulares, constituídos por proteoglicanos, sistema elástico e colágeno, são estruturas importantes entre as alterações histopatológicas nas doenças da aorta.

Os proteoglicanos parecem ter maior importância nos aneurismas e dissecções do segmento ascendente da aorta e lagos mucóides estão presentes nessas circunstâncias. Porém, Schlatmann e Becker ${ }^{26,27}$ relataram que essas alterações podem ser inespecíficas, pois ocorrem também em outras doenças da aorta, assim como na hipertensão arterial e 
no envelhecimento. Em algumas aortas com aneurismas ou dissecções, a presença de substância mucoide é mínima ou nula.

BORGES et $\mathrm{al}^{28}$; analisaram a expressão das metaloproteinases 3 e 7 (MMP-3 e MMP-7), estromelisina e matrilisina, e do complexo fibrinogênio/fibrina, que têm a capacidade de ativá-las, sugerindo, portanto, poder haver ação dessas enzimas degradando os proteoglicanos, levando ao acúmulo mucóide.

Em relação ao tecido elástico, há algum grau de destruição da camada média para que ocorra dilatação arterial aneurismática, como acontece no aneurisma aterosclerótico; entretanto, esta é uma complicação pouco frequente da doença aterosclerótica.

PIRES et $\mathrm{al}^{29}$; demonstraram que a quantidade de tecido elástico na camada média e na adventícia era menor na região dos aneurismas da aorta abdominal.

Na Síndrome de Marfan, há um defeito genético da fibrilina, principal constituinte das microfibrilas do sistema elástico. Entretanto, em muitos indivíduos sem esta síndrome, as causas da elastólise permanecem obscuras. Em recente estudo, GUTIERREZ et al ${ }^{11}$; descreveram queda dos valores teciduais de emilina, outro constituinte importante das microfibrilas, em pacientes portadores de aneurisma de aorta ascendente. Em indivíduos com aortas normais, com Síndrome de Marfan e dissecção de aorta não houve alterações significativas.

A avaliação do colágeno nos aneurismas não inflamatórios e nas dissecções não foi muito valorizada. Porém, DE FIGUEIREDO BORGES LF et $\mathrm{al}^{30}$; demonstraram que em aortas normais e naquelas com dissecção, há menos colágeno na metade próxima à adventícia, sendo que, nas dissecções, a quantidade é menor do que nas aortas normais. Nos aneurismas a diminuição de colágeno ocorre em toda a espessura da parede, provocando fragilidade mais global, enquanto que a diminuição situada na metade externa, aumentaria a chance de dissecção. 
A Síndrome de Marfan merece observação à parte, pois está intimamente relacionada às doenças da aorta. Trata-se de doença do tecido conjuntivo, com padrão hereditário autossômico dominante e expressividade variável, aparentemente com penetrância completa. Suas características fenotípicas principais correspondem aos sistemas esquelético, ocular e cardiovascular.

De todas as manifestações desta síndrome, as cardiovasculares são responsáveis, em 95\% dos casos, pela morte precoce destes indivíduos, devido a complicações na aorta ascendente, podendo provocar dilatações, aneurismas, dissecções ou ruptura. Insuficiência aórtica e mitral também podem ocorrer como manifestações cardiovasculares ${ }^{31,32}$.

O diagnóstico é eminentemente clínico, levando-se em consideração os critérios de Ghent, com alta especificidade para identificar pacientes com mutação do gene FBN1 (>97\%). Testes genéticos moleculares do FBN1 e outros genes (TGFBR 1 e 2 ) estão atualmente disponíveis ${ }^{33}$.

No Instituto Dante Pazzanese de Cardiologia (IDPC) há um crescente aumento nas internações de pacientes portadores de doença de aorta, envolvendo dissecções agudas e crônicas, assim como aneurismas verdadeiros, acometendo os mais variados segmentos da aorta, fazendo com que os pacientes necessitem de tratamento clínico, endovascular, cirúrgico ou híbrido. O número de operações anuais é de aproximadamente 100 procedimentos.

Entretanto, ainda existem muitas incertezas e controvérsias no diagnóstico e tratamento das doenças da aorta ${ }^{34}$. As medidas corretas do segmento aórtico acometido, a presença de insuficiência valvar aórtica e a presença de sinais peculiares da parede da aorta podem ser avaliadas por diferentes métodos, cada um com suas vantagens e limitações. Testes genéticos e biomarcadores ainda não são específicos, e carecem de maior desenvolvimento e aplicabilidade. Os diversos métodos se complementam, e nem todos os serviços dispõem da mesma estrutura e capacitação profissional para o diagnóstico preciso e conduta clínica e invasiva. 
A determinação do risco de desenvolver evento cardiovascular, incluindo cerebrovascular e óbito, reveste-se de importância para a análise do prognóstico. Ademais, tal determinação, como também tem o objetivo de determinar a conduta a ser instituída nesses pacientes de alta complexidade. Reconhecer qual a melhor forma de proteção neurológica em doenças mais extensas, uma vez que a parada circulatória total com hipotermia profunda pode ocasionar danos neurológicos permanentes, com descreveu CZERNY $M$ et $a^{35,36}$. Ou ainda, verificar se medicamentos de uso rotineiro na prática clínica, podem interferir no resultado no longo prazo, como comparou DIEHM ET AL ${ }^{37}$; com as estatinas.

De acordo com as diretrizes das doenças de aorta ${ }^{4,38}$, o principal fator determinante das condutas referem-se aos diâmetros do segmento aórtico acometido, assim como, o caráter agudo ou crônico da doença, na tentativa de combater o denominado "assassino silencioso". Entretanto, como publicado por ELEFTERIADES ET AL ${ }^{34}$; a determinação isolada do diâmetro absoluto, em muitos casos, pode ser considerada insuficiente.

A simples determinação do diâmetro absoluto da aorta não avalia fatores de risco dos pacientes que serão submetidos aos procedimentos cirúrgicos, como observou PAPE et al ${ }^{39}$.

Escores de risco de outros centros, como o EuroSCORE, não atualizados e referentes a outras doenças, não correspondem à realidade de cada serviço ${ }^{40,41}$.

Aneurismas de aorta ascendente e dissecção crônica da aorta tipo A de Stanford são doenças potencialmente letais, cuja única opção de tratamento, muitas vezes é a cirurgia. Porém, as indicações para tratamento cirúrgico baseiam-se principalmente nas condições anatômicas da aorta, havendo muitas dúvidas para essa avaliação.

Atualmente, são escassos os dados sobre as variáveis prognósticas associadas independentemente com óbito hospitalar e no longo prazo, havendo necessidade da identificação destes fatores para avaliação 
apropriada sobre o risco cirúrgico desta população. Tampouco existem dados disponíveis sobre as variáveis prognósticas independentemente associadas com outros desfechos clinicamente relevantes, como por exemplo, disfunção ventricular, complicações neurológicas e sangramento. Baseando-se na relevância clínica da dissecção crônica e do aneurisma de aorta em termos de prevalência populacional e indicação cirúrgica com os resultados consequentes da intervenção, um estudo identificando adequada e confiavelmente as variáveis prognósticas associados com desfechos clinicamente relevantes constitui ferramenta científica para aprimoramento da prática clínica cirúrgica dentro do cenário da medicina cardiovascular. 
2 OBJETIVOS 


\subsection{Primário}

Identificar as variáveis prognósticas associadas independentemente ao óbito hospitalar e em pacientes submetidos a procedimento cirúrgico para correção de doenças da aorta.

\subsection{Secundários}

a) Identificar as variáveis prognósticas associadas independentemente ao óbito tardio em pacientes submetidos a procedimento cirúrgico para correção de doenças da aorta.

b) Identificar as variáveis prognósticas associadas independentemente ao desfecho clínico composto (óbito, sangramento, disfunção ventricular, complicações neurológicas) na fase hospitalar em pacientes submetidos a procedimento cirúrgico para correção de doenças da aorta. 
3 CASUÍSTICA E MÉTODOS 


\subsection{Casuística}

\subsubsection{Delineamento da Pesquisa}

Esta pesquisa envolve um delineamento transversal, com coleta de dados retrospectiva e prospectiva e com um componente longitudinal.

\subsubsection{População do Estudo}

Pacientes encaminhados ao Instituto Dante Pazzanese de Cardiologia, com diagnóstico de aneurisma de aorta ascendente podendo ter outro segmento comprometido ou dissecção crônica de aorta tipo A de Stanford, confirmado por imagem (ecocardiograma e/ou tomografia coronária e por angiografia coronária) submetidos a procedimento cirúrgico de correção das patologias de aorta descritas acima.

\subsubsection{Estratégia de Recrutamento}

Pacientes consecutivos, com diagnóstico confirmado de aneurisma de aorta ascendente ou dissecção crônica tipo A de Stanford, foram incluídos a partir da revisão de prontuários, por meio de coleta de dados retrospectiva com início em janeiro de 2004. A partir de janeiro de 2009, pacientes consecutivos foram incluídos por meio de coleta de dados prospectiva, até dezembro de 2010.

\subsubsection{Elegibilidade}

\section{Critérios de Inclusão:}

a) pacientes operados por dissecção crônica de aorta tipo A de Stanford e aneurisma de aorta ascendente;

b) envolvimento da aorta ascendente em todos os pacientes;

c) comprometimento presente ou não de outros segmentos da aorta;

d) ambos os sexos; 
e) sem limite inferior ou superior de idade.

\section{Critérios de Exclusão:}

a) pacientes com dissecção aguda de aorta, de qualquer tipo;

b) pacientes com aneurisma envolvendo outros segmentos de aorta que não fossem aorta ascendente;

c) dissecção de aorta tipo B de Stanford.

\subsection{Métodos}

\subsubsection{Definições de Desfechos Clínicos}

a) Sangramento clinicamente relevante : Sangramento com necessidade de transfusão sanguínea, utilizando-se pelo menos 3 unidades de concentrado de hemácias.

b) Disfunção ventricular : presença de insuficiência cardíaca e/ou choque cardiogênico (pressão arterial sistólica $<90 \mathrm{mmHg}+$ uso de drogas vasoativas)

c) Complicação neurológica: presença de acidente vascular cerebral (isquêmico, hemorrágico ou indeterminado) ou coma (redução do nível de consciência em período superior a 24 h).

d) Óbito hospitalar e no longo prazo: óbito de qualquer etiologia (cardiovascular e não-cardiovascular) ocorrendo durante o período hospitalar (intra-operatório e pós-operatório) e durante o período após a alta hospitalar.

\subsubsection{Definições dos Tipos de Cirurgias}

a) Enxerto Supracoronário : Interposição de enxerto tubular protético em aorta ascendente, acima dos óstios coronários e abaixo do tronco braquiocefálico. Pode ser retirada ou preservada a valva aórtica nativa. 
b) Operação de Bentall De Bono : Implante de enxerto protético valvulado ( prótese biológica ou metálica ) associado a reimplante direto dos óstios coronários. Retira-se a valva aórtica nativa.

c) Reconstrução de Hemiarco : Reconstrução parcial do arco aórtico, retirando-se apenas o segmento que não contém os vasos da base, até próximo à aorta descendente.

d) Operação de Cabrol : Implante de enxerto protético valvulado (prótese biológica ou metálica) associado a reimplante indireto dos óstios coronários, através de outro enxerto protético unindo ambos óstios e este, anastomosado no enxerto valvulado. Retira-se a valva aórtica nativa.

e) Operação de Tirone-David: Também chamada de Técnica do Reimplante. Neste caso, reconstrói-se a raiz aórtica junto com seu aparelho valvar, utilizando-se enxerto protético, reimplantando a valva aórtica por dentro desse enxerto. Em seguida, reimplanta-se os óstios coronários. A valva aórtica é preservada.

f) Operação de Yacoub: Também conhecida como Técnica do Remodelamento. A reconstrução da raiz aótica e do aparelho valvar aórtico é feita remodelando os seios de Valsalva com o próprio enxerto protético, de modo a também preservar a valva aórtica e em seguida, reimplantar os óstios coronários.

g) Reimplante dos Vasos da Base e Bloco : É retirado todo o arco aórtico doente; porém, se os vasos da base são poupados da doença, estes são reimplantados em grupo, no enxerto protético utilizado para reconstrução do arco.

h) Reimplante dos Vasos da Base Separados: Após a ressecção do arco aórtico comprometido, caso os vasos da base não sejam acometidos, estes são reimplantados separadamente no enxerto protético utilizado na reconstrução do arco.

i) Endoprótese (Stent) em Aorta Descendente: Tratamento endovascular da aorta descendente por toracotomia. 


\subsubsection{Classificação das Dissecções de Aorta}

As classificações de DeBakey e a de Stanford, como mostra a figura 1, são as mais utilizadas nas dissecções agudas e crônicas da aorta.

Assim como, sua distinção entre um evento agudo e crônico, pois, tem relevante implicação no tratamento.

A classificação de Stanford para dissecção de aorta faz a distinção entre os tipos $A$ e $B$, como mostra a figura 1. O tipo A significa que a dissecção envolve a aorta ascendente, o que não ocorre no tipo B. A classificação de DeBakey subdivide o processo de dissecção: a dissecção tipo I, envolve toda a aorta, a dissecção tipo II envolve apenas a aorta ascendente e a dissecção tipo III poupa a aorta ascendente e o arco. Várias tentativas de subdividir ainda mais os dois sistemas de classificação não foram estabelecidas na comunidade médica, embora a região do arco mereça uma integração maior num sistema moderno de classificação ${ }^{42}$.

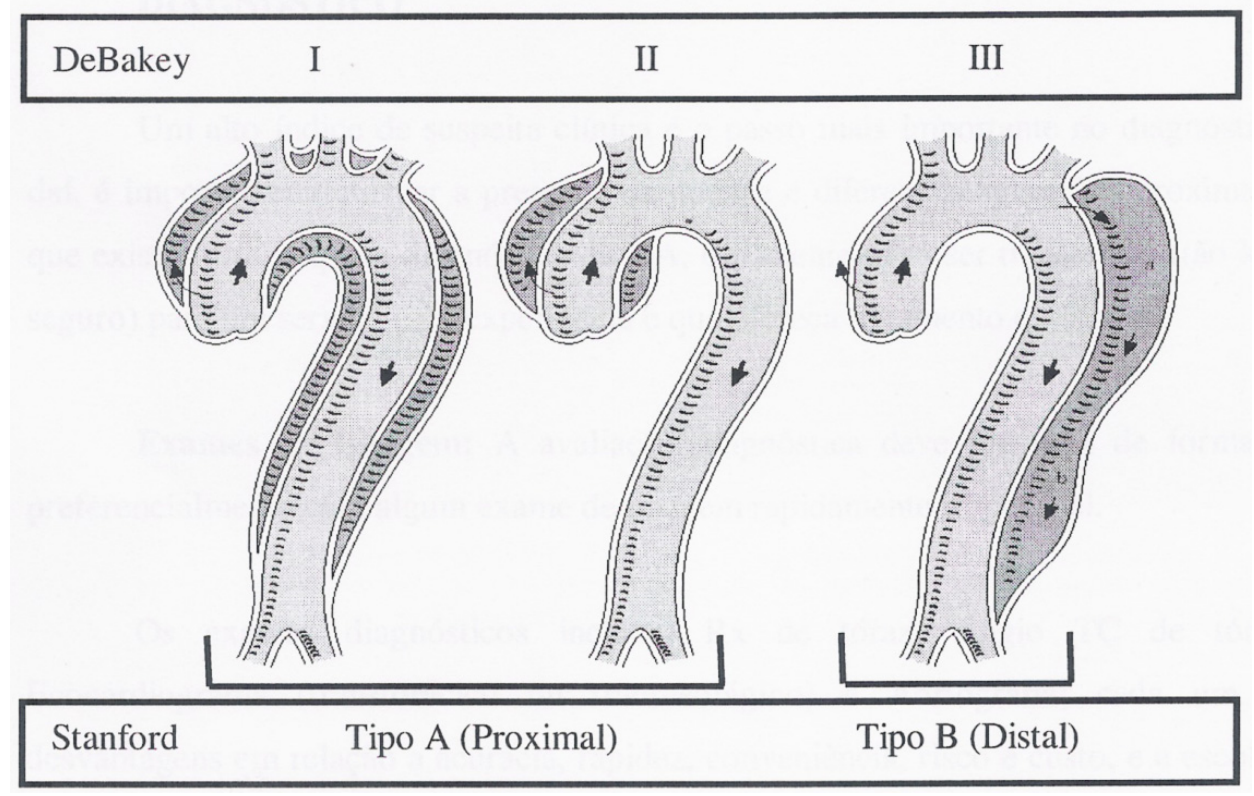

Figura 1. Classificação anatômica das dissecções de aorta 
Observações recentes destacam a importância de precursores de dissecção aórtica típicos, como hematoma intramural (HIM), úlceras penetrantes de aorta, ou fendas localizadas na camada íntima como variantes de um processo de dissecção da parede, como mostra a figura $2^{43}$.

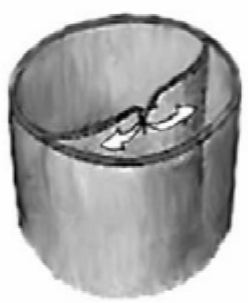

Dissecção de aorta
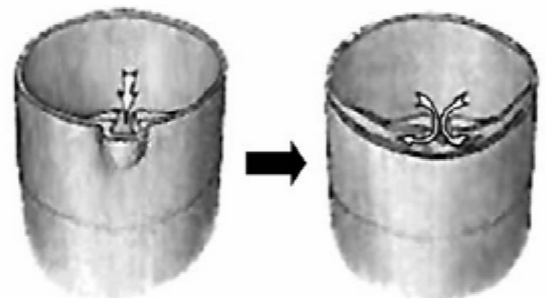

Úlcera Penetrante

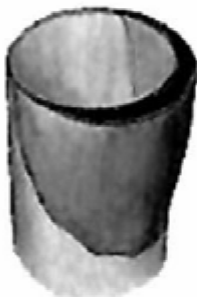

Hematoma Intramural

Figura 2. Precursores da dissecção

\section{Classificação Temporal}

Aguda : Até 2 semanas do início dos sintomas

Crônica : Após 2 semanas do início dos sintomas

\subsubsection{Apresentações Clínicas das Dissecções de Aorta}

A manifestação clínica mais frequente da dissecção aguda de aorta tipo A de Stanford é a dor torácica, de grande intensidade, com irradiação para a região dorsal e que não melhora mediante o repouso. $O$ déficit de pulso periférico na apresentação, está relacionado com maior mortalidade hospitalar ${ }^{44,45}$.

O choque pode ser um sinal presente, resultado de tamponamento, compressão coronária, insuficiência valvar aórtica aguda, ou perda de sangue e iminente exsanguíneo do paciente ${ }^{46,47}$.

Os aneurismas e as dissecções crônicas da aorta são assintomáticos, na maioria das vezes. As manifestações clínicas dependem da presença e da 
severidade da insuficiência valvar aórtica. A dor torácica pode aparecer caso a aorta esteja em expansão.

\subsubsection{Variáveis Prognósticas Avaliadas}

As variáveis prognósticas avaliadas para a identificação dos preditores independentes, associadas à mortalidade hospitalar e no longo prazo, bem como ao desfecho clínico composto, são descritas abaixo:

a) Diagnóstico: Aneurisma e Dissecção

b) Fatores Demográficos: Ano da Cirurgia, Etnia, Idade, Peso, Sexo, Classe Funcional

c) Fatores Pré-Operatórios: Tabagismo,IRC, Diabetes mellitus, AVC prévio, DAOP, DPOC, Hipertensão Arterial Sistêmica, Sintomas Neurológicos, Sd. Marfan, Cirurgia cardíaca prévia, Choque, Doença coronária, Síncope EuroScore, Entubado, Complicações Isquêmicas, Derrame Pericárdico,Fração de Ejeção, Dor Torácica, Creatinina

d) Indicações Cirúrgicas: Eletiva e Emergência

e) Fatores Intra-Operatórios: Sítio de Canulação, Valva Aórtica Bicúspide, CEC (min.), Insuficiência Aórtica, Parada Circulatória (min.),Hemopericárdio, Tempo de Anóxia (min.), Tipo de Operação, Temperatura $\left({ }^{\circ} \mathrm{C}\right)$, Revascularização Miocárdica, Proteção Cerebral Cardioplegia

f) Complicações Pós - Operatórias Imediatas: Sangramento nas primeiras 24 hs,Complicações Pulmonares, Revisão de hemostas, Complicações Vasculares, Antifibrinolítico, Complicações Gastrointestinais, Complicações Neurológicas, Complicações Cardíacas , Complicações Infecciosas, Sd. de Má perfusão, Falência de Múltiplos Órgãos, Choque Cardiogênico, Insuficiência Cardíaca, Hemoderivados.

g) Seguimento de Prazo Longo: Tempo de seguimento, Medicação CF,Óbito. 


\subsubsection{Cálculo de tamanho da amostra}

A amostra do presente trabalho pode ser considerada de conveniência aliada à publicação prévia de DIAS RR et al ${ }^{48}$; que incluiu 164 pacientes com características demográficas semelhantes. Portanto, a amostra incluindo 257 pacientes assegura, potencialmente, uma avaliação robusta e válida para os objetivos escolhidos. Para avaliação do óbito hospitalar, foram analisadas 56 variáveis selecionadas pelas observações em estudos anteriores, assim como, na experiência do pesquisador.

A amostra observada inclui 257 pacientes cujos eventos: óbito hospitalar, desfecho clínico composto e óbito tardio (após cirurgia) foram avaliados em função de medidas quantitativas e qualitativas (Anexos 1 e 2).

O desfecho clínico composto refere-se à presença de óbito hospitalar ou complicação neurológica (AVC ou coma > 24 horas) ou disfunção ventricular (insuficiência cardíaca sintomática e/ou choque cardiogênico) ou sangramento clinicamente relevante (presença de revisão de hemostasia e/ou necessidade de transfusão de concentrado de hemácias $\geq 3 U$ ), ou seja, o paciente que apresentou pelo menos um destes eventos foi caracterizado como portador de desfecho clínico composto.

Para os testes estatísticos com única variável ("univariada"), as medidas de óbito hospitalar, desfecho clínico composto e óbito tardio se comportam como grupos com duas categorias de resposta: ausente e presente.

\subsubsection{Análise Estatística}

A amostra de pacientes estudada foi descrita por estatísticas de frequências absolutas $(n)$ e relativas (\%) das medidas qualitativas (fatores) e estatísticas sumárias de média, mediana, desvio padrão (DP) e percentis 25 e 75 das medidas quantitativas (co-variáveis). 
A associação entre medidas qualitativas e os grupos (óbito e desfecho clínico composto) foi avaliada por teste qui-quadrado de Pearson (Pereira) ou exato de Fisher (Armitage, 1994). Para a comparação de medidas quantitativas entre dois grupos foi aplicado teste não paramétrico de Mann-Whitney (Siegel, 1988). Para o óbito após a cirurgia, foram observadas as curvas de sobrevivência de Kaplan-Meier (Armitage, 1994) ou de sobrevivência média, e, inicialmente, os efeitos de fatores avaliados por teste de Log-Rank e os de co-variáveis por regressão de Cox (Cox, 1984). Os efeitos de fatores e co-variáveis, considerados estatisticamente relevantes $(p<0,10)$ ou clinicamente relevantes, foram também observados, todos presentes, num modelo de regressão logística para múltiplas variáveis (Hosmer e Lemeshow, 1989) no óbito hospitalar e no desfecho clínico composto. Para o óbito tardio, no longo prazo após a cirurgia, múltiplas variáveis foram avaliadas por modelo de regressão de Cox (Cox, 1984).

O nível de significância dos testes foi arbitrado em $5 \%$, ou seja, diferenças foram consideradas significativas quando $o$ valor de $p$ dos testes foi menor que $5 \%$. Os casos em que o valor de $p$ se manteve entre $5 \%$ e $<10 \%$ sugeriram tendências de efeito significativo.

\subsubsection{Considerações Éticas}

Este estudo foi aprovado pelo Comitê de Ética em Pesquisa do Instituto Dante Pazzanese de Cardiologia na data 05 de Outubro de 2010, sob o protocolo de número 3994. 
4 RESULTADOS 
Foram incluídos 257 pacientes, no período de janeiro de 2004 a dezembro de 2010 , sendo $33,9 \%$ do sexo feminino, $7 \%$ de etnia negra e idade média de 57,7 anos. Desta população, 75\% tinham diagnóstico de aneurisma de aorta ascendente e $25 \%$ de dissecção crônica de aorta tipo A de Stanford, estando o tabagismo presente em 40,5\%, a diabetes melitus em $13,2 \%$ e a hipertensão arterial sistêmica em 78,6\%. A dor torácica esteve presente em 41,6\% dos pacientes, o diagnóstico de Síndrome de Marfan em 2,7\%, sendo a FEVE média avaliada em 57,8\%, EuroScore médio de 6,12. Nesta casuística, 55 pacientes $(21,4 \%)$ foram submetidos a reoperações, sendo que em $29(50,9 \%)$ deles foi realizada apenas a troca valvar aórtica no primeiro procedimento, em $9(16,4 \%)$ a cirurgia para revascularização do miocárdio, em 5 (9,1\%) a dissecção aguda da aorta, em 4 (7,3\%) a coarctação de aorta, em $3(5,4 \%)$ a aneurisma de aorta, e apenas um caso em cada uma das situações seguintes: troca da valva mitral, plastia da valva tricúspide, persistência do canal arterial, comunicação interventricular, tetralogia de Fallot, interrupção do arco aórtico. A cirurgia simultânea para revascularização do miocárdio foi necessária em 49 pacientes(19,1\%).

Os dados demográficos de todos os pacientes incluídos no presente estudo encontram-se descritos na Tabela 1. Medidas quantitativas estão resumidas em amplitude, média e desvio padrão; as medidas qualitativas em frequência absoluta e percentual. 
Tabela 1. Fatores demográficos e pré-operatórios.

\begin{tabular}{|c|c|c|c|c|}
\hline Idade (anos) & 18 a 81 & Média 57,7 & DP 13 & \\
\hline Peso (kg) & 41 a 115 & Média 72,8 & DP 13,27 & \\
\hline Sexo & $\begin{array}{c}\text { Masc. } \\
170(66,1 \%)\end{array}$ & $\begin{array}{c}\text { Fem. } \\
87(33,9 \%)\end{array}$ & & \\
\hline Etnia & $\begin{array}{l}\text { Negra } \\
18(7 \%)\end{array}$ & $\begin{array}{l}\text { Não Negra } \\
239(93 \%)\end{array}$ & & \\
\hline Classe Funcional (NYHA) & $\begin{array}{c}1 \\
70(27,2 \%)\end{array}$ & $\begin{array}{c}\| \\
119(46,3 \%)\end{array}$ & $\begin{array}{c}\text { III } \\
65(25,3 \%)\end{array}$ & $\begin{array}{c}\text { IV } \\
31,2 \%)\end{array}$ \\
\hline Diagnóstico & $\begin{array}{l}\text { Aneurisma } \\
193(75 \%)\end{array}$ & $\begin{array}{l}\text { Dissecção } \\
64(24,9 \%)\end{array}$ & & \\
\hline Métodos Diagnósticos & $\begin{array}{c}\text { Ecocardiograma } \\
242(94,2 \%)\end{array}$ & $\begin{array}{c}\text { TC } \\
162(63 \%)\end{array}$ & $\begin{array}{l}\text { Cateterismo } \\
181(70,4 \%)\end{array}$ & $\begin{array}{c}\text { RNM } \\
2(0,8 \%)\end{array}$ \\
\hline Tabagismo & $104(40,5 \%)$ & & & \\
\hline Diabetes mellitus & $34(13,2 \%)$ & & & \\
\hline DAOP & $11(4,3 \%)$ & & & \\
\hline HAS (mmhg) & $202(78,6 \%)$ & & & \\
\hline PAS & 110 a 220 & Média 151,5 & DP 20,1 & \\
\hline PAD & 40 a 130 & Média 85,5 & DP 14,9 & \\
\hline IRC & $21(8,2 \%)$ & & & \\
\hline IRC dialítica & $1(0,4 \%)$ & & & \\
\hline AVC prévio & $15(5,8 \%)$ & & & \\
\hline DPOC & $7(2,7 \%)$ & & & \\
\hline Doença Cerebrovascular & $4(1,6 \%)$ & & & \\
\hline Sd. Marfan & $7(2,7 \%)$ & & & \\
\hline Síncope & $7(2,7 \%)$ & & & \\
\hline Derrame Pericárdico & $3(1,2 \%)$ & & & \\
\hline Dor torácica & $107(41,6 \%)$ & & & \\
\hline Sintomas Neurológicos & $4(1,6 \%)$ & & & \\
\hline Cirurgia Cardíaca Prévia & $55(21,4 \%)$ & & & \\
\hline Doença Coronária & $53(20,6 \%)$ & & & \\
\hline RM associado & $49(19,1 \%)$ & & & \\
\hline $\mathrm{FE}(\%)$ & 20 a 80 & Média 57,8 & DP 11,6 & \\
\hline FE & $\begin{array}{c}\text { Ecocardiograma } \\
256(99,6 \%)\end{array}$ & $\begin{array}{c}\text { RNM } \\
1(0,4 \%)\end{array}$ & & \\
\hline Creatinina & 0,5 a 2,4 & Média 1,13 & DP 0,32 & \\
\hline EuroSCORE & 3 a 17 & Média 6,12 & DP 2,52 & \\
\hline Eletiva & $247(96,1 \%)$ & & & \\
\hline
\end{tabular}

\subsection{Fase Hospitalar}

Com o objetivo de identificar as variáveis prognósticas independentemente associadas com desfechos clinicamente relevantes, foi realizada análise univariada para selecionar variáveis a serem incluídas no 
modelo multivariado. A Tabela 2 mostra a análise univariada dos fatores demográficos pré-operatórios em relação ao óbito hospitalar.

Tabela 2. Fatores demográficos e pré-operatórios e óbito hospitalar.

\begin{tabular}{|c|c|c|c|c|}
\hline \multicolumn{5}{|c|}{ Variáveis } \\
\hline \multicolumn{5}{|c|}{ Óbito hospitalar } \\
\hline n (\%) & Não (N=236) & $\operatorname{Sim}(N=21)$ & Total $(\mathrm{N}=\mathbf{2 5 7})$ & P valor \\
\hline Feminino & $78(33,05 \%)$ & $9(42,86 \%)$ & $87(33,85 \%)$ & $0,360(P)$ \\
\hline Negra & $14(5,93 \%)$ & $4(19,05 \%)$ & $18(7 \%)$ & $0,085(F)$ \\
\hline Dissecção & $54(22,88 \%)$ & $10(47,62 \%)$ & $64(24,9 \%)$ & $0,012(P)$ \\
\hline ECO & $226(95,76 \%)$ & $16(76,19 \%)$ & $242(94,16 \%)$ & $0,004(F)$ \\
\hline Tabagismo & $96(40,68 \%)$ & $8(38,1 \%)$ & $104(40,47 \%)$ & $0,810(P)$ \\
\hline Diabetes & $29(12,29 \%)$ & $5(23,81 \%)$ & $34(13,23 \%)$ & $0,170(F)$ \\
\hline DAOP & $8(3,39 \%)$ & $3(14,29 \%)$ & $11(4,28 \%)$ & $0,018(P)$ \\
\hline HAS & $183(77,54 \%)$ & $19(90,48 \%)$ & $202(78,6 \%)$ & $0,160(P)$ \\
\hline IRC & $17(7,2 \%)$ & $4(19,05 \%)$ & $21(8,17 \%)$ & $0,058(P)$ \\
\hline AVC prévio & $13(5,51 \%)$ & $2(9,52 \%)$ & $15(5,84 \%)$ & $0,450(P)$ \\
\hline DPOC & $6(2,54 \%)$ & $1(4,76 \%)$ & $7(2,72 \%)$ & $0,540(P)$ \\
\hline Doença Cerebrovascular & $2(0,85 \%)$ & $2(9,52 \%)$ & $4(1,56 \%)$ & $0,002(P)$ \\
\hline Sd Marfan & $7(2,97 \%)$ & $0(0 \%)$ & $7(2,72 \%)$ & $0,420(P)$ \\
\hline Síncope & $6(2,54 \%)$ & $1(4,76 \%)$ & $7(2,72 \%)$ & $0,540(P)$ \\
\hline Derrame Pericárdico & $2(0,85 \%)$ & $1(4,76 \%)$ & $3(1,17 \%)$ & $0,220(F)$ \\
\hline Dor torácica & $102(43,22 \%)$ & $5(23,81 \%)$ & $107(41,63 \%)$ & $0,084(P)$ \\
\hline Sintomas Neurológicos & $3(1,27 \%)$ & $1(4,76 \%)$ & $4(1,56 \%)$ & $0,290(F)$ \\
\hline Cirurgia Cardíaca Prévia & $46(19,49 \%)$ & $9(42,86 \%)$ & $55(21,4 \%)$ & $0,012(P)$ \\
\hline Doença Coronária & $45(19,07 \%)$ & $8(38,1 \%)$ & $53(20,62 \%)$ & $0,039(P)$ \\
\hline Eletiva & $226(95,76 \%)$ & $21(100 \%)$ & $247(96,11 \%)$ & $0,330(P)$ \\
\hline Canulação da Aorta & $170(72,34 \%)$ & $14(66,67 \%)$ & $184(71,88 \%)$ & $0,580(P)$ \\
\hline Valva Aórtica Bicúspide & $37(15,68 \%)$ & $2(9,52 \%)$ & $39(15,18 \%)$ & $0,450(P)$ \\
\hline Insuficiência Aórtica & $147(62,29 \%)$ & $13(61,9 \%)$ & $160(62,26 \%)$ & $0,970(P)$ \\
\hline Hemopericárdio & $3(1,27 \%)$ & $2(9,52 \%)$ & $5(1,95 \%)$ & $0,055(F)$ \\
\hline \multirow{2}{*}{\multicolumn{5}{|c|}{$\begin{array}{c}\text { Média (DP) } \\
\text { Mediana (Per25;Per75) }\end{array}$}} \\
\hline & & & & \\
\hline \multirow[t]{2}{*}{ Idade (anos) } & $57,5(13,13)$ & $59,9(11,62)$ & $57,56(12,95)$ & \multirow{2}{*}{0,471} \\
\hline & $59(48,25 ; 68)$ & $60(53,5 ; 67,5)$ & $59(48 ; 67,25)$ & \\
\hline \multirow[t]{2}{*}{ Última Creatinina } & $1,11(0,33)$ & $1,26(0,29)$ & $1,13(0,32)$ & \multirow{2}{*}{0,019} \\
\hline & $1(0,9 ; 1,3)$ & $1,2(1,05 ; 1,45)$ & $1(0,9 ; 1,3)$ & \\
\hline
\end{tabular}

F: teste de Fisher;P: teste de Pearson

Na Tabela 3 estão descritos os fatores intra e pós-operatório associados ao óbito durante a fase hospitalar, por meio da análise univariada 
Tabela 3. Fatores intra e pós-operatórios e óbito hospitalar

\begin{tabular}{|c|c|c|c|c|}
\hline \multicolumn{5}{|c|}{ Variáveis } \\
\hline \multicolumn{5}{|c|}{ Óbito hospitalar } \\
\hline n (\%) & Não (N=236) & $\operatorname{Sim}(N=21)$ & Total $(\mathrm{N}=\mathbf{2 5 7})$ & $P$ valor \\
\hline Cirurgia de Coronárias & $42(17,8 \%)$ & $7(33,33 \%)$ & $49(19,07 \%)$ & $0,082(P)$ \\
\hline Hemiarco & $18(7,63 \%)$ & $2(9,52 \%)$ & $20(7,78 \%)$ & $0,750(P)$ \\
\hline Bentall & $85(36,02 \%)$ & $6(28,57 \%)$ & $91(35,41 \%)$ & $0,490(P)$ \\
\hline Cabrol & $7(2,97 \%)$ & $2(9,52 \%)$ & $9(3,5 \%)$ & $0,110(P)$ \\
\hline Tubo supra coronariano & $125(52,97 \%)$ & $12(57,14 \%)$ & $137(53,31 \%)$ & $0,710(P)$ \\
\hline Tirone David & $4(1,69 \%)$ & $1(4,76 \%)$ & $5(1,95 \%)$ & $0,340(F)$ \\
\hline Yacoub & $4(1,69 \%)$ & $0(0 \%)$ & $4(1,56 \%)$ & $1,000(F)$ \\
\hline Stent Aorta Descendente & $19(8,05 \%)$ & $3(14,29 \%)$ & $22(8,56 \%)$ & $0,320(P)$ \\
\hline $\begin{array}{l}\text { Reimplante de Vasos } \\
\text { da Base Bloco }\end{array}$ & $11(4,66 \%)$ & $3(14,29 \%)$ & $14(5,45 \%)$ & $0,060(P)$ \\
\hline Reimplante Separados & $2(0,85 \%)$ & $0(0 \%)$ & $2(0,78 \%)$ & $1,000(F)$ \\
\hline Aortoplastia & $3(1,27 \%)$ & $0(0 \%)$ & $3(1,17 \%)$ & $1,000(F)$ \\
\hline Revisão de Hemostasia & $15(6,36 \%)$ & $4(19,05 \%)$ & $19(7,39 \%)$ & $0,033(P)$ \\
\hline Hemoderivados & $178(75,42 \%)$ & $20(95,24 \%)$ & $198(77,04 \%)$ & $0,039(P)$ \\
\hline Antifibrinolítico & $84(35,59 \%)$ & $11(52,38 \%)$ & $95(36,96 \%)$ & $0,120(P)$ \\
\hline Complicação Neurológica & $13(5,51 \%)$ & $4(19,05 \%)$ & $17(6,61 \%)$ & $0,017(P)$ \\
\hline Complicação Renal & $13(5,51 \%)$ & $9(42,86 \%)$ & $22(8,56 \%)$ & $<0,001(\mathrm{P})$ \\
\hline Complicação Infecciosa & $31(13,14 \%)$ & $10(47,62 \%)$ & $41(15,95 \%)$ & $<0,001(\mathrm{P})$ \\
\hline Complicação Pulmonar & $33(13,98 \%)$ & $14(66,67 \%)$ & $47(18,29 \%)$ & $<0,001(\mathrm{P})$ \\
\hline Complicação Vascular & $1(0,42 \%)$ & $6(28,57 \%)$ & $7(2,72 \%)$ & $<0,001(\mathrm{P})$ \\
\hline Complicação Gastrointestinal & $4(1,69 \%)$ & $0(0 \%)$ & $4(1,56 \%)$ & $1,000(F)$ \\
\hline Arritmia & $66(27,97 \%)$ & $14(66,67 \%)$ & $80(31,13 \%)$ & $<0,001(\mathrm{P})$ \\
\hline Falência Múltiplos Órgãos & $0(0 \%)$ & $14(66,67 \%)$ & $14(5,45 \%)$ & $<0,001(\mathrm{P})$ \\
\hline Insuficiência Cardíaca & $12(5,08 \%)$ & $13(61,9 \%)$ & $25(9,73 \%)$ & $<0,001(\mathrm{P})$ \\
\hline Choque Cardiogênico & $2(0,85 \%)$ & $15(71,43 \%)$ & $17(6,61 \%)$ & $<0,001(\mathrm{P})$ \\
\hline Síndrome Má Perfusão & $0(0 \%)$ & $16(76,19 \%)$ & $16(6,23 \%)$ & $<0,001(\mathrm{P})$ \\
\hline AAS & $165(69,92 \%)$ & $0(0 \%)$ & $165(64,2 \%)$ & $<0,001(\mathrm{P})$ \\
\hline Clopidogrel & $1(0,42 \%)$ & $0(0 \%)$ & $1(0,39 \%)$ & $1,000(F)$ \\
\hline IECA/BRA & $193(81,78 \%)$ & $0(0 \%)$ & $193(75,1 \%)$ & $<0,001(\mathrm{P})$ \\
\hline Betabloqueador & $169(71,61 \%)$ & $0(0 \%)$ & $169(65,76 \%)$ & $<0,001(\mathrm{P})$ \\
\hline Estatina & $58(24,58 \%)$ & $0(0 \%)$ & $58(22,57 \%)$ & $0,010(P)$ \\
\hline Anti-arritmico & $44(18,64 \%)$ & $0(0 \%)$ & $44(17,12 \%)$ & $0,030(P)$ \\
\hline Diurético & $92(38,98 \%)$ & $0(0 \%)$ & $92(35,8 \%)$ & $<0,001(\mathrm{P})$ \\
\hline Espironolactona & $13(5,51 \%)$ & $0(0 \%)$ & $13(5,06 \%$ & $0,270(P)$ \\
\hline
\end{tabular}




\begin{tabular}{lcccc}
\hline \multicolumn{1}{c}{ Média (DP) } \\
Mediana (Per25;Per75) & & & & \\
\hline Sangramento nas & $509,39(303,3)$ & $594,62(465,31)$ & $516,35(319,23)$ & \multirow{2}{*}{0,756} \\
primeiras 24hs (ml) & $434(320 ; 640)$ & $450(275 ; 999)$ & $438(320 ; 650)$ & \\
Tempo de CEC (min) & $138,83(45,25)$ & $185,95(90,31)$ & $142,67(50,24)$ & 0,006 \\
& $137,5(105 ; 162,25)$ & $180(122,5 ; 195)$ & $140(110 ; 170)$ & \\
Tempo de Anóxia (min) & $101,44(32,87)$ & $115,95(57)$ & $103,6(35,29)$ & 0,464 \\
& $101(79 ; 123)$ & $99(86,5 ; 138,5)$ & $103(80 ; 125)$ & \\
EuroSCORE & $5,98(2,5)$ & $7,62(2,18)$ & $6,05(2,47)$ & 0,002 \\
& $6(4 ; 7)$ & $7(6 ; 9)$ & $6(4 ; 7,25)$ & \\
\hline
\end{tabular}

F: teste de Fisher;P: teste de Pearson 
A Tabela 4 analisa os fatores demográficos e pré-operatórios associados ao desfecho clínico composto por meio de análise univariada

Tabela 4. Fatores pré-operatórios e desfecho clínico composto

\begin{tabular}{|c|c|c|c|c|}
\hline \multicolumn{5}{|c|}{ Variáveis } \\
\hline \multicolumn{5}{|c|}{ Evento combinado } \\
\hline n (\%) & Não (N=159) & $\operatorname{Sim}(N=98)$ & Total $(\mathrm{N}=257)$ & P valor \\
\hline Feminino & $103(64,78 \%)$ & $67(68,37 \%)$ & $170(66,15 \%)$ & $0,550(P)$ \\
\hline Etnia Negra & $11(6,92 \%)$ & $7(7,14 \%)$ & $18(7 \%)$ & $0,560(F)$ \\
\hline Dissecção & $33(20,75 \%)$ & $31(31,63 \%)$ & $64(24,9 \%)$ & $0,500(P)$ \\
\hline Tabagismo & $69(43,4 \%)$ & $35(35,71 \%)$ & $104(40,47 \%)$ & $0,220(P)$ \\
\hline Diabetes & $18(11,32 \%)$ & $16(16,33 \%)$ & $34(13,23 \%)$ & $0,250(P)$ \\
\hline DAOP & $3(1,89 \%)$ & $8(8,16 \%)$ & $11(4,28 \%)$ & $0,016(P)$ \\
\hline HAS & $125(78,62 \%)$ & $77(78,57 \%)$ & $202(78,6 \%)$ & $0,990(P)$ \\
\hline IRC & $11(6,92 \%)$ & $10(10,2 \%)$ & $21(8,17 \%)$ & $0,350(P)$ \\
\hline AVC prévio & $8(5,03 \%)$ & $7(7,14 \%)$ & $15(5,84 \%)$ & $0,480(P)$ \\
\hline DPOC & $5(3,14 \%)$ & $2(2,04 \%)$ & $7(2,72 \%)$ & $0,710(F)$ \\
\hline Doença Cerebrovascular & $2(1,26 \%)$ & $2(2,04 \%)$ & $4(1,56 \%)$ & $0,630(F)$ \\
\hline Sd Marfan & $4(2,52 \%)$ & $3(3,06 \%)$ & $7(2,72 \%)$ & $1,000(F)$ \\
\hline Síncope & $3(1,89 \%)$ & $4(4,08 \%)$ & $7(2,72 \%)$ & $0,430(F)$ \\
\hline Derrame Pericárdico & $1(0,63 \%)$ & $2(2,04 \%)$ & $3(1,17 \%)$ & $0,560(F)$ \\
\hline Dor torácica & $68(42,77 \%)$ & $39(39,8 \%)$ & $107(41,63 \%)$ & $0,630(P)$ \\
\hline Sintomas Neurológicos & $2(1,26 \%)$ & $2(2,04 \%)$ & $4(1,56 \%)$ & $0,630(F)$ \\
\hline Cirurgia Cardíaca Prévia & $23(14,47 \%)$ & $32(32,65 \%)$ & $55(21,4 \%)$ & $0,001(P)$ \\
\hline Doença Coronária & $27(16,98 \%)$ & $26(26,53 \%)$ & $53(20,62 \%)$ & $0,066(P)$ \\
\hline Eletiva & $155(97,48 \%)$ & $92(93,88 \%)$ & $247(96,11 \%)$ & $0,140(P)$ \\
\hline Canulação da Aorta & $121(76,58 \%)$ & $63(64,29 \%)$ & $184(71,88 \%)$ & $0,033(P)$ \\
\hline Valva Aórtica Bicúspide & $28(17,61 \%)$ & $11(11,22 \%)$ & $39(15,18 \%)$ & $0,160(P)$ \\
\hline Insuficiência Aórtica & $103(64,78 \%)$ & $57(58,16 \%)$ & $160(62,26 \%)$ & $0,280(P)$ \\
\hline Hemopericárdio & $1(0,63 \%)$ & $4(4,08 \%)$ & $5(1,95 \%)$ & $0,071(F)$ \\
\hline \multicolumn{5}{|l|}{ Média (DP) } \\
\hline \multicolumn{5}{|l|}{ Mediana (Per25;Per75) } \\
\hline \multirow[t]{2}{*}{ Idade (anos) } & $57,35(12,38)$ & $58,26(14,01)$ & $57,7(13,01)$ & \multirow{2}{*}{0,393} \\
\hline & $59(49 ; 67)$ & $60,5(48,75 ; 69)$ & $59(49 ; 68)$ & \\
\hline \multirow[t]{2}{*}{ Última Creatinina } & $1,08(0,31)$ & $1,19(0,34)$ & $1,13(0,32)$ & \multirow{2}{*}{0,004} \\
\hline & $1(0,9 ; 1,2)$ & $1,2(1 ; 1,4)$ & $1(0,9 ; 1,3)$ & \\
\hline
\end{tabular}

Teste de Mann-Whitney; F: teste de Fisher;P: teste de Pearson 
$\mathrm{Na}$ Tabela 5 estão descritos os fatores intra e pós-operatórios associados ao desfecho clínico composto por meio da análise univariada.

Tabela 5 - Fatores intra e pós-operatório e desfecho clínico composto

\begin{tabular}{|c|c|c|c|c|}
\hline \multicolumn{5}{|c|}{ Variáveis } \\
\hline \multicolumn{5}{|c|}{ Evento combinado } \\
\hline$n(\%)$ & Não (N=159) & $\operatorname{Sim}(N=98)$ & Total $(\mathrm{N}=257)$ & $P$ valor \\
\hline Cirurgia de Coronárias & $24(15,09 \%)$ & $25(25,51 \%)$ & $49(19,07 \%)$ & $0,039(P)$ \\
\hline Hemiarco & $10(6,29 \%)$ & $10(10,2 \%)$ & $20(7,78 \%)$ & $0,250(P)$ \\
\hline Bentall & $52(32,7 \%)$ & $39(39,8 \%)$ & $91(35,41 \%)$ & $0,240(P)$ \\
\hline Cabrol & $3(1,89 \%)$ & $6(6,12 \%)$ & $9(3,5 \%)$ & $0,073(\mathrm{P})$ \\
\hline Tubo supra coronariano & $89(55,97 \%)$ & $48(48,98 \%)$ & $137(53,31 \%)$ & $0,270(P)$ \\
\hline Tirone David & $4(2,52 \%)$ & $1(1,02 \%)$ & $5(1,95 \%)$ & $0,650(F)$ \\
\hline Yacoub & $4(2,52 \%)$ & $0(0 \%)$ & $4(1,56 \%)$ & $0,300(F)$ \\
\hline Stent Aorta Descendente & $12(7,55 \%)$ & $10(10,2 \%)$ & $22(8,56 \%)$ & $0,460(P)$ \\
\hline $\begin{array}{l}\text { Reimplante de Vasos } \\
\text { da Base Bloco }\end{array}$ & $9(5,66 \%)$ & $5(5,1 \%)$ & $14(5,45 \%)$ & $0,840(P)$ \\
\hline Reimplante Separados & $0(0 \%)$ & $2(2,04 \%)$ & $2(0,78 \%)$ & $0,140(F)$ \\
\hline Aortoplastia & $1(0,63 \%)$ & $2(2,04 \%)$ & $3(1,17 \%)$ & $0,560(F)$ \\
\hline Revisão de Hemostasia & $0(0 \%)$ & $19(19,39 \%)$ & $19(7,39 \%)$ & $<0,001(\mathrm{P})$ \\
\hline Hemoderivados & $101(63,52 \%)$ & $97(98,98 \%)$ & $198(77,04 \%)$ & $<0,001(\mathrm{P})$ \\
\hline Antifibrinolítico & $37(23,27 \%)$ & $58(59,18 \%)$ & $95(36,96 \%)$ & $<0,001(\mathrm{P})$ \\
\hline Complicação Neurológica & $1(0,63 \%)$ & $16(16,33 \%)$ & $17(6,61 \%)$ & $<0,001(\mathrm{P})$ \\
\hline Complicação Renal & $2(1,26 \%)$ & $20(20,41 \%)$ & $22(8,56 \%)$ & $<0,001(\mathrm{P})$ \\
\hline Complicação Infecciosa & $10(6,29 \%)$ & $31(31,63 \%)$ & $41(15,95 \%)$ & $<0,001(\mathrm{P})$ \\
\hline Complicação Pulmonar & $11(6,92 \%)$ & $36(36,73 \%)$ & $47(18,29 \%)$ & $<0,001(\mathrm{P})$ \\
\hline Complicação Vascular & $1(0,63 \%)$ & $6(6,12 \%)$ & $7(2,72 \%)$ & $0,013(F)$ \\
\hline Complicação Gastrointestinal & $1(0,63 \%)$ & $3(3,06 \%)$ & $4(1,56 \%)$ & $0,150(F)$ \\
\hline Arritmia & $44(27,67 \%)$ & $36(36,73 \%)$ & $80(31,13 \%)$ & $0,120(P)$ \\
\hline Falência de Múltiplos Órgãos & $0(0 \%)$ & $14(14,29 \%)$ & $14(5,45 \%)$ & $<0,001(P)$ \\
\hline Insuficiência Cardíaca & $0(0 \%)$ & $25(25,51 \%)$ & $25(9,73 \%)$ & $<0,001(\mathrm{P})$ \\
\hline Choque Cardiogênico & $0(0 \%)$ & $17(17,35 \%)$ & $17(6,61 \%)$ & $<0,001(\mathrm{P})$ \\
\hline Sindrome de Má Perfusão & $0(0 \%)$ & $16(16,33 \%)$ & $16(6,23 \%)$ & $<0,001(P)$ \\
\hline AAS & $110(69,18 \%)$ & $55(56,12 \%)$ & $165(64,2 \%)$ & $0,034(P)$ \\
\hline Clopidogrel & $1(0,63 \%)$ & $0(0 \%)$ & $1(0,39 \%)$ & $1,000(F)$ \\
\hline IECA/BRA & $132(83,02 \%)$ & $61(62,24 \%)$ & $193(75,1 \%)$ & $<0,001(\mathrm{P})$ \\
\hline Betabloqueador & $114(71,7 \%)$ & $55(56,12 \%)$ & $169(65,76 \%)$ & $0,011(P)$ \\
\hline Estatina & $40(25,16 \%)$ & $18(18,37 \%)$ & $58(22,57 \%)$ & $0,200(P)$ \\
\hline Anti-arítmico & $33(20,75 \%)$ & $11(11,22 \%)$ & $44(17,12 \%)$ & $0,049(P)$ \\
\hline Diurético & $51(32,08 \%)$ & $41(41,84 \%)$ & $92(35,8 \%)$ & $0,110(P)$ \\
\hline Espironolactona & $7(4,4 \%)$ & $6(6,12 \%)$ & $13(5,06 \%)$ & - \\
\hline
\end{tabular}




\begin{tabular}{lcccc}
\hline \multicolumn{1}{c}{ Média (DP) } & \multicolumn{3}{c}{} & \\
\multicolumn{1}{c}{ Mediana (Per25;Per75) } & & & & \\
\hline Tempo de CEC (min) & $130,72(39,96)$ & $162,09(62,19)$ & $142,68(51,81)$ & $<0,001$ \\
& $130(100 ; 155)$ & $152,5(123,75 ; 185)$ & $140(110 ; 170)$ & \\
Sangramento nas primeiras & $430,84(187,27)$ & $655,1(424,72)$ & $516,35(319,23)$ & $<0,001$ \\
24hs (ml) & $380(290 ; 520)$ & $540(350 ; 873,75)$ & $438(320 ; 650)$ & \\
& $96,72(31,05)$ & $112,19(40,12)$ & $102,62(35,52)$ & 0,002 \\
Tempo de Anóxia (min) & $98(75 ; 116)$ & $111(83 ; 137,5)$ & $101(80 ; 123)$ & \\
& $5,55(2,2)$ & $7,04(2,73)$ & $6,12(2,52)$ & $<0,001$ \\
EuroSCORE & $6(4 ; 7)$ & $7(5,75 ; 8)$ & $6(4 ; 8)$ & \\
\end{tabular}

Teste de Mann-Whitney; F: teste de Fisher;P: teste de Pearson

A Tabela 6 descreve, por meio de modelo logístico, as variáveis preditoras independentes associadas ao óbito hospitalar.

Tabela 6. Modelo logístico para óbito hospitalar

\begin{tabular}{l|c|c|c|c|c|c}
\hline & \multicolumn{1}{c}{ Efeito } & \multicolumn{2}{c}{ EP } & \multicolumn{2}{c}{ RC } & \multicolumn{2}{c}{ IC95\% } & \multirow{2}{*}{ P valor } \\
\hline Etnia Negra & 1,92 & 0,76 & 6,82 & 1,54 & 30,2 & 0,011 \\
Doença Cerebrovascular & 2,35 & 1,14 & 10,51 & 1,12 & 98,7 & 0,04 \\
Dor torácica & $-1,32$ & 0,64 & 0,27 & 0,08 & 0,94 & 0,04 \\
Hemopericárdio & 3,56 & 1,14 & 35,08 & 3,73 & 330,2 & 0,002 \\
Tipo de operação: Cabrol & 2,29 & 0,97 & 9,86 & 1,47 & 66,36 & 0,019 \\
Cirurgia de Coronárias & 1,49 & 0,62 & 4,43 & 1,31 & 15,06 & 0,017 \\
Revisão de hemostasia & 1,74 & 0,76 & 5,72 & 1,29 & 25,29 & 0,021 \\
Tempo de CEC (min) & 0,02 & 0 & 1,016 & 1,007 & 1,026 & 0,001 \\
Constante & $-5,8$ & 1,01 & 0 & & & $<0,001$ \\
\hline
\end{tabular}

Valor de p (Hosmer e Lemeshow)=0,553; RC : Razão de Chances; EP: Erro Padrão

$\mathrm{O}$ valor de $\mathrm{p}$ (Hosmer e Lemeshou $)=0,553$ mostrou um ajuste adequado do modelo. A medida de efeito neste modelo é a razão de chances com respectivo intervalo de confiança de 95\%. Indivíduos de etnia negra, presença de doença cerebrovascular, hemopericárdio, operação de Cabrol, cirurgia de coronárias associada, revisão de hemostasia e tempo de CEC prolongado foram preditores de óbito hospitalar. A dor torácica como manifestação clínica, foi identificada como fator protetor. 
Esse mesmo modelo, ajustado para sexo e idade, como mostra a Tabela 7, demonstrou que apenas a doença cerebrovascular foi excluída como preditor de mortalidade, confirmando a robustez do modelo multivariado na descrição das variáveis prognósticas independentes associadas ao óbito hospitalar.

Tabela 7. Modelo logístico para óbito hospitalar ajustado para sexo e idade.

\begin{tabular}{|c|c|c|c|c|c|c|}
\hline & Efeito & EP & RC & \multicolumn{2}{|c|}{ IC95\% } & $P$ valor \\
\hline Sexo Feminino & 0,55 & 0,61 & 1,74 & 0,53 & 5,73 & 0,362 \\
\hline Idade (anos) & 0,03 & 0,03 & 1,03 & 0,97 & 1,08 & 0,317 \\
\hline Etnia Negra & 1,88 & 0,79 & 6,56 & 1,38 & 31,13 & 0,018 \\
\hline Doença Cerebrovascular & 1,91 & 1,19 & 6,73 & 0,65 & 69,22 & 0,109 \\
\hline Dor torácica & $-1,42$ & 0,66 & 0,24 & 0,07 & 0,88 & 0,031 \\
\hline Hemopericárdio & 3,2 & 1,19 & 24,6 & 2,38 & 254,25 & 0,007 \\
\hline Tipo de operação: Cabrol & 2,34 & 0,99 & 10,43 & 1,5 & 72,57 & 0,018 \\
\hline Cirurgia de coronárias & 1,23 & 0,65 & 3,432 & 0,959 & 12,278 & 0,058 \\
\hline Revisão de hemostasia & 1,74 & 0,78 & 5,67 & 1,2413 & 25,903 & 0,025 \\
\hline Tempo de CEC (min) & 0,02 & 0,01 & 1,019 & 1,008 & 1,03 & 0,001 \\
\hline Constante & $-7,92$ & 2,23 & 0 & & & 0 \\
\hline
\end{tabular}

Valor de p (Hosmer e Lemeshow) =0,554; RC : Razão de Chances; EP: Erro Padrão 
A análise multivariada realizada para identificar as variáveis independentemente associadas com o desfecho clínico composto encontrase descrita na Tabela 8.

Tabela 8. Modelo logístico para desfecho clínico composto

\begin{tabular}{l|c|c|c|c|c|c}
\hline & Efeito & EP & RC & \multicolumn{2}{|c|}{ IC95\% } & P valor \\
\hline Sítio canulação: axilar & 1,011 & 0,54 & 2,75 & 0,95 & 7,96 & 0,062 \\
Antifibrinolítico & 1,169 & 0,34 & 3,22 & 1,65 & 6,27 & 0,0006 \\
Tipo de cirurgia: Cabrol & 1,662 & 0,857 & 5,27 & 0,98 & 28,25 & 0,0524 \\
Complicação Renal $^{\star *}$ & 2,001 & 0,81 & 7,40 & 1,52 & 36,01 & 0,0132 \\
Complicação Pulmonar** $_{\text {Arritmia Grave }}^{\star \star * *}$ & 1,295 & 0,45 & 3,65 & 1,51 & 8,84 & 0,0041 \\
EuroESCORE & 1,196 & 0,64 & 3,31 & 0,95 & 11,51 & 0,0602 \\
Tempo de CEC (min) & 0,209 & 0,07 & 1,23 & 1,08 & 1,41 & 0,0026 \\
& 0,009 & 0,004 & 1,01 & 1 & 1,02 & 0,0265 \\
Constante & & & & & & \\
\hline
\end{tabular}

Valor de $p$ (Hosmer e Lemeshow) $=0,432$;

Complicação Renal**: creatinina $>2 \mathrm{mg} / \mathrm{dl}$ ou $2 x>$ pré-opertório.

Complicação Pulmonar ${ }^{\star * *}$ : necessidade de ventilação invasiva em período $>48 \mathrm{~h}$.

Arritmia grave $^{* \star * *}$ : TV,FV e BAVT

Fatores como uso de antifibrinolítico, complicação renal, complicação respiratória, EuroScore e tempo de CEC apresentaram associação independente com risco aumentado de ocorrência do desfecho clínico composto hospitalar (óbito, sangramento, complicação neurológica e disfunção ventricular). Fatores como sítio de canulação axilar, cirurgia de Cabrol e arritmia grave, sugerem aumento de risco de desfecho composto, entretanto, não houve significância estatística destas variáveis, devendo ser interpretadas como tendência de risco aumentado.

$\mathrm{Na}$ Tabela 9, está descrito o modelo logístico para desfecho clínico composto, ajustado para sexo e idade, o qual não altera as observações da análise anterior. Deve ser enfatizado que quando as variáveis sexo e idade foram incluídas, o ajuste do modelo foi rejeitado (Valor de $p$ [Hosmer e Lemeshow] $=0,028)$, ou seja, esta análise não deve ser valorizada devido à falta de ajuste adequado com base nas variáveis incluídas. Portanto, em relação ao desfecho clínico composto, devemos nos ater aos resultados expostos na Tabela 8. 
Tabela 9. Modelo logístico para desfecho clínico composto ajustado para sexo e idade.

\begin{tabular}{|c|c|c|c|c|c|c|}
\hline & Efeito & EP & $\mathrm{RC}$ & \multicolumn{2}{|c|}{ IC95\% RC } & P valor \\
\hline Sexo Masculino & $-0,040$ & 0,38 & 0,96 & 0,46 & 2,00 & 0,9155 \\
\hline Idade & $-0,025$ & 0,016 & 0,98 & 0,95 & 1,01 & 0,1158 \\
\hline Sítio canulação: axilar & 0,856 & 0,6 & 2,35 & 0,81 & 6,88 & 0,117 \\
\hline Antifibrinolítico & 1,175 & 0,35 & 3,24 & 1,64 & 6,39 & 0,0007 \\
\hline Tipo de cirurgia: Cabrol & 1,703 & 0,85 & 5,49 & 1,04 & 28,99 & 0,0448 \\
\hline Complicação Renal* & 2,172 & 0,82 & 8,78 & 1,76 & 43,88 & 0,0081 \\
\hline Complicação Pulmonar** & 1,290 & 0,47 & 3,63 & 1,46 & 9,04 & 0,0056 \\
\hline Arritmia Grave ${ }^{* \star *}$ & 1,147 & 0,62 & 3,15 & 0,94 & 10,66 & 0,064 \\
\hline EuroESCORE & 0,286 & 0,09 & 1,33 & 1,13 & 1,57 & 0,0008 \\
\hline Tempo de CEC (min): & 0,008 & 0,004 & 1,01 & 1 & 1,02 & 0,0538 \\
\hline Constante & $-3,099$ & 1,033 & 0,05 & & & 0,0027 \\
\hline
\end{tabular}

Valor de $p$ (Hosmer e Lemeshow) $=0,028$

Complicação Renal* : creatinina $>2 \mathrm{mg} / \mathrm{dl}$ ou $2 x>$ pré-op.

Complicação Pulmonar ${ }^{* *}$ : necessidade de ventilação invasiva em período $>48 \mathrm{~h}$.

Arritmia grave $^{* * *}$ : TV,FV e BAVT (taquicardia ventricular, fibrilação ventricular, bloqueio átrioventricular total)

\subsection{Seguimento no Longo Prazo}

O tempo de acompanhamento após a alta hospitalar foi em média 970 dias com desvio-padrão de 157 dias. A mediana foi de 772 dias. Neste período, ocorreram 10 óbitos $(4,5 \%)$. Neste grupo de pacientes que apresentou óbito, o tempo médio de sobrevivência foi de 355 dias, com mediana de 298 dias e desvio-padrão de 427 dias. 
A Tabela 10 mostra a análise univariada fatores demográficos e préoperatórios para óbito tardio.

Tabela 10. Fatores demográficos e pré-operatórios para óbito tardio.

\begin{tabular}{|c|c|c|c|c|}
\hline \multicolumn{5}{|c|}{ Variáveis } \\
\hline \multicolumn{5}{|c|}{ Óbito tardio } \\
\hline n (\%) & Não (N=224) & $\operatorname{Sim}(N=10)$ & Total $(\mathrm{N}=\mathbf{2 3 4})$ & $\mathbf{P}$ \\
\hline Feminino & $74(33,04 \%)$ & $3(30 \%)$ & $77(32,91 \%)$ & 0,929 \\
\hline Etnia Negra & $16(7,14 \%)$ & $0(0 \%)$ & $16(6,84 \%)$ & 0,120 \\
\hline Dissecção & $51(22,77 \%)$ & $5(50 \%)$ & $56(23,93 \%)$ & 0,044 \\
\hline Tabagismo & $96(42,86 \%)$ & $5(50 \%)$ & $101(43,16 \%)$ & 0,738 \\
\hline Diabetes & $31(13,84 \%)$ & $0(0 \%)$ & $31(13,25 \%)$ & 0,224 \\
\hline DAOP & $9(4,02 \%)$ & $2(20 \%)$ & $11(4,7 \%)$ & 0,009 \\
\hline HAS & $175(78,13 \%)$ & $10(100 \%)$ & $185(79,06 \%)$ & 0,109 \\
\hline IRC & $15(6,7 \%)$ & $1(10 \%)$ & $16(6,84 \%)$ & 0,571 \\
\hline AVC prévio & $12(5,36 \%)$ & $3(30 \%)$ & $15(6,41 \%)$ & $\begin{array}{c}< \\
0,001\end{array}$ \\
\hline DPOC & $6(2,68 \%)$ & $0(0 \%)$ & $6(2,56 \%)$ & 0,568 \\
\hline Doença Cerebrovascular & $3(1,34 \%)$ & $0(0 \%)$ & $3(1,28 \%)$ & 0,767 \\
\hline Sd Marfan & $5(2,23 \%)$ & $2(20 \%)$ & $7(2,99 \%)$ & 0,001 \\
\hline Síncope & $6(2,68 \%)$ & $0(0 \%)$ & $6(2,56 \%)$ & 0,595 \\
\hline Derrame Pericárdico & $2(0,89 \%)$ & $0(0 \%)$ & $2(0,85 \%)$ & 0,767 \\
\hline Dor torácica & $90(40,18 \%)$ & $4(40 \%)$ & $94(40,17 \%)$ & 0,879 \\
\hline Sintomas neurológicos & $3(1,34 \%)$ & $0(0 \%)$ & $3(1,28 \%)$ & 0,725 \\
\hline Cirurgia Cardíaca Prévia & $47(20,98 \%)$ & $1(10 \%)$ & $48(20,51 \%)$ & 0,432 \\
\hline Doença Coronária & $46(20,54 \%)$ & $2(20 \%)$ & $48(20,51 \%)$ & 0,948 \\
\hline Eletiva & $215(95,98 \%)$ & $10(100 \%)$ & $225(96,15 \%)$ & 0,509 \\
\hline Canulação da Aorta & $162(72,65 \%)$ & $7(70 \%)$ & $169(72,53 \%)$ & 0,862 \\
\hline Valva Aórtica Bicúspide & $35(15,63 \%)$ & $0(0 \%)$ & $35(14,96 \%)$ & 0,170 \\
\hline Insuficiência Aórtica & $141(62,95 \%)$ & $4(40 \%)$ & $145(61,97 \%)$ & 0,175 \\
\hline Hemopericárdio & $3(1,34 \%)$ & $0(0 \%)$ & $3(1,28 \%)$ & 0,767 \\
\hline
\end{tabular}




\begin{tabular}{lcccc}
\hline \multicolumn{1}{c}{ Média (DP) } & & & \\
\multicolumn{1}{c}{ Mediana (Per25;Per75) } & & & & \\
\hline Idade (anos) & $57,36(12,93)$ & $62,1(13,2)$ & $57,56(12,95)$ & 0,240 \\
& $59(48 ; 67)$ & $63(51,75 ; 76,25)$ & $59(48 ; 67,25)$ & \\
Tempo de CEC (min) & $143,35(50,84)$ & $127,5(32,17)$ & $142,67(50,24)$ & 0,359 \\
& $140(111 ; 170)$ & $122,5(98,75 ; 170)$ & $140(110 ; 170)$ & \\
Última creatinina & $1,12(0,3)$ & $1(0,35)$ & $1,11(0,31)$ & 0,223 \\
& $1(0,9 ; 1,3)$ & $0,9(0,8 ; 1,05)$ & $1(0,9 ; 1,3)$ & \\
Sangramento nas primeiras & $508,16(309,49)$ & $749,30(459,41)$ & $518,47(319,71)$ & 0,020 \\
24hs (ml) & $434(320 ; 640)$ & $752,5(325 ; 1010,5)$ & $439(320 ; 642,5)$ & \\
& $104,19(35,8)$ & $90,3(16,53)$ & $103,6(35,29)$ & 0,237 \\
Tempo de Anóxia (min) & $105,5(80 ; 125)$ & $85(79,25 ; 107,75)$ & $103(80 ; 125)$ & \\
& $6,01(2,46)$ & $6,9(2,81)$ & $6,05(2,47)$ & 0,253 \\
EuroSCORE & $6(4 ; 7)$ & $7(4 ; 8,5)$ & $6(4 ; 7,25)$ & \\
\hline
\end{tabular}


A Tabela 11 mostra a análise univariada dos fatores intra e pósoperatório para óbito tardio.

Tabela 11. Fatores intra e pós-operatórios para óbito tardio.

\begin{tabular}{|c|c|c|c|c|}
\hline \multicolumn{5}{|c|}{ Variáveis } \\
\hline \multicolumn{5}{|c|}{ Óbito tardio } \\
\hline$n(\%)$ & Não (N=224) & $\operatorname{Sim}(N=10)$ & Total $(\mathrm{N}=\mathbf{2 3 4})$ & $\mathbf{P}$ \\
\hline Cirurgia de Coronárias & $42(18,75 \%)$ & $2(20 \%)$ & $44(18,8 \%)$ & 0,946 \\
\hline Hemiarco & $18(8,04 \%)$ & $0(0 \%)$ & $18(7,69 \%)$ & 0,335 \\
\hline Bentall & $82(36,61 \%)$ & $2(20 \%)$ & $84(35,9 \%)$ & 0,304 \\
\hline Cabrol & $7(3,13 \%)$ & $1(10 \%)$ & $8(3,42 \%)$ & 0,189 \\
\hline Tubo supra coronariano & $118(52,68 \%)$ & $6(60 \%)$ & $124(52,99 \%)$ & 0,673 \\
\hline Tirone David & $4(1,79 \%)$ & $0(0 \%)$ & $4(1,71 \%)$ & 0,673 \\
\hline Yacoub & $4(1,79 \%)$ & $0(0 \%)$ & $4(1,71 \%)$ & 0,661 \\
\hline Stent Aorta Descendente & $17(7,59 \%)$ & $2(20 \%)$ & $19(8,12 \%)$ & 0,140 \\
\hline $\begin{array}{l}\text { Reimplante de Vasos } \\
\text { da Base Bloco }\end{array}$ & $8(3,57 \%)$ & $3(30 \%)$ & $11(4,7 \%)$ & $<0,001$ \\
\hline Reimplante Separados & $1(0,45 \%)$ & $0(0 \%)$ & $1(0,43 \%)$ & 0,800 \\
\hline Aortoplastia & $3(1,34 \%)$ & $0(0 \%)$ & $3(1,28 \%)$ & 0,713 \\
\hline Revisão de Hemostasia & $13(5,8 \%)$ & $2(20 \%)$ & $15(6,41 \%)$ & 0,058 \\
\hline Hemoderivados & $171(76,34 \%)$ & $7(70 \%)$ & $178(76,07 \%)$ & 0,583 \\
\hline Antifibrinolítico & $81(36,16 \%)$ & $2(20 \%)$ & $83(35,47 \%)$ & 0,384 \\
\hline Complicação Neurológica & $11(4,91 \%)$ & $2(20 \%)$ & $13(5,56 \%)$ & 0,017 \\
\hline Complicação Renal & $15(6,7 \%)$ & $0(0 \%)$ & $15(6,41 \%)$ & 0,488 \\
\hline Complicação Infecciosa & $34(15,18 \%)$ & $2(20 \%)$ & $36(15,38 \%)$ & 0,603 \\
\hline Complicação Pulmonar & $36(16,07 \%)$ & $2(20 \%)$ & $38(16,24 \%)$ & 0,554 \\
\hline Complicação Vascular & $4(1,79 \%)$ & $0(0 \%)$ & $4(1,71 \%)$ & 0,879 \\
\hline Complicação Gastrointestinal & $3(1,34 \%)$ & $1(10 \%)$ & $4(1,71 \%)$ & 0,063 \\
\hline Arritmia & $63(28,13 \%)$ & $4(40 \%)$ & $67(28,63 \%)$ & 0,373 \\
\hline Falência Múltiplos Órgãos & $9(4,02 \%)$ & $0(0 \%)$ & $9(3,85 \%)$ & - \\
\hline Insuficiencia Cardíaca & $17(7,59 \%)$ & $0(0 \%)$ & $17(7,26 \%)$ & 0,429 \\
\hline Choque Cardiogênico & $10(4,46 \%)$ & $0(0 \%)$ & $10(4,27 \%)$ & 0,738 \\
\hline $\begin{array}{l}\text { Síndrome } \\
\text { Má Perfusão }\end{array}$ & $9(4,02 \%)$ & $0(0 \%)$ & $9(3,85 \%)$ & - \\
\hline AAS & $149(66,52 \%)$ & $7(70 \%)$ & $156(66,67 \%)$ & 0,963 \\
\hline Clopidogrel & $1(0,45 \%)$ & $0(0 \%)$ & $1(0,43 \%)$ & 0,841 \\
\hline IECA/BRA & $174(77,68 \%)$ & $9(90 \%)$ & $183(78,21 \%)$ & 0,469 \\
\hline Betabloqueador & $156(69,64 \%)$ & $4(40 \%)$ & $160(68,38 \%)$ & 0,028 \\
\hline Estatina & $52(23,21 \%)$ & $5(50 \%)$ & $57(24,36 \%)$ & 0,065 \\
\hline Anti-arrítmico & $35(15,63 \%)$ & $3(30 \%)$ & $38(16,24 \%)$ & 0,269 \\
\hline Diurético & $83(37,05 \%)$ & $5(50 \%)$ & $88(37,61 \%)$ & 0,464 \\
\hline Espironolactona & $13(5,8 \%)$ & $0(0 \%)$ & $13(5,56 \%)$ & 0,2 \\
\hline
\end{tabular}


A Tabela 12 mostra as variáveis relacionadas independente com óbito durante o seguimento no prazo longo com ajuste do modelo de Cox.

Tabela 12 - Modelo de Regressão de Cox para óbito tardio.

\begin{tabular}{|c|c|c|c|c|c|c|}
\hline Modelo Inicial & Efeito & EP & $\mathbf{P}$ valor & RC & \multicolumn{2}{|c|}{ IC $95 \%$} \\
\hline Diagnóstico Aneurisma & $-0,8306$ & 0,7911 & 0,2937 & 0,4358 & 0,0925 & 2,0542 \\
\hline DAOP & 2,0988 & 1,1488 & 0,0677 & 8,156 & 0,8582 & 77,5119 \\
\hline AVC prévio & 1,4975 & 0,9128 & 0,1009 & 4,4703 & 0,7471 & 26,7487 \\
\hline Sd. Marfan & 1,6067 & 1,3182 & 0,2229 & 4,9865 & 0,3765 & 66,0406 \\
\hline Sítio canulação: carótida bilateral & 0,1976 & 1,2019 & 0,8694 & 1,2184 & 0,1155 & 12,848 \\
\hline Revisão de hemostasia: & $-0,5394$ & 1,7323 & 0,7555 & 0,5831 & 0,0196 & 17,3879 \\
\hline Neurológico & 0,554 & 1,3219 & 0,6752 & 1,7402 & 0,1304 & 23,2168 \\
\hline Complicação Gastrointestinal: & 1,0547 & 1,79 & 0,5557 & 2,871 & 0,086 & 95,8681 \\
\hline Medicação alta: Betabloqueador & $-0,5655$ & 0,8393 & 0,5004 & 0,5681 & 0,1096 & 2,9432 \\
\hline Medicação alta: Estatina & 1,6367 & 0,8491 & 0,0539 & 5,1383 & 0,9729 & 27,137 \\
\hline Fração de ejeção\% & 0,0631 & 0,0474 & 0,1832 & 1,0652 & 0,9706 & 1,1689 \\
\hline $\begin{array}{l}\text { Sangramento nas primeiras } 24 \mathrm{hs} \text { : } \\
(\mathrm{ml})\end{array}$ & 0,002 & 0,0014 & 0,1651 & 1,002 & 0,9992 & 1,0048 \\
\hline \multicolumn{7}{|l|}{ Modelo Final } \\
\hline DAOP & 2,0082 & 0,8293 & 0,0155 & 7,4499 & 1,4664 & 37,8495 \\
\hline AVC prévio & 1,9496 & 0,803 & 0,0152 & 7,0257 & 1,456 & 33,9019 \\
\hline Sd. Marfan & 1,9148 & 0,9853 & 0,052 & 6,7854 & 0,9838 & 46,8022 \\
\hline Medicação alta: Estatina & 1,6081 & 0,7387 & 0,0295 & 4,9935 & 1,1739 & 21,2408 \\
\hline $\begin{array}{l}\text { Sangramento nas primeiras } 24 \mathrm{hs} \text { : } \\
(\mathrm{ml})\end{array}$ & 0,0017 & 0,0008 & 0,0209 & 1,0017 & 1,0003 & 1,0032 \\
\hline
\end{tabular}

DAOP aumentou a chance de óbito em 7,4 vezes

AVC prévio aumentou a chance de óbito em 7 vezes

Sd Marfan aumentou a chance de óbito em 6,7 vezes

Medicação alta: Estatina aumentou a chance de óbito em 5 vezes

O aumento a cada $1 \mathrm{ml}$ de sangramento nas primeiras 24 horas aumentou a chance de óbito em $0,17 \%$

O Modelo de Regressão de Cox, final, demonstra que a presença de doença arterial obstrutiva periférica, acidente vascular cerebral prévio, a utilização de estatina na alta hospitalar e sangramento aumentado nas primeiras 24 horas de pós-operatório, estiveram independentemente associados com risco aumentado de óbito tardio, ou seja durante o prazo longo com média de 970 dias (32,2 meses ou 2,7 anos). 
Com a inclusão dos fatores sexo e idade no modelo, como mostra a Tabela 13, houve perda de significância estatística para os fatores uso de estatina na alta hospitalar e sangramento nas primeiras 24 horas, permanecendo tendência da associação destes fatores com óbito tardio. $\mathrm{O}$ fator Síndrome de Marfan mostrou associação estatisticamente significante com óbito tardio, sendo que no modelo anterior, havia apenas tendência desta associação. Esta análise corrobora a robustez do modelo para avaliação de óbito tardio nesta população.

Tabela 13. Modelo de Regressão de Cox ajustado para sexo e idade.

\begin{tabular}{l|c|c|c|c|c|c}
\hline & \multicolumn{1}{c}{ Efeito } & EP & \multicolumn{1}{c}{ P valor } & RC & \multicolumn{2}{c}{ IC 95\% } \\
\hline Idade & 0,045 & 0,0367 & 0,2156 & 1,0465 & 0,9739 & 1,1245 \\
Sexo & $-0,33$ & 0,7801 & 0,6721 & 0,7188 & 0,1558 & 3,316 \\
DAOP & 1,896 & 0,8436 & 0,0246 & 6,6594 & 1,2745 & 34,7952 \\
AVC prévio & 2,048 & 0,8211 & 0,0126 & 7,7488 & 1,5498 & 38,7429 \\
Sd Marfan & 2,691 & 1,2126 & 0,0265 & 14,7501 & 1,3698 & 158,8301 \\
Medicação alta: Estatina & 1,362 & 0,7576 & 0,0722 & 3,9036 & 0,8842 & 17,2332 \\
Sangramento nas primeiras 24hs: $(\mathrm{ml})$ & 0,001 & 0,0008 & 0,0917 & 1,0014 & 0,9998 & 1,0029 \\
\hline
\end{tabular}

Com a inclusão de Sexo e Idade no modelo os fatores mantiveram-se significativos,porém diminuiu um pouco a significância de Estatina e Sangramento nas primeiras 24 horas

\subsection{Análises Exploratórias no Longo Prazo}

As análises abaixo descritas devem ser interpretadas como exploratórias para avaliação da sobrevida no prazo longo em relação a eventos selecionados, características demográficas, diagnóstico da patologia de aorta e procedimento cirúrgico. 
A representação do seguimento de longo prazo, no Gráfico 1, mostra a curva de sobrevida ao longo de aproximadamente 7 anos.

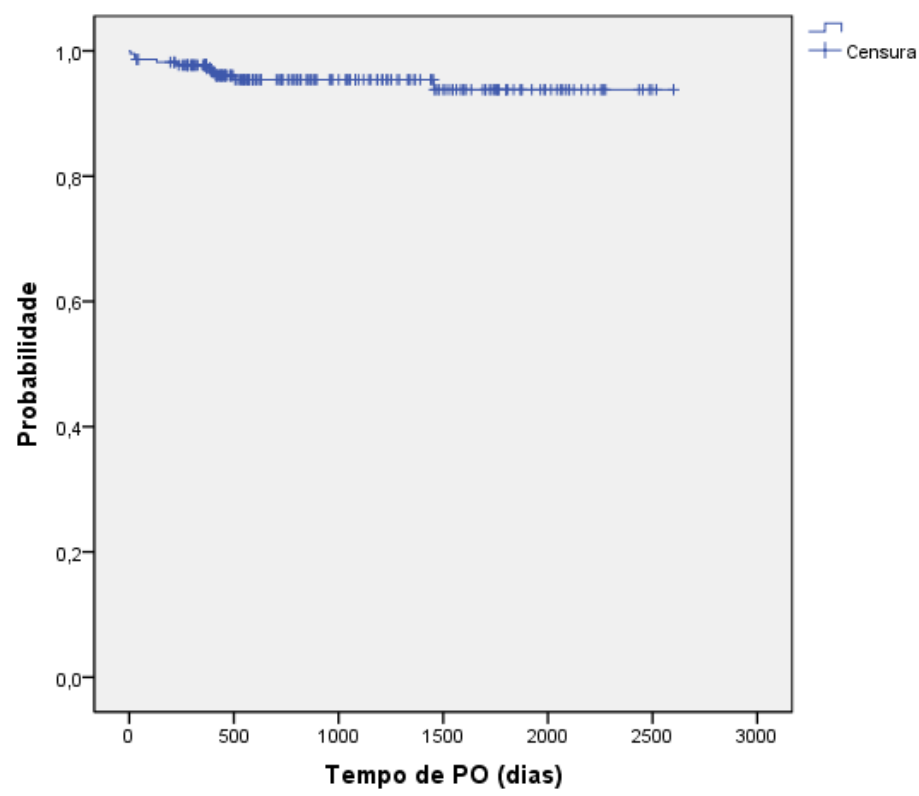

Gráfico 1. Curva de Sobrevida com seguimento médio de 7 anos 
O Gráfico 2 representa a sobrevida no longo prazo de pacientes que apresentaram sangramento aumentado durante as primeiras 24 horas após o procedimento cirúrgico (média de sangramento de 512,73 ml).

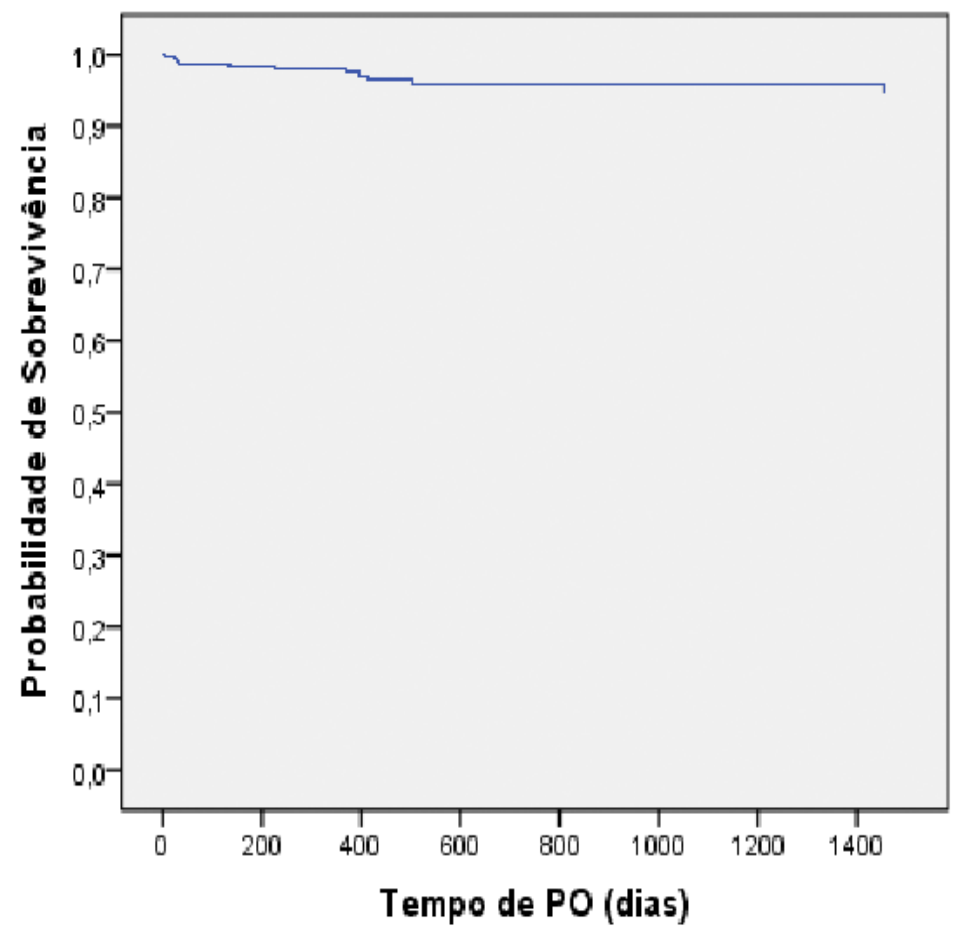

Gráfico 2. Curva de Sobrevida em pacientes com sangramento aumentado nas primeiras 24 horas 
O Gráfico 3 representa a sobrevida no longo prazo de pacientes com diagnóstico pré-operatório de aneurisma de aorta ascendente e dissecção crônica de aorta tipo A de Stanford.

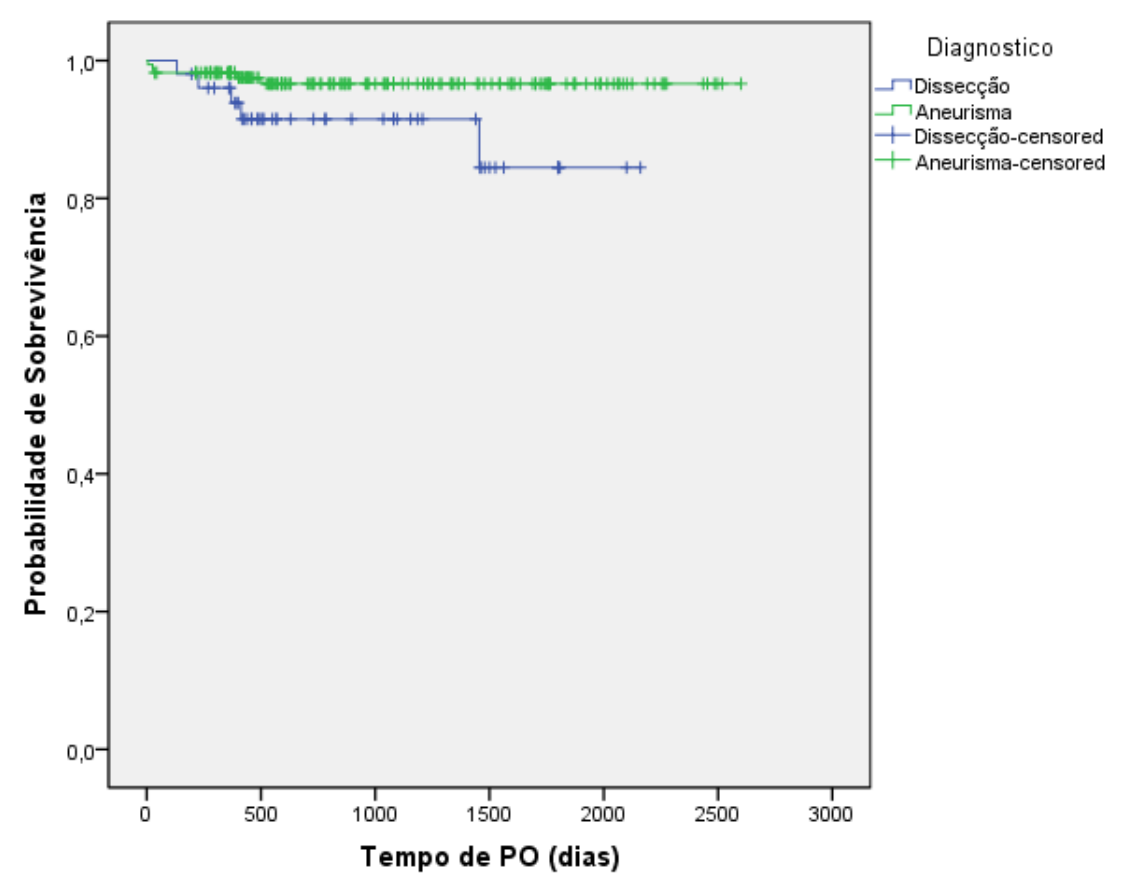

Gráfico 3. Curvas de Sobrevida dos pacientes com aneurisma de aorta e dissecção crônica de aorta tipo A de Stanford. 
O Gráfico 4 representa a sobrevida no longo prazo de pacientes com antecedente de doença arterial obstrutiva periférica.

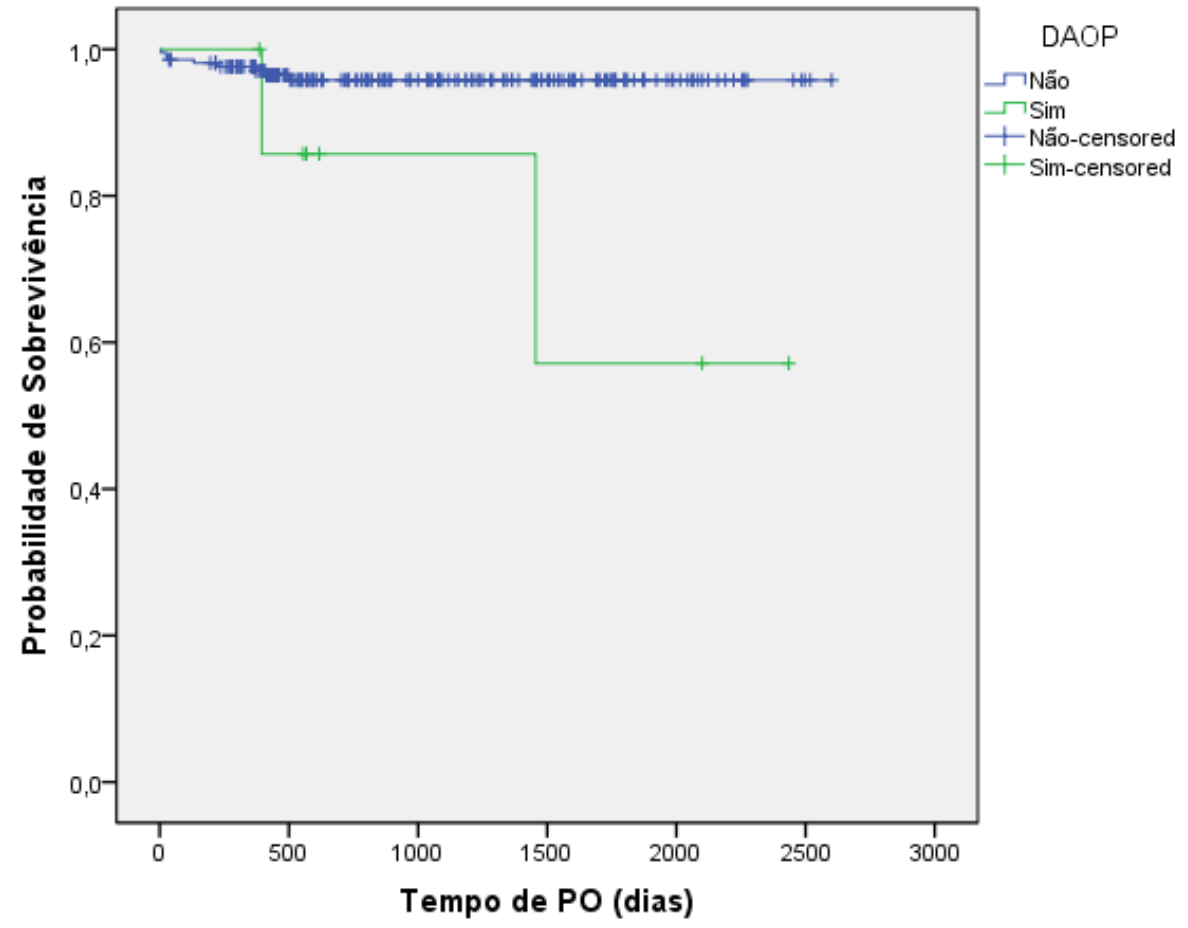

Gráfico 4. Curvas de Sobrevida dos pacientes com e sem Doença Arterial Obstrutiva Periférica 
O Gráfico 5 representa a sobrevida no longo prazo de pacientes com antecedente de acidente vascular cerebral.

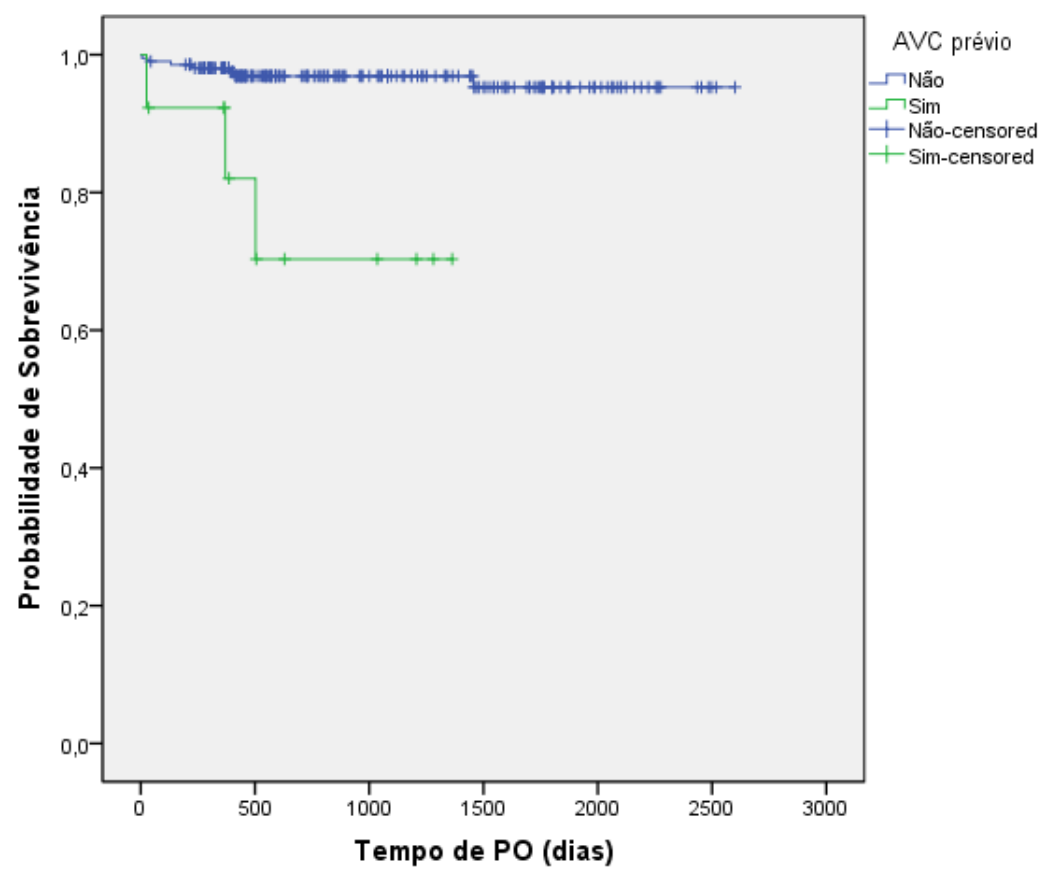

Gráfico 5. Curva de Sobrevida de pacientes com antecedentes de Acidente Vascular Cerebral. 
O Gráfico 6 representa a sobrevida no longo prazo de pacientes com diagnóstico prévio de Síndrome de Marfan.

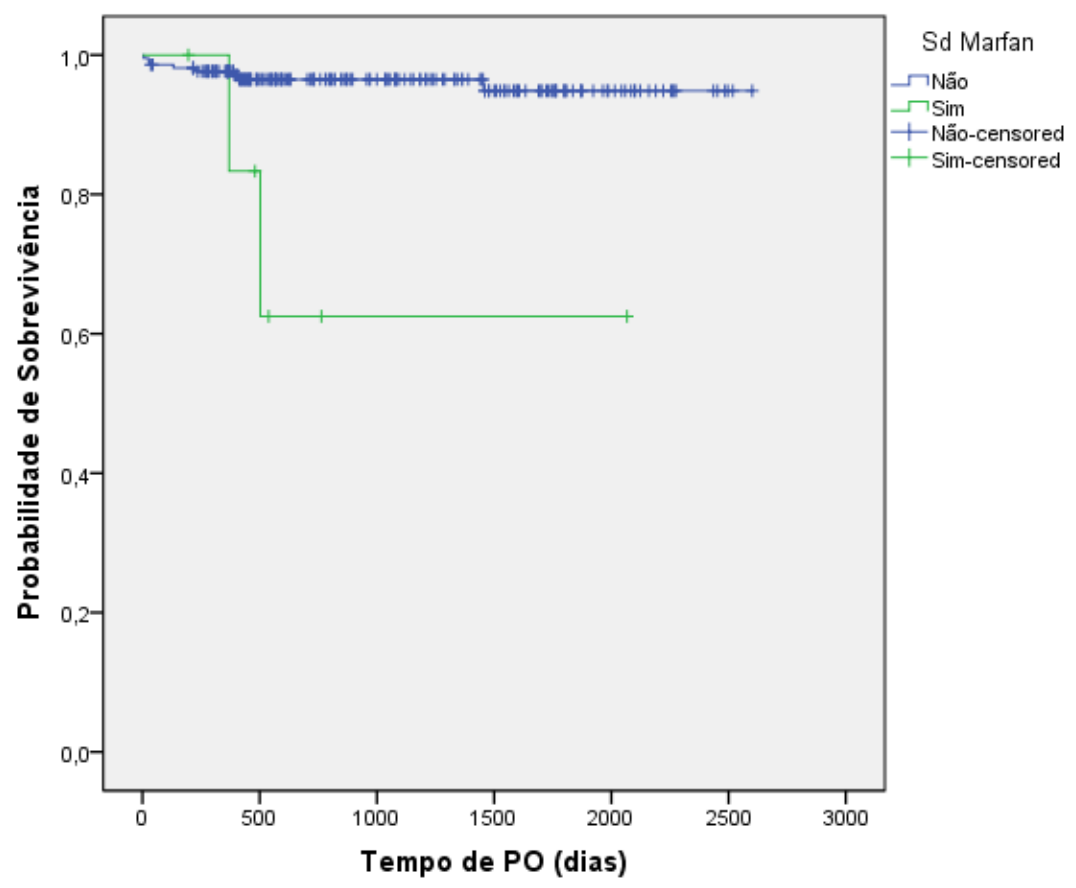

Gráfico 6. Curva de Sobrevida no longo prazo de pacientes com diagnóstico prévio de Síndrome de Marfan. 
5 DISCUSSÃO 
Nesta análise incluindo 257 pacientes consecutivos, operados durante o período de janeiro de 2004 a dezembro de 2010, a taxa de mortalidade total hospitalar de $8,17 \%$. Por meio de análise multivariada, o modelo logístico identificou os seguintes fatores associados independentemente ao óbito durante a fase hospitalar: pacientes de etnia negra, revascularização do miocárdio associada, operação de Cabrol, presença de doença cerebrovascular, necessidade de revisão de hemostasia, tempo prolongado de CEC e a presença de hemopericárdio. A presença de dor torácica, foi identificada como fator protetor. Fatores como sítio de canulação axilar, uso de antifibrinolítico, complicação neurológica, presença de arritmia grave, EuroSCORE, tempo de anóxia ( $\mathrm{min}$ ) e sangramento nas primeiras 24 horas, por meio de análise multivariada, estiveram associados independentemente à ocorrência do desfecho clínico composto. Quanto ao óbito tardio, os seguintes fatores foram identificados como independentemente associados ao aumento nas taxas deste evento por meio de análise multivariada: DAOP, AVC prévio, uso de estatina prévio à alta hospitalar e sangramento nas primeiras 24 horas.

Séries cirúrgicas contemporâneas envolvendo pacientes portadores de doença da aorta ascendente, com a utilização de modernas técnicas de enxertos e métodos de proteção cerebral e miocárdica, apresentam taxas de mortalidade hospitalar variando de $1,7 \%$ a $17,1 \%$, provavelmente devido à heterogeneidade da população de pacientes avaliada. As causas de mortalidade incluem hemorragia, AVC e insuficiência respiratória, sendo que a insuficiência cardíaca é considerada a causa mais comum de morte prematura nesta população ${ }^{49,50,51,52,53,54,55,56}$.

GAZONI et $a^{56}{ }^{56}$; compararam resultados imediatos de cirurgia eletiva de aneurisma de aorta torácica, entre centros de baixo volume $\quad<40$ cirurgias/ano) e de alto volume ( $>80$ cirurgias/ano). A mortalidade operatória foi de $8,3 \%$ e $3,7 \%$, respectivamente $(p=0,02)$. $\mathrm{Na}$ análise de regressão 
logística, centros de baixo volume, estiveram significativamente associados com aumento nas taxas de complicações e de mortalidade $(p<0,05)$.

Neste estudo, 66,1\% dos pacientes eram do sexo masculino e daqueles que evoluíram com óbito hospitalar $57,1 \%$ eram do sexo masculino. O sexo e a idade não apresentaram impacto com significância estatística nas taxas de mortalidade hospitalar e no longo prazo, após o ajuste entre as diferentes variáveis no modelo multivariado. Deve ser comentado que a idade apresenta-se como fator de risco independente para mortalidade em outros cenários da doença cardiovascular, como síndrome coronária aguda, fibrilação atrial ou insuficiência cardíaca, como também, pacientes do sexo feminino apresentam maiores taxas de mortalidade quando submetidas à cirurgia de revascularização miocárdica, em comparação com pacientes do sexo masculino. Os resultados da pesquisa em questão, podem ser explicados por meio de duas considerações: idade e sexo não representam fatores preditores independentemente associados com mortalidade em pacientes com doenças da aorta avaliadas neste trabalho ou devido à falta de poder estatístico, não foi possível demonstrar o efeito destas duas variáveis sobre desfechos clinicamente relevantes. A inclusão de número adicional de pacientes poderia esclarecer as considerações supracitadas. Estes dados são corroborados pela análise de GRUBB et al $^{57}$; demonstraram que resultados semelhantes são detectados no manuseio de mulheres com dissecção da aorta torácica. NIENABER et $\mathrm{al}^{58}$; observaram a distribuição das variáveis sexo e idade nas dissecções agudas e dos 1078 pacientes com dissecção aguda da aorta no IRAD, $32,1 \%$ eram mulheres e $2 / 3$ eram homens. As mulheres apresentavam idade superior aos homens e $28,6 \%$ dos homens com dissecção tinham idade $\geq 70$ anos, sendo que metade $(49,7 \%)$ das mulheres nesta faixa etária $(p<0,001)$. Apesar destas diferenças, quando todas as variáveis são inseridas no modelo logístico, na pesquisa atual, estas variáveis não emergiram como preditoras independentes de mortalidade.

Numa pesquisa sobre a qualidade de vida dos pacientes operados de aneurisma de aorta, LOHSE et $\mathrm{al}^{59}$; demonstraram conexão altamente 
significativa entre a operação cardíaca prévia e morte no pós-operatório $(p=0,001)$. Houve também associação significativa entre morte e infarto do miocárdio $(p<0,001)$, AVC $(p=0,001)$, tempo de ventilação prolongada $(p<0,001)$, aumento do uso de produtos de transfusão $(p=0,016)$ e tempos cirúrgicos prolongados $(p<0,001)$. A alta incidência de infarto do miocárdio peri-operatório esteve associada à alta porcentagem de pacientes com doença arterial coronariana. No que diz respeito à qualidade de vida, a classe funcional melhorou segundo a classificação da Canadian Cardiovascular Society. Um dos maiores impactos na redução da qualidade de vida desses pacientes foi a presença de AVC, assim como a internação prolongada.

No estudo publicado por CZERNY et $\mathrm{al}^{36}$; a idade não esteve associada com risco aumentado de mortalidade e lesão neurológica em pacientes submetidos a correção cirúrgica para doenças agudas ou crônicas da aorta torácica com parada circulatória hipotérmica, achado este concordante com os resultados desta tese.

Em nossa casuística, 55 pacientes $(21,4 \%)$ eram reoperações, sendo que em $29(51 \%)$ foi realizada apenas a troca valvar aórtica no primeiro procedimento, em $9(16,4 \%)$ houve a cirurgia para revascularização do miocárdio, em 5 (9,1\%) a dissecção aguda da aorta, em 4 (7,3\%) a coarctação de aorta, em 3 (5,5\%) o aneurisma de aorta. Cada um dos seguintes eventos: troca da valva mitral, plastia da valva tricúspide, persistência do canal arterial, comunicação interventricular, tetralogia de Fallot, interrupção do arco aórtico ocorreram em apenas 1 caso.

Embora esta variável, Cirurgia Cardíaca Prévia, na análise univariada para óbito hospitalar, os valores tivessem significância estatística $(p=0,012)$, na análise multivariada não houve persistência do nível de significância desta variável, mostrando não ser um preditor independente. Como demonstraram ESTRERA et $\mathrm{al}^{60}$; pacientes com dissecção aguda tipo $\mathrm{A}$ após cirurgia cardíaca prévia apresentaram riscos semelhantes de má- 
perfusão, hipotensão e tamponamento cardíaco. Este achado sugere que as aderências formadas após a operação não eliminam o risco de tamponamento cardíaco por ruptura de aorta. Embora os resultados sejam plausíveis, a mortalidade hospitalar foi maior $(31 \%$ vs $13,8 \%, p<0,007)$ do que entre os pacientes sem história prévia de cirurgia cardíaca.

Recomenda-se a substituição profilática da aorta ascendente, mesmo que aparentemente normal, onde houver alguma dilatação, nos casos de troca de valva aórtica bicúspide. Mesmo na ausência de doença significativa da valva aórtica, existe associação frequente com a dilatação da raiz da aorta, ectasia ânulo-aórtica e dissecção da aorta. Após a substituição da valva aórtica bicúspide, este achado é relatado como fator de risco para dissecção aguda tardia e aneurisma de aorta ascendente ${ }^{62,63,64,65,66}$.

A dilatação progressiva do arco aórtico levando à reoperação após o reparo do aneurisma da aorta ascendente em pacientes com valva aórtica bicúspide é um evento incomum, sendo a abordagem seletiva para a substituição do arco aórtico transverso considerada apropriada. Apesar de a dilatação progressiva da aorta ascendente após a substituição da valva aórtica bicúspide ser bem documentada, a dilatação progressiva dos seios de Valsalva não é evidente. A utilização separada de enxerto e da prótese aórtica é uma opção razoável desde que os seios não apresentem alargamento significativo ${ }^{67,68}$.

Para pacientes com valva aórtica bicúspide normofuncionante e dilatação da aorta ascendente, recomenda-se a operação para aqueles com diâmetro $>5 \mathrm{~cm}$ e conduta diferenciada para pacientes sob vigilância na ausência de aumento significativo (>0,5 cm/ano). A sobrevida global é considerada equivalente àquela de uma população considerada normal da mesma idade e sexo. A operação foi necessária em aproximadamente $10 \%$ dos pacientes acompanhados a cada ano ${ }^{69}$.

Todas essas recomendações são feitas com o objetivo de se evitar reintervenção cirúrgica, sobretudo na aorta ascendente, que por vezes pode ocorrer em condições clínicas desfavoráveis. 


\subsection{Variáveis associadas ao óbito hospitalar}

5.1.1. Etnia Negra: De um total de 257 pacientes 18 eram da etnia negra, correspondendo a $6(9,4 \%)$ das 64 dissecções e $12(6,2 \%)$ dos 193 aneurismas. Esta variável, por meio do modelo multivariado emergiu como forte preditor de mortalidade, apresentando razão de chance de 6,82 ( $p=$ 0,011). Quando o modelo foi ajustado para sexo e idade, houve persistência de valores similares da razão de chance passando $(6,56 ; p=0,018)$, denotando a robustez do modelo de análise.

A população negra tem incidência aumentada de doença cerebrovascular e doença renal crônica em relação aos caucasianos e menor incidência de doença cardíaca crônica, enquanto que asiáticos do sul apresentam alta incidência de doença cardíaca crônica, como relatou CHATURVEDI et $\mathrm{al}^{69}$. Estudos recentes observaram que afro-americanos apresentavam níveis elevados de PCR e fibrinogênio comparados à etnia brancos não-hispânicos e que PCR e fibrinogênio aumentados foram fatores independentes e significativamentes associados com valores reduzidos do índice tornozelo-braquial (ITB). Quando incluídos com fatores de risco convencionais em modelo de regressão linear multivariado, PCR e fibrinogênio ainda permanecem independentemente associados com ITB em negros; achados estes não encontrados na etnia brancos não-hispânicos $71,73,74$. Os caucasianos, por outro lado, aparecem com alta incidência de aneurisma de aorta abdominal (AAA), entretanto, não há estudos populacionais significativos estimando a prevalência de AAA num grupo étnico minoritário. É interessante que, quando AAA são encontrados na etnia negra, estão presentes em idades significativamente mais jovens do que em Caucasianos e a aterosclerose é o fator causal menor, segundo HOBBS et al $^{71}$.

ALEXANDER et $\mathrm{al}^{74}$; estudaram o padrão de aneurismas entre a população jovem negra do Quênia. Foram divididos em dois grupos : $\leq 40$ anos (Grupo I) e > 40 anos (Grupo II). Localizados na aorta, 49,6\% eram do grupo I e $68,6 \%$ do grupo II. A maioria na aorta abdominal (64,9\%), 
especialmente no segmento infrarrenal. No segmento ascendente da aorta, abaixo de $5 \%$, sendo equivalente nos dois grupos. A proporção entre os sexos é de 2,7: 1, com predominância para o sexo masculino. Nos segmentos intracraniano e aórtico,a maior incidência ocorreu entre 31 e 40 anos, e entre 21 e 30 na periferia. As comorbidades associadas em ambos os grupos, foram : hipertensão arterial, tabagismo, SIDA, alcoolismo,obesidade e síndrome de Marfan. Entretanto, apenas no grupo de pacientes com idade acima de 40 anos, aterosclerose e dislipidemia estiveram presentes, estando diabetes mellitus relacionado com aneurismas periféricos e intracranianos, mas não na aorta.

A prevalência de fatores de risco tradicionais aterotrombóticos variou significativamente entre os grupos étnicos. O uso de terapias médicas para reduzir o risco foi comparável entre todos os grupos. Em menos de 2 anos de seguimento, a taxa de mortalidade cardiovascular foi significativamente maior em negros $(6,1 \%)$ em comparação com todos os outros grupos étnicos $(3,9 \% ; p=0,01)$, segundo relato de MEADOWS et $\mathrm{al}^{75}$.

DEIRDRE $A$ et $a^{76}$ descreveram que, provavelmente a etnia em si não seja um fator de risco independente para todas as causas e mortalidade cardiovascular entre os brancos europeus e africanoscaribenhos. Os dados referentes a diferenças étnicas em todas as causas e mortalidade cardiovascular para o indivíduo sul-asiático são limitados, dado que número significativamente menor de homens sul-asiáticos poderia ser rastreado pelo ONS (Office for National Statistics), havendo falta de precisão dos dados de sobrevivência, como também a expressiva falta de dados sobre as mulheres sul-asiáticas.

Na amostra atual, a população negra apresentou menor incidência de aneurisma e dissecção de aorta do que a população não negra, entretanto, com taxa de mortalidade estatisticamente significativa mais elevada; talvez por apresentar maior gravidade dos fatores de risco. Tais investigações necessitam serem realizadas, para determinar qual o fator protetor que evitaria o desenvolvimento de aneurisma da aorta ascendente. 
Provavelmente, este fator geneticamente determinado, torna a parede da aorta menos vulnerável e frágil às labilidades pressóricas ao longo da vida, resultando ou pode ser resultado do equilíbrio metabólico da inibição ou ativação de enzimas de degradação da matriz extracelular.

5.1.2. Cirurgia de Revascularização Miocárdica: Outro fator relevante, em nosso estudo, foi a cirurgia para revascularização do miocárdio simultânea ao procedimento aórtico, que ocorreu em 53 pacientes (20,6\%). Este fator, foi considerado preditor de risco aumentado, com razão de chance de 4,43 $(p=0,017)$. Quando ajustado para sexo e idade, apresentou ligeira queda nos valores $(p=0,058$ e OR $=3,45)$. Em estudos prévios ${ }^{78,80}$, observou-se que $\mathrm{o}$ procedimento simultâneo para correção da aorta ascendente e revascularização do miocárdio pode ser realizado com segurança e com resultados satisfatórios. UEDA et $\mathrm{al}^{78}$; demonstraram que a revascularização coronária incompleta foi identificada como fator de risco para eventos cardiovasculares $(p=0,016)$. FERRO et $\mathrm{al}^{80}$; avaliaram 95 pacientes, dos quais 26 possuíam Aneurisma de Aorta Torácico (TAA) (21 na aorta ascendente, 1 no arco aórtico e 4 na aorta descendente), 10 tinham Aneurisma de Aorta Toracoabdominal (TAAA) (5 Crawford I, 1 Crawford II e 4 Carwford III) e 59 tinham Aneurisma de Aorta Abdominal (AAA) (56 infrarrenal). Pacientes com Aneurisma de Aorta Ascendente com 50 anos ou mais apresentaram maior prevalência de DAC quando comparados àqueles com idade inferior a $50(p=0,01)$. A prevalência para DAC foi de $63,1 \%$, e foi maior no grupo AAA do que nos grupos TAA e TAAA ( $p=0,001)$.

$A$ associação de doenças e de procedimentos agregam risco adicional; entretanto, o diagnóstico não realizado ou o tratamento parcial pode conduzir a resultados mais desfavoráveis.

5.1.3. Operação de Cabrol: Outra variável identificada como preditor independente foi a Operação de Cabrol, com razão de chance de 9,86 ( $p=$ $0,019)$ e quando ajustado para sexo e idade, manteve-se como preditor independente com razão de chance mais elevada(10,4; $p=0,018)$. Vários autores obtiveram bons resultados imediatos e tardios, porém com uma 
mensagem de alerta de acordo com KITAMURA et $\mathrm{al}^{81}$. Nesta série, a sobrevida atuarial foi de $83,3 \%$ em 5 anos e $72,9 \%$ em 10 anos, e $87,9 \%$ permaneceram livres de reoperação em 5 anos e $76,6 \%$ em 10 anos. Os óstios coronários foram examinados por angiografia ou angiotomografia computadorizada em 18 pacientes entre 43 e 189 meses após a operação. Dois pacientes desenvolveram estenose ou oclusão do óstio coronariano direito. Os resultados em relação à aorta ascendente foram favoráveis, com exceção de complicações coronarianas. A importância de acompanhamento cuidadoso para complicações coronárias tardias não pode ser subestimado. Em uma análise para o tratamento cirúrgico da raiz da aorta, comparando o tubo valvulado com a preservação da valva aórtica, Dias RR e $\mathrm{col}^{48}$, demonstraram, de maneira consistente com os achados da presente tese, a Operação de Cabrol como um dos preditores independentes de mortalidade hospitalar e tardia.

Nesta análise, foi realizada preferencialmente a Operação de Bentall DeBono modificada (Técnica do Botão), com resultados imediatos e tardios satisfatórios, comprovados em vários estudos. Como demonstado por GELSOMINO et al ${ }^{82}$, a taxa de mortalidade média de 30 dias foi de $5,5 \pm$ $2 \%$, a taxa de sobrevivência média de 16 anos foi de $91,7 \pm 3,2 \%$ e o risco médio livre de morte foi constante por mais de 3 ano (8,5 $\pm 3,5 \%)$. Nenhum paciente necessitou de reoperação durante o período de observação, como também não houve casos de endocardite, falhas de anticoagulação ou trombose da prótese. Estes dados sugerem que esta deveria ser a técnica de escolha para o tratamento cirúrgico da raiz da aorta.

A Operação de Cabrol, em muitos serviços, tem sido reservada para reoperações, nas quais a dissecção das aderências e a individualização das estruturas cardiovasculares muitas vezes foge dos padrões de segurança habitual e o risco de lesão dessas estruturas pode comprometer o resultado final do procedimento. Não obstante, é necessário ter extrema cautela na utilização de um enxerto artificial para reimplantar os óstios coronários. 
5.1.4. Doença Cerebrovascular: A doença cerebrovascular, aquí caracterizada como presença de lesão no sistema carotídeo, com indicação de intervenção ou não apresentou razão de chance de 10,5 ( $p=0,040)$. Quando ajustado para sexo e idade, esta variável permaneceu com significância estatística $(R C=6,7 ; p=0,109)$, mostrando a robustez do modelo multivariado. DAVIES et al ${ }^{83}$ em uma revisão de 514 pacientes com aneurisma de aorta ascendente não reparado, encontraram 70 pacientes $(13,4 \%)$ com diagnóstico da valva aórtica bicúspide (grupo A) e os restantes 445 pacientes, sem este diagnóstico (grupo B). Também avaliaram a taxa de crescimento da aorta e os fatores de risco para complicações. Pacientes do grupo A apresentaram menor incidência de $\operatorname{HAS}(p=0,0185)$, doença carotídea e AVC $(p=0,0184)$. O grupo A também apresentou maior taxa de crescimento da aorta $(0,19$ contra $0,13 \mathrm{~cm} / \mathrm{ano}, \mathrm{p}=0,0102)$. A incidência de ruptura ou dissecção foram semelhantes e a sobrevida global foi melhor entre os pacientes com VAB ( $p<0,0001)$. Entre os pacientes com VAB, aqueles com estenose aórtica apresentaram maior risco de ruptura, dissecção ou morte antes da correção cirúrgica do que aqueles que apresentavam valvas normofuncionantes ( $R C=10,5$; IC 95\% 1,15- 95,6). Aterosclerose carotídea e aterosclerose aórtica podem estar ambas associadas com doença arterial coronária e tromboembolismo cerebral. No entanto, a relação entra a doença carotídea assintomática e aterosclerose aórtica não é bem esclarecida. KALLIKAZAROS et al ${ }^{84}$, relataram alta prevalência de placas aórticas e carotídeas combinadas, em pacientes cardíacos, sem evidência clínica de doença cardiovascular. Concluíaram que a presença de placa carotídea reflete a presença de placa aórtica, entretanto a ausência de placa carotídea pode não refletir a ausência de placa aórtica. Porcentagem maior de pacientes com placas carotídeas e aórtica apresentavam HAS e diabetes mellitus em comparação com pacientes sem as referidas placas $(p<0,001)$.

Em pacientes com dissecção de aorta, preferencialmente, é utilizado o sítio de canulação direta da artéria axilar direita ao nível da prega axilar, pois ele proporciona fluxo anterógrado e raramente esta artéria está 
acometida por aterosclerose e a dissecção da aorta raramente progride até este local. Provavelmente, sua maior limitação seja o diâmetro em pacientes obesos. Nos aneurismas, a preferência é pelo tronco braquiocefálico, desde que não apresente doença aterosclerótica. A dlgito-pressão é potencialmente falha e às vezes existe a possibilidade de promover a embolização de material aterosclerótico, durante a manipulação. É reservado como terceira opção a canulação das artérias carótidas, caso haja falha nas outras opções ou se houver a necessidade de reimplantar os vasos supra-aórticos, separadamente. Esta sequência de opções ocorre justamente para minimizar os riscos de embolização durante a manipulação dessas artérias ou mesmo durante a CEC.

5.1.5. Revisão de Hemostasia: A necessidade de revisão de hemostasia foi identificado como preditor de óbito hospitalar com RC=5,7; IC 95\% 1,325,$3 ; p=0,0210$ ). Quando ajustado para sexo e idade, esta variável manteve a característica de preditor independente ( $R C=5,7$; IC 95\% 1,2-25,9; $p=0,025)$. MURPHY et $a^{25}$, em recente publicação, observaram que a transfusão sanguínea em pacientes submetidos à cirurgia cardíaca esteve fortemente associada com infecção e morbidade pós-operatória isquêmica, tempo de internação prolongado, aumento da mortalidade precoce e tardia e aumento de custos hospitalares. Os custos foram substancialmente maiores em pacientes que necessitaram de re-exploração por sangramento, como demonstrado por ALSTROM et $\left.a\right|^{86}$.

Habitualmente, a Cirurgia de Revascularização do Miocárdio (CRM) com CEC envolve menor incidência de sangramento e menor necessidade de transfusão sanguínea do que grandes cirurgias para tratamento das doenças da aorta. No entanto, a anemia pós-operatória é comum, ela muitas vezes persiste por meses após a CRM e está associada a resultados desfavoráveis. Em pacientes com anemia, que fazem uso de IECA houve diminuição da recuperação da anemia no pós-operatório e aumentou a incidência de eventos cardiovasculares após CRM, conforme publicado por WESTENBRINK et $a^{87}$. A transfusão peri-operatória de concentrado de 
hemácias é um fator de risco independente, e dose-dependente, para óbito hospitalar, mas não para mortalidade tardia após CRM. Em comparação com a sobrevida esperada, quem não recebe nenhuma transfusão sanguínea apresenta melhor sobrevida no longo prazo, enquanto o paciente que receber três ou mais unidades de concentrado de hemácias tem a sobrevida significativamente diminuída. Este efeito é causado principalmente por maior mortalidade nos primeiros 30 dias de pós-operatório nestes pacientes $^{89}$.

Como relatado por SVENSSON et $\mathrm{al}^{89}$, pacientes submetidos a procedimentos cirúrgicos em aorta ascendente e arco aórtico, e que participaram de técnicas de conservação de sangue, apresentaram significativamente $(p<0,05)$ menor incidência de transfusões homólogas, foram extubados em tempo mais precoce, apresentaram menor tempo de internação e receberam alta hospitalar em melhor classe funcional. A análise multivariada desses 60 pacientes mostrou que os preditores de transfusão homóloga intra-hospitalar, com valor de $p<0,05$, foram: idade, tempo de CEC e drenagem aumentada no pós-operatório.

SHIBATA et $\mathrm{al}^{90}$, demonstraram que pequenas quantidades de doação autóloga, maior perda de sangue e maior tempo cirúrgico foram preditores independentes para a transfusão de sangue homólogo. Dentre os pacientes com doação autóloga de $1600 \mathrm{ml}$ ou mais, $75 \%$ não necessitaram de transfusão de sangue homólogo no intra-operatório e $69 \%$ não necessitaram durante a internação hospitalar. A taxa de mortalidade perioperatória foi de $4,5 \%$ e entubação prolongada e infecção pós-operatória foram significativamente mais frequentes entre os pacientes que necessitaram de transfusão de sangue homólogo.

É absolutamente necessário extremo rigor técnico na ressecção e reconstrução de uma aorta com aneurisma ou dissecção, pois nas duas situações, trata-se de uma estrutura frágil e muitas vezes friável. Além do preparo pré-operatório, inclusive com doação de sangue autólogo, se possível, bem como a utilização de materiais modernos, no intra-operatório, 
que auxiliam na redução de sangramento. O controle pós-operatório deve ser mantido dentro de limites que mantenham a estabilidade hemodinâmica do paciente, e que ao mesmo tempo não provoquem uma ruptura ou laceração em tantas linhas de suturas em cavidades de alta pressão.

5.1.6. Hemopericárdio: A presença de hemopericárdio neste estudo apresentou Razão de Chance de 35,1; p=0,002) e quando ajustado para sexo e idade, persistiu como preditor independente $(R C=24,6 ; p=0,007)$. ISSELBACHER et al $^{91}$ demonstraram que pacientes com dissecção de aorta complicada por tamponamento cardíaco tiveram mortalidade precoce de $60 \%$. Enquanto 3 pacientes morreram por dissociação eletromecânica imediatamente após a apresentação, outras 3 mortes ocorreram após uma pericardiocentese bem sucedida, com intervalo de tempo de 5 a 40 minutos após o procedimento. A presença de hemopericárdio pode sinalizar a iminência de ruptura de aorta, entretanto GODA et $\mathrm{al}^{92}$ relataram que os fatores de risco para mortalidade hospitalar em pacientes com dissecção aguda de aorta tipo A de Stanford foram ressucitação cardiopulmonar, disfunção renal $e$ isquemia em extremidades inferiores. Choque e tamponamento cardíaco não foram fatores de risco nesta análise, entretanto, estes casos referem-se à dissecção aguda de aorta, diferente da análise do presente trabalho que avaliou dissecção crônica tipo A de Stanford.

O derrame pericárdico é mais comum na dissecção aguda de aorta ou durante a agudização de uma dissecção crônica. MEHTA et al $^{93}$ publicaram que a taxa de mortalidade hospitalar em dissecção aguda de aorta tipo A de Stanford é alta e pode ser prevista com o uso de um modelo clínico incorporado em uma ferramenta simples de previsão de risco. O derrame pericárdico na apresentação clínica desses pacientes, apresentou foi identificado como preditor independente $(p=0,07)$, como também a complicação tamponamento cardíaco $(p<0,0001)$. Neste modelo preditor proposto, o desfecho composto hipotensão arterial, choque e tamponamento esteve associado com maior mortalidade ( $R C=2,97$; IC 95\% 1,83-4,81; $p<0,001)$. A presença de derrame pericárdico sugere a necessidade de intervenção cirúrgica precoce, pois pode ser o evento precursor de um 
tamponamento cardíaco, complicação relacionada com maior mortalidade. O tratamento deve ser a correção da doença na aorta, e não a simples descompressão da cavidade pericárdica por meio de pericardiocentese.

5.1.7. Tempo de Circulação Extra-Corpórea: No que diz respeito ao tempo de CEC, a análise demonstrou ser fator preditor independente de mortalidade hospitalar ( $R C=1,016 / \mathrm{min} ; \mathrm{p}=0,001)$ Ou seja, para cada minuto de tempo de CEC ocorre aumento de $1,6 \%$ na mortalidade hospitalar. Após ajuste para sexo e idade, esta variável manteve-se como fator preditor independente de mortalidade hospitalar $(R C=1,019 \mathrm{~min} ; \mathrm{p}=0,001)$, novamente demonstrando a robustez do modelo multivariado utilizado nesta avaliação. HESSEL e Al II et al ${ }^{94}$ desceveram que ocorrem incidentes com risco de vida em $0,4 \%$ a 2,7\% das operações com CEC e a incidência de lesões graves ou morte encontra-se entre $0,06 \%$ e 0,08\%. A incidência de embolia aérea maciça situa-se entre $0,003 \%$ e $0,007 \%$, com $50 \%$ de resultados adversos. Em análise retrospectiva e não randomizada envolvendo 4.000 pacientes, PAROLARI et al ${ }^{95}$, compararam a utilização de bomba centrífuga e com rolete. Os resultados da regressão logística multivariada para mortalidade hospitalar, mostraram tempo de CEC prolongado, cirurgia cardíaca prévia e creatinina sérica $>2 \mathrm{mg} / \mathrm{dl}$ como fatores de risco independentes para este evento. Em análise multivariada avaliando o desfecho déficit neurológico permanente, o tempo de CEC, presença de AVC prévio e idade foram fatores de risco, e o uso de bomba centrífuga no circuito extracorpóreo foi identificado como fator protetor.

RANUCCl et $\mathrm{al}^{96}$, sugerem que a abordagem multifatorial parece ser mais adequada para responder as reações complexas que conduzem à lesões inflamatórias e ativação da cascata de coagulação durante as operações cardíacas. Provavelmente, a questão fundamental é a formação de trombina, que ao mesmo tempo, é um marcador da ativação da cascata de coagulação e um gatilho para as reações de base endotelial, incluindo o consumo de antitrombina e proteína C, ativação, agregação e adesão plaquetária, expressão de adesão de moléculas e de ativação e 
adesão de leucócitos. Portanto, não é surpreendente que uma intervenção limitada à modulação das superfícies de sangue parece insuficiente para produzir benefício clínico. Em metanálise realizada por BIANCARI et $\mathrm{al}^{97}$ sugere que o uso de Mini-CEC pode estar associado à redução de risco dos seguintes eventos: AVC no pós-operatório, sangramento e mortalidade.

Com o avanço tecnológico dos circuitos extracorpóreos, a cirurgia cardiovascular tornou-se muito mais segura, atualmente, entretanto o contato do sangue com meio ambiente e com superfícies artificiais, ainda produz reações inflamatórias que, na maioria dos pacientes, não têm tradução clínica. Porém, em outros, a repercussão desta reação pode ser catastrófica e um número crescente de pesquisas relacionam o tempo de CEC como um dos fatores responsáveis por estas complicações. Operações de reconstrução da aorta, nos seus vários segmentos, muitas vezes, são procedimentos demorados, pois depende da extensão do problema ou da destruição da aorta, e nele não existe margem para retrocesso, sob pena de um prolongamento da operação com consequências irreversíveis, em certos casos. Em centros de baixo volume os resultados são piores e os custos maiores ${ }^{57}$ e em centros de referência, com grande volume de pacientes graves, é imperativa a formação de um grupo especializado e com experiência na abordagem desse tipo de doença e de doentes.

5.1.8. Presença de Dor Torácica: $O$ aparecimento de dor torácica com um fator protetor, reduzindo o risco de mortalidade hospitalar em $73 \%(p=0,04)$ pode ser interpretado, e consubstanciado por plausibilidade epidemiológica e clínica, pelo fato de o tempo de espera para a realização da operação ser abreviado, independentemente do diâmetro da aorta, evitando-se assim a ruptura, dissecção ou tamponamento cardíaco. Devido à presença deste sintoma, o paciente procura atendimento médico e hospitalar com maior brevidade, o encaminhamento dignóstico é mais acurado e preciso, assim como a conduta clínica e, principalmente, cirúrgica são instituídas de modo eficiente, precoce e ordenado, permitindo, consequentemente, resultados mais favoráveis, inclusive com redução nas taxas de mortalidade hospitalar 


\subsection{Variáveis associadas ao desfecho clínico composto}

5.2.1. Sítio de Canulação Axilar: A escolha da canulação da artéria axilar direita para a instalação da circulação extracorpórea não apresentou associação independente com o desfecho clínico composto $(p=0,062)$, mesmo sendo considerada alternativa segura e viável, permitindo fluxo anterógrado pela luz verdadeira, garantindo fluxo arterial adequado, e minimizando o risco de embolia retrógrada. Esta via pode diminuir o risco de má-perfusão de orgãos viscerais e AVC, que estão associados com CEC periférica neste grupo de alto risco de pacientes, conforme publicado por KOKOTSAKIS et al ${ }^{98}$.

Segundo relato de SVENSSON et a $^{99}$, a utilização da canulação indireta da artéria axilar, através da interposição de um enxerto, reduz a incidência de AVC, sendo considerada um método para utilização em operações cardíacas complexas que necessitam de parada circulatória.

URBANSKI et $\mathrm{al}^{100}$, publicaram estudo incluindo 347 pacientes submetidos a cirurgias eletivas de arco, com parada circulatória, perfusão cerebral seletiva e resfriamento a $28^{\circ} \mathrm{C}$. A taxa de mortalidade em 30 dias foi de $0,9 \%$, o déficit neurológico permanente ou disfunção temporária ocorreu em $0,9 \%$ e 2,3\%, respectivamente. Paraplegia e insuficiência hepática não foram relatados, no entanto, isquemia mesentérica ocorreu em 1 paciente com estenose severa do tronco celíaco e da artéria mesentérica superior. A diálise temporária foi necessária em 5 pacientes. Todos eles foram submetidos à reconstrução do hemiarco e 4 apresentaram elevação nos níveis séricos de creatinina. Hipotermia sistêmica leve a moderada, é um método simples, seguro e eficaz de proteção dos órgãos, podendo ser recomendada como procedimento de rotina em cirurgia do arco aórtico com parada circulatória e perfusão cerebral seletiva.

A interpretação plausível aliada com a prática clínica dos achados de aumento de desfechos clínicos durante a fase hospitalar, observada nesta 
análise, é de que a canulação da artéria axilar direita é uma boa escolha para o sítio de canulação, como já exposto anteriormente. Porém, faz-se necessária a complementação do lado contralateral nos casos mais complexos de operações que envolvam o arco aórtico e com tempo de CEC prolongado. De qualquer modo, esta variável associa-se com maior chance de ocorrência de óbito, complicações neurológicas, disfunção ventricular e sangramento relevante, durante a fase hospitalar.

5.2.2.Uso de Antifibrinolítico: A utilização de antifibrinolíticos manteve associação independente com desfechos clínicos compostos durante a fase hospitalar $(\mathrm{RC}=3,2 ; \mathrm{p}=0,0006)$. CASATI et $\mathrm{al}^{101}$; relataram que pacientes tratados com ácido tranexâmico, em cirurgias eletivas da aorta torácica, apresentaram menor necessidade de transfusão sanguínea $(p=0,033)$, não havendo diferença estatisticamente significativa nas taxas de complicações trombóticas. Na série publicada por SOUZA et al $^{102}$; medidas adotadas, com o uso de antifibrinolíticos, hemodiluição normovolêmica e reposição total do perfusato, permitiram a redução da necessidade de hemotransfusão no pósoperatório de cirurgia cardíaca. Pacientes com tempo de CEC maior que 120 minutos tenderam a necessitar de hemotransfusão. A associação de cirurgia em pacientes idosos e tempo de CEC superior a 120 minutos resultou em maior utilização de sangue e hemoderivados no período pós-operatório. BROWN et al $^{103}$; realizaram meta-análise para comparar a aprotinina, ácido épsilon-aminocapróico e o ácido tranexâmico. Os resultados incluíram a perda de sangue total, transfusão de concentrado de hemácias, reexploração, mortalidade, AVC, infarto do miocárdio, insuficiência renal dialítica e disfunção renal. Todos os antifibrinolíticos foram eficazes na redução da perda de sangue e transfusão. Não houve riscos significativos ou benefícios para a mortalidade, AVC, infarto do miocárdio ou insuficiência renal. No entanto, a dose alta de aprotinina foi associada a um risco estatisticamente significativo aumentado de disfunção renal. $\mathrm{Na}$ análise atual, o uso de antifibrinolíticos esteve associado com maiores taxas de eventos relevantes, achado este que encontra correspondência na literatura, devendo ser valorizado na correta avaliação de risco de pacientes 
submetidos ao procedimento cirúrgico de aorta conforme descrito neste trabalho.

5.2.3. EuroScore: A variável EuroSCORE mostrou associação com risco aumentado de desfecho clínico composto na fase hospitalar $(R C=1,23$; $p=0,003$ ). O EuroSCORE ( European System for Cardiac Operative Risk Evaluation) é um método de calcular preditores de mortalidade operatória para pacientes submetidos a cirurgia cardíaca. Cerca de 20 mil pacientes consecutivos de 128 hospitais em 8 países europeus foram estudados. Cerca de 97 fatores de risco foram coletados em todos os pacientes. O resultado (sobrevivência ou óbito) foi relacionado com os fatores de risco pré-operatórios. Os fatores de riscos mais importantes, confiáveis e objetivos foram então utilizados para preparar um sistema de pontuação, com base em parte do banco de dados e testados e validados com base em outra parte. São analisados fatores relacionados ao paciente: idade, sexo, DPOC, arteriopatia extracardíaca, doença com disfunção neurológica, cirurgia cardíaca prévia, níveis de creatinina sérica, endocardite ativa e estado crítico pré-operatório. Fatores cardíaco-relacionados : angina instável, disfunção do VE, infarto miocárdico recente e hipertensão pulmonar. Fatores relacionados à operação: cirurgia de emergência, associação com revascularização do miocárdio, cirurgia na aorta torácica e CIV pós-infarto ${ }^{73,74}$.

Este modelo de risco, o EuroSCORE, mostrou associação clara com a ocorrência de desfechos clínicos compostos, nessa população estudada, devendo ser considerado importante ferramenta na determinação do risco desses pacientes, mesmo tendo sido elaborado em outros países, com serviços médicos e população distintos. Como todo escore de risco, o EuroSCORE também deve ser interpretado com ferramenta imperfeita, porém com utilidade com validade interna e externa na avaliação do risco destes pacientes. Os dados da presente análise são consistentes com informações disponíveis da literatura, fornecendo mais uma variável que permite identificar pacientes com risco aumentado de apresentarem taxas aumentadas de eventos clinicamente relevantes durante a fase hospitalar. 
5.2.4. Tempo de CEC: Como anteriormente discutido em relação à associação desta variável com óbito durante a fase hospitalar, este fator apresentou associação independente com desfecho clínico composto (RC: 1.01; $p=0,027$ ), ou seja, a cada minuto de tempo de CEC existe associação com aumento de $1 \%$ nas taxas dos eventos óbito, complicação neurológica, sangramento ou disfunção ventricular. Esta associação com desfecho clínico composto é consistente com a associação significante demonstrada com o desfecho óbito tardio, isoladamente.

5.2.5. Complicação Renal: A complicação renal emergiu como fator relevante associado independentemente com o desfecho clínico composto ( $R C=7,40 ; p=0,0132$ ). MC CHERTOW et al ${ }^{104}$; avaliaram 42.773 pacientes submetidos à cirurgia cardíaca valvar ou revascularização do miocárdio para determinar a associação entre insuficiência renal aguda e necessidade de diálise e mortalidade operatória. Insuficiência renal aguda ocorreu em $1,1 \%$ dos pacientes. A motalidade operatória foi de $63,7 \%$ nestes pacientes, comparados com 4,3\% nos pacientes sem esta complicação. Após o ajuste para fatores relacionados a comorbidades a RC foi de 27 ; IC $95 \% 22-34$. Foi concluído que IRA esteve associada independentemente com mortalidade precoce após cirurgia cardíaca e que intervenções para previnir ou melhorar o tratamento dessa condição são necessárias, devendo ser implementadas com brevidade dentro deste cenário clínico-cirúrgico.

THAKAR et $\mathrm{al}^{105}$; estudaram mais de 31 mil pacientes e relataram que disfunção renal não dialítica também foi um fator de risco independente de mortalidade após cirurgia cardíaca.

Segundo relato de KARKOUTI et al ${ }^{106}$; a IRA após cirurgia cardíaca apresenta alta prevalência e importância prognóstica e que terapias destinadas a atenuar a anemia pré-operatória, transfusão de hemácias e reexploração cirúrgica, podem oferecer proteção contra esta complicação.

A incidência de IRA após cirurgia cardíaca varia de $1 \%$ a $30 \%$, provavelmente devido à diferenças na prevalência de comorbidades ou qualidade assistencial do centro ${ }^{107}$. 
Cateterismo cardíaco realizado dentro de 5 dias antes da operação, taxa de filtração glomerular basal $<60 \mathrm{ml} / \mathrm{min}$, e tempo de CEC, são fatores de risco associados significativamente com IRA após cirurgia cardíaca, demonstrando que IRA após cirurgia cardíaca foi um preditor independente de mortalidade hospitalar ${ }^{108}$.

Por ser um importante preditor de risco para desfechos clínicos compostos, medidas profiláticas devem ser incorporadas para evitar a IRA no pós-operatório de cirugia cardíaca.

5.2.6. Complicação Pulmonar: A variável complicação respiratória apresentou associação independente com o desfecho clínico composto $(R C=3,65 ; p=0,0041)$.

Uma vez iniciada a CEC, a cessação da ventilação pulmonar resulta em colapso pulmonar, distensão alveolar insuficiente para ativar a produção de surfactante, situação que potencializa o colapso alveolar, mecânica alveolar anormal, retenção de secreções e atelectasias. A circulação pulmonar é interrompida, o sangue é exposto a condições de hipotermia, solução cardioplégica e superfícies estranhas ${ }^{109}$. O sequestro de sangue na microcirculação, isquemia pulmonar, lesão das paredes capilares, liberação de mediadores inflamatórios, aumento da permeabilidade capilar ${ }^{110}$, inundação do interstício pulmonar ${ }^{111}$, aumento do shunt intrapulmonar ${ }^{112}$, e formaçào de microtrombos ${ }^{113}$ podem ocorrer e todas essas causas aumentam anormalidades na troca gasosa, podendo levar ao fechamento de pequenas vias aéreas. Em uma tentativa de minimizar os distúrbios da microcirculação e para aumentar a perfusão tecidual e liberação de oxigênio, a anemia hemodilucional induzida é uma rotina da $\mathrm{CEC}^{114}$. Recentes pesquisas demonstram associação entre hematócrito baixo com necessidade de reintubação, insuficiência respiratória, permanência hospitalar aumentada ${ }^{114,115}$ e transfusão maciça de sangue, à síndrome do desconforto respiratório do adulto ${ }^{116}$. A melhora constante dos materiais de CEC e técnicas anestésicas e operatórias têm limitado a injúria pulmonar ${ }^{117}$. 
A literatura científica é contraditória em relação à modalidade de fisioterapia respiratória a ser utilizada no cenário da cirurgia cardíaca. $\mathrm{O}$ impacto da fisioterapia sobre a função pulmonar dos pacientes após a cirurgia cardíaca foi objeto de diversas investigações, com resultados ambíguos. Quando se compara a eficácia do treinamento muscular inspiratório, pré-operatório profilático, técnicas de respiração ${ }^{122}$, espirometria de incentivo 118,119,120,121, aplicação de pressões positivas inspiratória e expiratória através de máscara ${ }^{123,124}$ e primeiras mobilizações ${ }^{125}$, para prevenção de compliações pulmonares pós-operatórias, nenhum método foi considerado superior ao outro.

Complicacões pulmonares após cirurgias não-cardíacas são mais frequentes do que complicações cardíacas e estão associadas com prolongamento substancial do períodos de internação ${ }^{126}$.

Wynne e Botti ${ }^{127}$; descreveram a frequência de complicações pulmonares após cirurgia cardíaca: derrame pleural (25-95\%), atelectasia (17- 88\%), paralisia do nervo frênico (30-75\%), ventilação mecânica prolongada (6$58 \%$ ), disfunção diafragmática (2-54\%), pneumonia (4-20\%), paralisia diafragmática $(9 \%)$, embolia pulmonar $(0,4-3,2 \%)$, SDRA $(0,4-2 \%)$, aspiração $(1,9 \%)$ e pneumotórax $(1,4 \%)$.

Diante de tantas alterações respiratórias, durante a CEC e da incidência de complicações, descritas em vários centros, a variável complicação respiratória, da presente análise, encontra-se consistentemente associada com o desfecho clínico composto, de modo plausível epidemiologica e clinicamente, indicando que medidas preventivas, como também de intervenção clínica e fisioterápica são fundamentalmente recomendadas dentro do cenário em questão.

5.2.7. Operação de Cabrol: Como anteriormente discutido em relação à associação deste procedimento cirúrgico com óbito durante a fase hospitalar, esta variável apresentou associação com desfecho clínico composto, entretanto sem significância estatística $(p=0,052)$. Nominalmente, o $\mathrm{p}$ valor foi $>0,05$, entretanto, devido à proximidade da significância estatística este achado deve ser interpretado como tendência e que, 
provavelmente, com tamanho maior de amostra ou número maior de eventos clínicos, esta variável poderia mostrar significância estatística. Esta associação com desfecho clínico composto é consistente com a associação significante com óbito tardio.

5.2.8. Arritmias Graves : A presença de arritmias graves (bloqueio atrioventricular total, fibrilação ventricular e taquicardia ventricular) não mostrou associação independente com aumento na ocorrência do desfecho clínico composto $(p=0,060)$. Alguns pacientes possuem estenose aórtica associada ao aneurisma de aorta. MORITA et al ${ }^{128}$; relataram o uso de amiodarona para pacientes com $\mathrm{FV}$ refratária à lidocaína em pacientes com estenose aórtica severa e hipertrofia ventricular esquerda, durante o desmame da CEC, visando reduzir a ocorrência de arritmias graves.

Espasmo arterial coronário é complicação de risco alto durante a cirurgia cardíaca, causando dificuldade no desmame da CEC e perda de tecido miocárdico, com consequente disfunção ventricular esquerda e direita.

SANSONE et al $^{129}$; relatam o caso de um paciente submetido à substituição da aorta ascendente, que durante o desmame da CEC, apresentou vários episódios de taquiarritmias malignas. No estudo angiográfico pré-operatório apresentava apenas uma lesão de 50\% em ramo diagonal. A administração intravenosa de diltiazem permitiu melhora dos resultados desta grave complicação.

BHAN et al ${ }^{130}$; estudaram 82 pacientes operados para substituição da aorta ascendente por um enxerto protético para o tratamemnto de aneurisma da aorta ascendente ou dissecção. Houve 6 mortes precoces $(7,3 \%)$ e 8 pacientes necessitaram de reintervenção por sangramento excessivo. Dezoito pacientes apresentaram baixo débito cardíaco e arritmia pósoperatória em 26 pacientes. Durante o seguimento de 1 mês a 8 anos, ocorrearm 8 óbitos tardios, sendo 3 por insuficiência cardíaca congestiva, 3 por hemorragia cerebral e 2 apresentarm morte súbita. 
A presença de arritmias consideradas malignas, após correção da doença em aorta ascendente, pode estar associada à hipertrofia ventricular esquerda, lesão coronária significativa, proteção miocárdica inadequada, reimplante inadequado dos óstios coronários ou intensa calcificação do anel aórtico. Qualquer que seja causa, seu diagnóstico, nem sempre fácil, e o tratamento adequado e precoce, se impõem diante das consequências desastrosas, se houver persistência das arritmias.

\subsection{Variáveis associadas ao óbito no longo prazo}

5.3.1. Doença Arterial Obstrutiva Periférica prévia: No modelo de Regressão de Cox para óbito tardio, a DAOP emergiu como fator preditor independente $(R C=7,44 ; p=0,015)$. Quando ajustado para sexo e idade, o modelo conserva sua robustez $(R C=6,65 ; p=0,025)$. Como demonstrado por BENETT et $\mathrm{al}^{131}$; a DAOP é importante problema de saúde pública e também indicador de aterosclerose difusa em vários territórios vasculares, tais como, circulação cerebral e coronária. A DAOP encontra-se associada com morbidade e mortalidade consideráveis. Indivíduos com DAOP apresentam risco entre 4 e 5 vezes maior de óbito de causa cardiovascular comparados com aqueles sem DAOP entre 2 e 3 vezes maior de morte por todas as causas. LIBBY et $\mathrm{al}^{132}$;e BREVETTI et al ${ }^{133}$; relataram que a inflamação tem importante papel em todos estágios da doença vascular aterosclerótica. Certamente, a inflamação ocorre em resposta a uma variedade de estímulos e está associada a fatores de risco cardiovascular convencionais, como tabagismo, dislipidemia, HAS, diabetes mellitus e obesidade. Marcadores inflamatórios como Interleucina-6 (IL-6), Proteína Creativa e fibrinogênio têm sido avaliados em numerosos estudos e estão associados com o desenvolvimento, progressão e gravidade da DAOP. SABIK et al $^{134}$, demonstraram que a canulação da artéria axilar constituiu meio seguro e eficaz de proporcionar fluxo arterial anterógrado durante a CEC em pacientes com doença aterosclerótica ou aneurismática grave. Da mesma forma, KOKOTSAKIS et al ${ }^{98}$; concluíram que a canulação da artéria 
axilar é alternativa segura e viável, permitindo fluxo anterógrado pela luz verdadeira, garantindo fluxo arterial adequado, e minimizando o risco de embolia retrógrada. Esta via pode diminuir o risco de má-perfusão de orgãos viscerais e AVC, que está associado com a CEC periférica neste grupo de pacientes de alto risco. Com expectativa de vida menor, pacientes com DAOP merecem atenção especial durante o procedimento cirúrgico, pois são mais suscetíveis a efeitos adversos que podem comprometer os resultados hospitalares e no longo prazo.

5.3.2. Uso de estatina na alta hospitalar: Ainda que os benefícios comprovados do uso de estatinas sejam conhecidos, na redução confiável de eventos cardiovasculares, como por exemplo, óbito, infarto do miocárdio, acidente vascular cerebral e procedimentos de revascularização miocárdica, na presente análise, esta variável esteve associada com o aumento de mortalidade no longo prazo $(R C=4,99 ; p=0,029)$. A interpretação plausível, embasada epidemiológica e clinicamente, é que o uso de estatina na alta hospitalar talvez, seja um marcador de risco cardiovascular dos pacientes. Ou seja, pacientes considerados de alto risco de desenvolver eventos cardiovasculares têm indicação de utilização de estatina. Portanto, pacientes com infarto do miocárdio, acidente vascular cerebral, revascularização miocárdica, DAOP e diabéticos, têm indicação clara e definida para a prescrição de estatina, de acordo com diretrizes atuais de sociedades médicas. Deste modo, pelo fato de serem pacientes de alto risco, o uso de estatina era recomendado e não o fato de utilizarem estatina conduziu ao aumento de risco de mortalidade. Complementarmente, como descrito por VERMA et al $^{135}$; as estatinas podem ser capazes de modificar diretamente os processos que contribuem para a progressão da estenose aórtica em pacientes com VAB com funcionamento aparentemente normal. Primeiramente, em virtude da redução do LDL-colesterol, um importante fator de risco para progressão da doença em VAB. De modo adicional, as estatinas, por meio de ação anti-inflamatória, podem limitar a extensão de calcificação da válvula aórtica, fundamental para o desenvolvimento de estenose $\mathrm{VAB}$, como também, as estatinas podem limitar a dilatação da 
aorta, reduzindo a produção de MMPs, que são críticos para a remodelação aberrante da aorta visto em doença de VAB. Supõe-se que os pacientes com doença de $\mathrm{VAB}$ tenham endotélio anormal, volumes anormais da matriz vascular (aumento de MMPs) e respostas metabólicas anormais (síndrome metabólica), podendo-se esperar então, que as estatinas limitariam a deterioração do VAB e dilatação da aorta, melhorando a função endotelial restaurando o equilíbrio das MMPs e combatendo os efeitos adversos da síndrome metabólica. De fato, em estudos clínicos, a terapia com estatina tem demonstrado redução da estenose aórtica, diminuição na valva aórtica nativa de acúmulo de cálcio e retardo na degeneração da prótese biológica aórtica. Seria uma proposta atraente para sugerir que a intervenção precoce com um medicamento amplamente utilizado e relativamente seguro, poderia alterar a história natural da anormalidade cardíaca congênita, havendo revisões relatando que estatinas são seguras e custo-efetivas. Apesar dos múltiplos efeitos benéficos da terapia com estatina, há evidências sugerindo que uma grande porcentagem de pacientes cirúrgicos cardiotorácicos são tratados de maneira sub-ótima no que diz respeito às estatinas como demonstrado em revisão feita por PARASKEVAS et a ${ }^{136}$.

\subsubsection{Síndrome de Marfan: Em nossa casuística, apenas 7} pacientes $(2,7 \%)$ eram portadores de síndrome de Marfan, entretanto esta variável foi identificada como preditor independentemente associado com óbito no longo prazo ( $R C=6,8 ; p=0,052)$. Nominalmente, o valor de $p$ não atingiu significância estatística, entretanto, quando a análise multivariada é, ajustada para idade e sexo, a robustez do modelo é assegurada e esta variável apresenta significância estatística $(p=0,027)$. DETTER et $\mathrm{al}^{31}$ demonstraram que as reoperações e as recidivas foram consideravelmente mais frequentes em pacientes com síndrome de Marfan do que naqueles com etiologias não-fibrilínicas de doença aórtica. Múltiplas operações da aorta em diferentes segmentos são características desses pacientes.

Pacientes com síndrome de Marfan ou marfanóides têm características físicas e resultados semelhantes no pós-operatório, apesar de a reoperação ser mais frequente neste subgrupo (Marfan). A cirurgia antes da ocorrência 
da dissecção aórtica ou o reparo da valva mitral reduz o risco de reoperação ${ }^{32}$. YETMAN et al $^{137}$ observaram que complicações cardíacas são raras em pacientes jovens com síndrome de Marfan que estão recebendo tratamento médico e tendo acompanhamento clínico. A morte súbita ainda ocorre, e parece ser mais comum em pacientes com um ventrículo esquerdo dilatado, provavelmente devido a alterações da repolarização e arritmias ventriculares fatais. A expectativa de vida de pacientes com síndrome de Marfan submetidos a correção cirúrgica dos aneurismas da aorta, tem melhorado de modo consistente. Após o reparo inicial de um aneurisma da aorta ascendente, um número significativo de pacientes é submetido a cirurgias subsequentes em outros locais ao longo da aorta. Pacientes que apresentaram dissecção da aorta no momento da cirurgia, estiveram mais propensos a necessitar de reoperação, do que pacientes submetidos ao reparo devido a um aneurisma ${ }^{138}$. No estudo de GOTT et al $^{139}$, a mortalidade de 30 dias foi de $3,3 \%$, mas apenas de $1,5 \%$ quando o reparo foi eletivo. A taxa de sobrevivência foi de 93\% em 1 ano, 84\% em 5 anos, 75\% em 10 anos e 59\% em 20 anos. Complicações relacionadas à aorta torácica e arritmias foram as principais causas de morte. As reoperações e alterações em outros segmentos da aorta são esperados mais frequentemente em pacientes com síndrome de Marfan. É necessário haver um acompanhamento mais próximo destes pacientes, a fim de se realizar diagnóstico e intervenção precoce, se necessário, para que não haja interferência negativa no resultado de longo prazo.

5.3.4. Acidente Vascular Cerebral Prévio: O AVC prévio mostrou associação independente com óbito no longo prazo $(R C=7,03 ; p=0,015)$. ANYANWU et al ${ }^{140}$ conduziram análise retrospectiva envolvendo banco de dados prospectivo com 5.085 adultos submetidos a cirurgia cardíaca, de uma única instituição durante período de 6 anos. Após análise de regressão logística foi possível identificar 10 preditores pré-operatórios associados com AVC : sexo, idade, cirurgia de aorta, AVC prévio, estado pré-operatório crítico, função ventricular com comprometimento grave, diabetes mellitus, 
doença vascular periférica, angina instável e hipertensão pulmonar. PATLOLLA et al ${ }^{141}$ analisaram 1.078 pacientes com doença cerebrovascular sintomática (DCVs) e 16.765 sem DCVs. Foi relatado que pacientes com DCVs apresentam risco aumentado de AVC e declínio funcional, independentemente de outras variáveis, entretanto sem associação com óbito, durante período de seguimento longo. MCKHANN et al ${ }^{142}$ descreveram que o grau de doença vascular significativa, funcionalmente, do cérebro, antes da cirurgia deve ser parte essencial da avaliação préoperatória. Pela grande relevância desta variável, história clínica detalhada poderá estimar o risco do procedimento cirúrgico e, se considerado muito alto, dependendo da condição clínica do paciente, contraindicar a operação. Portanto, a presença desta variável associa-se com aumento de mortalidade no longo prazo, sendo a identificação simples e factível.

5.3.5. Sangramento aumentado nas primeiras 24 horas: A necessidade de revisão de hemostasia e transfusão sanguínea estiveram associadas ao aumento nas taxas de óbito no longo prazo $(R C=1,002 ; p=0,02)$. Embora estas variáveis (revisão de hemostasia e transfusão sanguínea) tenham ocorrido durante a fase hospitalar, a magnitude e relevância das mesmas promovem impacto no longo prazo, aumentando significativamente as taxas de mortalidade tardia. Ou seja, pacientes que apresentaram estas variáveis durante a fase hospitalar têm risco aumentado de mortalidade mesmo após a alta hospitalar. A prevenção de sangramento aumentado com a consequente necessidade de transfusão permitiria aumento na sobrevida média dos pacientes após procedimento cirúrgico de aorta como especificado no presente trabalho. MURPHY et $\mathrm{al}^{85}$, em recente publicação, observaram que a transfusão sanguínea em pacientes submetidos a cirurgia cardíaca estava fortemente associada com infecção e morbidade pósoperatória isquêmica, tempo de internação prolongado, aumento da mortalidade precoce e tardia e dos custos hospitalares. Adicionalmente, os custos foram substancialmente maiores em pacientes que necessitaram de re-exploração por sangramento, como bem demonstrado por ALSTRON et al ${ }^{86}$. Em estudo publicado com mais de 10 mil pacientes submetidos a 
cirurgia de revascularização do miocárdio isolada, $\mathrm{KOCH}$ et $\mathrm{al}^{143}$ demonstraram que a sobrevida dos pacientes transfundidos foi significativamente menor em comparação com pacientes não transfundidos.O risco de morte exibiu um padrão bifásico : uma fase de declínio de risco a partir do momento da operação até 6 meses de pósoperatório (risco precoce) e, em seguida, um impacto negativo final que continuou até cerca de 10 anos depois. A transfusão de concentrado de hemácias esteve associada à redução de risco ajustado de sobrevivência inicial $(0,34 \pm 0,02, p<0,0001)$ e tardio $(0,074 \pm 0,016, p<0,0001)$. $A$ transfusão sanguínea esteve associada a sequelas nefastas no longo prazo em cirurgias de revascularização miocárdica isolada. Portanto, cuidados e atenção devem ser direcionados para métodos de conservação de sangue e um uso mais criterioso do concentrado de hemácias.

SURGENOR et al ${ }^{144}$ realizaram estudo com mais de 9 mil pacientes submetidos a vários tipos de cirurgia cardíaca, em 8 centros no norte da Inglaterra. Os pacientes com maiores chances de serem transfundidos eram do sexo feminino, anêmicos, mais idosos, tinham menor altura e apresentavam outras comorbidades associadas. A sobrevivência foi significativamente diminuída para todos os pacientes que receberam 1 ou 2 unidades de concentrados de hemácias durante a internação para cirurgia cardíaca em comparação com aqueles que não foram transfundidos $(p<0,001)$. Após ajuste para as características do paciente e comorbidades, os pacientes expostos a 1 ou 2 unidades de concentrado de hemácias apresentaram risco de mortalidade $16 \%$ maior no longo prazo $(R C=1,16$; IC $95 \% 1,01-1,34 ; p=0,035)$.

Estratégias de manuseio de sangue são cruciais a fim de diminuir os riscos de uma transfusão sanguínea, além da relativa escassez e do custo dos derivados do sangue. MASUD et al $^{145}$ descreveram iniciativa de qualidade de colaboração para reduzir a utilização de sangue em cirurgias de revascularização do miocárdio (CRM) e na população de unidades de terapia intensiva cardiovascular (UTIC). Uma equipe multidisciplinar foi contratada em todos os níveis de atendimento ao paciente. Os autores 
observaram redução no uso de hemoderivados, no período pós-operatório, em pacientes submetidos à CRM $(14,3 \%$ de redução no primeiro ano; $30,6 \%$ ) e redução de $18,2 \%$ no uso de hemoderivados na UTIC, sem nenhum dano adicional para os pacientes, com tendência para melhores resultados.

Apesar de ser um procedimento com maior potencial de sangramento, as operações de aorta são realizadas com segurança, graças ao grande avanço dos materiais utilizados, à menor necessidade de hipotermia profunda, sabidamente deletéria ao equilíbrio hemostático, favorecendo a discrasia sanguínea. Os esforços em utilizar sangue e seus derivados devem ser realizados não apenas pela equipe cirúrgica, mas por toda a cadeia de profissionais que atende o paciente, pois sua criteriosa utilização trará maiores benefícios. 
6 LIMITAÇÕES 
As seguintes limitações potenciais podem ser consideradas em relação aos dados obtidos por meio da análise proposta em pacientes portadores de aneurisma de aorta ascendente e dissecção crônica tipo A de Stanford submetidos a procedimento cirúrgico:

1. Tamanho de amostra insuficiente: idealmente, o cálculo formal de tamanho de amostra deveria ser conduzido com base em premissas disponíveis na literatura científica; entretanto, são escassos os dados em relação ao tema em questão. A possibilidade de o tamanho de amostra ter sido insuficiente para detectar associações presentes não pode ser descartada, contudo, a chance de isso ter ocorrido desta é pequena, pois mais relevante que o número de pacientes é o número de eventos de interesse para a análise.

2. Poder estatístico insuficiente: se $o$ tamanho da amostra for insuficiente, o poder estatístico poderá ser reduzido, ou seja, a chance de demonstrar uma diferença quando esta estiver presente é, reduzida pelo número não ideal de pacientes. Conforme comentado, o poder estatístico insuficiente é mais relacionado ao número insuficiente de eventos de interesse e este não foi o caso na presente análise com base no número de eventos avaliados.

3. Imprecisão das estimativas de risco: algumas variáveis prognósticas apresentaram intervalos de confiança $95 \%$ relativamente amplos, o que nos conduz a interpretar com cautela a verdadeira dimensão do risco por meio das razões de chances. Portanto, a verdadeira estimativa de risco encontra-se entre os limites inferior e superior do intervalo de confiança e quanto mais amplo for este intervalo, maior o grau de imprecisão do achado.

4. Vieses e validade externa: os resultados obtidos no presente trabalho, não obrigatoriamente, poderiam ser extrapolados para outros hospitais, devido às características do centro, capacitação e 
treinamento do operador, risco e demografia dos pacientes incluídos e rotinas de tratamento instituídas. Certamente, estes resultados podem ser aplicados à instituição onde a pesquisa foi conduzida, mas dentro do grau de liberdade com cautela que a extrapolação de resultados pode permitir, não há limitações importantes e proibitivas para que estes dados não sejam utilizados por outras instituições em nosso país e, provavelmente, em outros países. Os seguintes vieses ou erros sistemáticos não podem ser excluídos da análise: centro único, experiência do operador, definições utilizadas, seleção de pacientes, fatores de confusão e diagnóstico padronizado das doenças de aorta avaliadas. Mais importante do que a presença do viés, que sempre estará presente em qualquer pesquisa, em maior ou menor extensão, é a magnitude do impacto do mesmo, alterando sistematicamente os resultados, trazendo perda ou limitação da validade das conclusões obtidas.

5. Efeito do acaso ("play of chance"): em qualquer pesquisa científica, a chance do acaso nunca pode ser afastada. A possibilidade do erro randômico ou chance do acaso, somente pode ser reduzida por meio do aumento da amostra, incluindo o maior número possível de pacientes para garantir a representatividade dos dados e, portanto, refletir mais fielmente a verdade da avaliação em questão. A análise atual envolve um número substancial de pacientes, sendo considerada uma das maiores séries em um estudo transversal com componente longitudinal em nosso país e, provavelmente considerando estudos conduzidos em outros países. 
7 CONCLUSÕES 
Este estudo transversal com componente longitudinal, delineado para identificar as variáveis prognósticas independentemente associadas com desfechos clinicamente relevantes, em pacientes com diagnóstico de aneurisma de aorta ascendente e dissecção crônica tipo A de Stanford, submetidos à intervenção cirúrgica, permite as seguintes conclusões:

1. Etnia negra, doença cerebrovascular, hemopericárcio, cirurgia de Cabrol, revascularização miocárdica cirúrgica associada, revisão de hemostasia e tempo de CEC associaram-se independentemente com risco aumentado de óbito hospitalar. A presença de dor torácica associou-se independentemente com risco reduzido de óbito hospitalar.

2. Uso de antifibrinolítico, complicação renal, complicação pulmonar, EuroScore e tempo de circulação extracorpórea associaram-se independentemente com risco aumentado de desfecho clínico composto hospitalar (óbito, sangramento, disfunção ventricular e complicações neurológicas).

3. Doença arterial obstrutiva periférica prévia, acidente vascular cerebral prévio, uso de estatina na alta hospitalar e sangramento aumentado nas primeiras 24 horas associaram-se independentemente com risco aumentado de óbito no longo prazo. 
8 ANEXOS 


\section{Anexo 1. Variáveis quantitativas utilizadas para análise estatística}

Idade, Peso, HAS-Sim PAS, HAS-Sim PAD, Fração de ejeção\%, Última creatinina, EuroSCORE, CEC ( $\mathrm{min})$, Clampeamento-anoxia (min), Hipotermia profunda + parada total tempo $(\mathrm{min})$, Hipotermia moderada + hipofluxo tempo (min), Hipotermia moderada + hipofluxo $(\mathrm{ml} / \mathrm{Kg})$, Sangramento nas primeiras 24hs (ml), Hemoderivados Se sim - Hemácias, Hemoderivados Se sim - Plaquetas, Hemoderivados Se sim - Plasma, Hemoderivados Se sim - Crioprecipitado, Dias de internação na UTI e Tempo após a cirurgia (dias).

\section{Anexo 2. Variáveis qualitativas utilizadas para análise estatística}

Sexo, Etnia, Diagnóstico, Método diagnóstico - Tomografia, Método diagnóstico - ECO, Método diagnóstico - Cateterismo, Método diagnóstico Ressonância magnética, Tabagismo, Diabetes, DAOP, HAS, IRC, IRCDiálise, AVC prévio, DPOC, Doença cerebrovascular, Síndrome Marfan, Choque, Síncope, Entubado, Derrame pericárdico, dor torácica, sintomas neurológicos, Complicações isquêmicas, cirurgia cardíaca prévia, Doença coronária, Fração de ejeção \% - Método, Eletiva, Emergência, EmergênciaSim Choque, Emergência-Sim Isquemia, Emergência-Sim Ruptura, Emergência-Sim dor, Sítio canulação aorta, Sítio canulação axilar, Sítio canulação carótida unilateral, Sítio canulação carótida bilateral, Sítio canulação femoral, Sítio canulação TBC, Temperatura, Proteção neurológica, Valva aórtica bicúspide, Valva aórtica bicúspide Grau de estenose, Insuficiência aórtica, Insuficiência aórtica, Grau de insuficiência, Hemopericárdio, Hemopericárdio Sim, tipo de operação Hemiarco, tipo de operação Bentall, tipo de operação Cabrol, tipo de operação Tubo supra coronariano, tipo de operação Tirone David, tipo de operação Yacoub, tipo de operação Stent aorta descendente, tipo de operação Reimplante de vasos da base bloco, tipo de operação Separados, tipo de cirurgia Aortoplastia, Cirurgia de coronárias, Cardioplegia, Valvular, Aórtica, Aórtica Se Troca, Mitral, Mitral Se Troca, Tricúspide, Tricúspide Se Troca, Revisão 
de hemostasia, Hemoderivados, Antifibrinolítico, Antifibrinolítico Ácido aminocapróico, Antifibrinolítico Ácido Tranexâmico, Antifibrinolítico Aprotinina, Neurológico, Neurológico Se Sim, Renal, Renal IRA (creat $>2,0$ $\mathrm{mg} / \mathrm{dL}$ ou $2 X>$ pré-op), Renal Diálise, Infecciosa, Infecciosa Mediastinite, Infecciosa BCP, Infecciosa Cateter, Infecciosa ITU, Infecciosa Endocardite, Infecciosa Toracotomia, Pulmonar, Pulmonar VM prolongada (> 48hs), Pulmonar TEP, Pulmonar SARA, Pulmonar Traqueostomia, Pulmonar Derrame Pleural, Vascular, Vascular Dissecção da aorta, Vascular Isquemia membro superior, Vascular Isquemia membro inferior, Vascular dissecção ilíaca-femural, Complicação Gastrointestinal, Complicação Gastrointestinal Sangramento TGI requerendo transfusão, Complicação Gastrointestinal Pancreatite com amilase/lípase anormais requerendo SNG, Complicação Gastrointestinal Colecistite necessitando de colecistectomia ou drenagem, Complicação Gastrointestinal Isquemia mesentérica necessitando de exploração, Arritmia, Arritmia FA/flutter, Arritmia TV, Arritmia FV, Arritmia BAVT - MP, Arritmia TPSV, Falência de múltiplos órgãos, Insuficiência cardíaca, Choque cardiogênico, Sindrome de máperfusão, Medicação alta AAS, Medicação alta Clopidogrel, Medicação alta IECA/BRA, Medicação alta Betabloqueador, Medicação alta Estatina, Medicação alta Anti-arrítmico, Medicação alta Diurético, Medicação alta Espironolactona, Medicação alta AAS, Medicação alta Clopidogrel, Medicação alta IECA/BRA, Medicação alta Betabloqueador, Medicação alta Estatina, Medicação alta Anti-arrítmico, Medicação alta Diurético, Medicação alta Espironolactona, Bolsa de Hemácias, Sangramento Clinicamente Relevante, Disfunção Ventricular, Intervenção Valvar e Arritmia Grave. 
9 REFERÊNCIAS BIBLIOGRÁFICAS 
1) Hunter $W$. The history of an aneurysm of the aorta with some remarks on aneurysms in general. Med Obs Enq. 1757;1:323-357.

2) The Gale Encyclopedia of Medicine. $3^{\text {rd }}$ ed. Stanford, Conn: Gale; 2008

3) Catholic Encyclopedia : René-Théophile-Hyacinthe Laennec.

4) L. F. Hiratzka, G. L. Bakris, J. A. Beckman, R. M. Bersin, V. F. Carr, D. E. Casey Jr, K. A. Eagle, L. K. Hermann, E. M. Isselbacher e col. 2010 ACCF /AHA /AATS /ACR /ASA /SCA /SCAI /SIR /STS /SVM Guidelines for the Diagnosis and Management of Patients With Thoracic Aortic Disease: A Report of the American College of Cardiology Foundation/American Heart Association Task Force on Practice Guidelines, American Association for Thoracic Surgery, American College of Radiology, American Stroke Association, Society of Cardiovascular Anesthesiologists, Society for Cardiovascular Angiography and Interventions, Society of Interventional Radiology, Society of Thoracic Surgeons, and Society for Vascular Medicine Circulation, April 6, 2010; 121(13): e266 - e369.

5) Bickerstaff LK, Pairolero PC, Hollier LH, Melton LJ, Van Peenen HJ,Cherry KJ, Joyce JW, Lie JT. Thoracic aortic aneurysms: apopulation-based study. Surgery. 1982;92:1103-1108.

6) Johansson G, Markström U, Swedenborg J. Ruptured thoracic aortic aneurysms: a study of incidence and mortality rates. $J$ Vasc Surg. 1995;21:985-988.

7) DeBakey ME, McCollum CH, Crawford ES, Morris GC Jr, Howell J, Noon GP, Lawrie G. Dissection and dissecting aneurysms of the aorta: twenty-year follow-up of five hundred twenty-seven patients treated surgically. Surgery. 1982;92:1118-1134. 
8) Trimarchi $S$, Nienaber CA, Rampoldi $V$, Myrmel T, Suzuki T, Mehta $\mathrm{RH}$, Bossone E, Cooper JV, Smith DE, Menicanti L, Frigiola A, Oh JK, Deeb MG, Isselbacher EM, Eagle KA. Contemporary results of surgery in acute type A aortic dissection: The International Registry of Acute Aortic Dissection experience. $J$ Thorac Cardiovasc Surg. 2005;129:112-122.)

9) Clouse WD, Hallett JW Jr, Schaff HV, Gayari MM, Ilstrup DM, MeltonLJ 3rd. Improved prognosis of thoracic aortic aneurysms: a population-based study. JAMA 1998;280:1926-1929.

10) Fann JI, Smith JA, Miller DC, Mitchell RS, Moore KA, Grunkemeier G,Stinson EB, Oyer PE, Reitz BA, Shumway NE. Surgical management of aortic dissection during a 30 -year period. Circulation 1995;92:II113-II121.

11) Paulo Sampaio Gutierrez. Doenças da Aorta Torácica : Alterações Morfológicas e o Papel das Metaloproteinases na Gênese dos Aneurismas e das Dissecções. Rev Soc Cardiol Estado de São Paulo. 2011;21(1):46-53.

12) Christian Olsson, MD; Stefan Thelin, MD, PhD; Elisabeth Ståhle, MD, PhD; Anders Ekbom, MD, PhD; Fredrik Granath, PhD.Increasing Prevalence and Improved Outcomes Reported in a Nationwide Population-Based Study of More Than 14000 Cases From 1987 to 2002. Circulation. 2006; 114: 2611-2618.

13) Hannuksela $M$, Lundqvist $S$, Carlberg $B$. Thoracic aorta--dilated or not? Scand Cardiovasc J. 2006;40(3):175-8.

14) De Bakey ME, Beall AC, Cooley DA, et al. Dissecting aneurysms of the aorta. Surg Clin North Am. 1966;46: 1045-1055. 
15) Daily PO, Trueblood HW, Stinson EB, et al. Management of acute aortic dissection. Am Thorac Surg. 1970;10: 237-247.

16) Lansmann SL, McCullough JN, Nguyen $\mathrm{KH}$, et al. Subtypes of acute aortic dissection. Ann Thorac Surg. 1999;67: 1975-1978.

17) Erbel R, Oelert $H$, Meyer J, et al. Effect of medical and surgical therapy on aortic dissection evaluated by transesophageal echocardiography: implication for prognosis and therapy (The European Cooperative Study Group on Echocardiography). Circulation. 1993;83: 1604-1615.

18) Richartz BM, Smith DE, Cooper JV, et al. New classification of aortic dissection with improved impact on prognosis. J Am Coll Cardiol. 2002;39: A 863.

19) Larson EW, Edwards WD. Risk factors for aortic dissection: a necropsy study of 161 cases. Am J Cardiol. 1984;53: 849-855.

20) von Kodolitsch $Y$, Aydin MA, Loose R, et al. Predictors of aneurysm formation after surgery of aortic coarctation. J Am Coll Cardiol. 2002;39: 617-624.

21) Erdheim, J (1929). Virchows Arch, 273,454.

22) Jacob MP. Extracellular matrix remodeling and matrix metalloproteinases in the vascular wall during aging and in pathological conditions. Biomed Pharmacother.2003;57(5-6):195202. 
23) Kobayashi N, Kostka G, Garbe JH, Keene DR, Bächinger HP, Hanisch FG, et al. A comparative analysis of the fibulin protein family: biochemical characterization, binding interactions, and tissue localization. J Biol Chem. 2007;282(16): 11805-16.

24) Tang BL.ADAMST : a novel family of extracellular matriz proteases. Int J Biochem Cell Biol.2001;33(1):33-44.

25) Pires LJT, Gutierrez PS. Quantificação morfométrica de Chlamydia pneumoniae e Mycoplasma pneumoniae em aneurismas de aorta abdominal humana. Rev Bras Cir Cardiovasc.2007;22(3):322-31.

26) Schlatmann TJ, Becker AE. Pathogenesis of dissecting aneurysm of aorta : comparative histopathologic study of significance of medial changes. Am J Cardiol. 1977; 39(1):21-6.

27) Schlatmann $T J$, Becker $A E$. Histologic changes in the normal aging aorta: implications for dissecting aortic aneurysm. Am J Cardiol. 1977;39(1):13-20.

28) Borges LF, Touat $Z$, Leclercq $A$, Zen AAH, Jondeau G, Franc $B$, et al. Tissue diffusion and retention of metalloproteinases in ascending aortic aneurysms and dissections. Hum Pathol. 2009;40(3):306-13.

29) Pires LJT, Gutierrez PS. Quantificação morfométrica de Chlamydia pneumoniae e Mycoplasma pneumoniae em aneurismas de aorta abdominal humana. Rev Bras Cir Cardiovasc. 2007;22(3):322-31.

30) De Figueriredo Borges LF, Jaldin RG, Dias RR, Stolf NA, Gutierrez PS. Collagen is reduced and disrupted in human aneurysms and dissections of ascending aorta. Hum Pathol. 2008;39(3):437-43. 
31) Christian Detter, Helmut Mair, Hanns-Georg Klein, Carmina Georgescu, Armin Welz and Bruno Reichart. Long-term prognosis of surgically-treated aortic aneurysms and dissections in patients with and without Marfan syndrome. Eur J Cardiothorac Surg 1998;13:416-423.

32) Lars G. Svensson MD, $P h D$, Eugene $H$. Blackstone MD, Jingyuan Feng MS, Daniel de Oliveira MD, A. Marc Gillinov MD, Maran Thamilarasan MD, Richard A. Grimm DO, Brian Griffin MD, Donald Hammer MD, Timothy Williams MD, Deborah H. Gladish BA, Bruce W. Lytle MD. Are Marfan Syndrome and Marfanoid Patients Distinguishable on Long-Term Follow-Up? The Annals of Thoracic Surgery Volume 83, Issue 3, March 2007, Pages 1067-1074.

33) Carlos Manoel de Castro Monteiro, Antonio Carlos de Camargo Carvalho, Victor Manuel Oporto Lopez. Síndrome de Marfan: como fazer o diagnóstico e a investigação familiar ? Rev Soc Cardiol Estado de São Paulo. 2011;21(1):60-6.

34) John A. Elefteriades and Emily A. Farkas. Thoracic Aortic Aneurysm : Clinically Pertinent Controversies and Uncertainties. J.Am.Coll.Cardiol 2010; 55;841-857.

35) Czerny M, Fleck T, Zimpfer D, Dworschak M, Hofmann W, Hutschala D, Dunkler D, Ehrlich M, Wolmer E, Grabenwoger M. Risk factors of mortality and permanent neurologic injury in patients undergoing ascending aortic and arch repair. J Thorac Cardiovasc Surg. 2003 Nov;126(5): 1296-301. 
36) Czerny $M$, Krähenbühl $E$, Reineke $D$, Sodeck G, Englberger L, Weber A, Schmidli J, Kadner A, Erdoes G, Schoenhoff F, Jenni H, Stader M, Carrel T. Mortality and neurologic injury after surgical repair with hypothermic circulatory arrest in acute and chronic proximal thoracic aortic pathology: effect of age on outcome. Circulation. 2011 Sep 27;124(13): 1407-13. Epub 2011 Aug 29.

37) Diehm N, Becker G, Katzen B, Benenati J, Kovacs M, Dick F. Statins are associated with decreased mortality in abdominal, but not in thoracic aortic aneurysm patients undergoing endovascular repair: propensity score-adjusted analysis. Vasa. 2008 Aug;37(3):241-9.

38) Albuquerque ELC, Braile DM, Palma JH, Gomes EKSRWJ, Buffolo E. Diretrizes para o tratamento cirúrgico das doenças da aorta da Sociedade Brasileira de Cirurgia Cardiovascular. Rev Bras Cir Cardiovasc. 2007;22(2):137-159.

39) Linda A. Pape e col. Aortic Diameter $>5.5 \mathrm{~cm}$ Is Not a Good Predictor of Type A Aortic Dissection Observations From the International Registry of Acute Aortic Dissection (IRAD).Circulation. 2007; 116:1120-1127.

40) Manoel J. Antunes. The EuroScore - 10 years later. Time to change ? Eur J Cardiothorac Surg 2010; 37:253-254.

41) Márcio Roberto Moraes de Carvalho e col. Aplicação do EuroScore na cirurgia de revascularização do miocárdio em hospitais públicos do Rio de Janeiro. Rev Bras Cir Cardiovasc 2010;25(2):209-217.

42) Mohr-Kahaly $S$, Erbel $R$, Kearney $P$, et al. Aortic intramural hematoma visualized by transesophageal echocardiography: findings and prognostic implications. J Am Coll Cardiol. 1994;23: 658-664. 
43) Nienaber CA, Sievers $\mathrm{HH}$. Intramural hematoma in acute aortic syndrome: more than one variant of dissection? Circulation. 2002;106: 284-285.

44) Hagan PG, Nienaber CA, Isselbacher EM, et al. The international registry of acute aortic dissection (IRAD): new insights into an old disease. JAMA. 2000;283: 897-903.

45) Bossone E, Rampoldi V, Nienaber CA, et al. Pulse deficits: a simple clinical sign as independent predictor of in-hospital complications and mortality in patients with type A aortic dissection. Am J Cardiol. 2002;89: 851-855.

46) Nesser HJ, Eggebrecht $H$, Baumgart $D$, et al. Emergency stent-graft placement for impending rupture of the descending thoracic aorta. $J$ Endovasc Ther. 2002;9: II-72-II-78.

47) Mehta RH, Suzuki T, Hagan PG, et al. Predicting death in patients with acute type A aortic dissection. Circulation. 2002;105: 200-206.

48) Dias RR, Mejia OAV, Fiorelli Al, Pomerantzeff PMA, Dias AR, Mady C, Stolf NAG. Análise do tratamento cirúrgico da raiz da aorta com tubo valvulado e com a preservação da valva aórtica. Rev Bras Cir Cardiovasc 2010; 25(4): 491-499.

49) Kouchoukos NT, Wareing TH, Murphy SF, Perrillo JB: Sixteen-year experience with aortic root replacement: results of 172 operations. Ann Surg 1991; 214:308.

50) Stowe CL, Baertlein MA, Wierman MD, et al: Surgical management of ascending and aortic arch disease: refined techniques with improved results. Ann Thorac Surg .1998; 66:388. 
51) Crawford ES, Svensson LG, Coselli JS, Safi HJ, Hess KR: Surgical treatment of aneurysm and/or dissection of the ascending aorta, transverse aortic arch, and ascending aorta and transverse aortic arch: factors influencing survival in 717 patients. $\boldsymbol{J}$ Thorac Cardiovasc Surg. 1989; 98:659.

52) Ergin MA, Spielvogel $D$, Apaydin A, et al: Surgical treatment of the dilated ascending aorta: when and how? Ann Thorac Surg 1999; 67:1834.

53) Cohn LH, Rizzo RJ, Adams DH, et al: Reduced mortality and morbidity for ascending aortic aneurysm resection regardless of cause. Ann Thorac Surg 1996; 62:463.

54) Bhan A, Choudhary SK, Saikia M, et al: Surgical experience with dissecting and nondissecting aneurysms of the ascending aorta. Indian Heart J 2001; 53:319.

55) Okita $Y$, Ando M, Minatoya $K$, et al: Early and long-term results of surgery for aneurysms of the thoracic aorta in septuagenarians and octogenarians. Eur J Cardiothorac Surg 1999; 16:317.

56) Gazoni LM, Speir AM, Kron IL, Fonner E, Crosby IK.Elective thoracic aortic aneurysm surgery: better outcomes from high-volume centers. $J$ Am Coll Surg. 2010 May;210(5):855-9, 859-60.

57) Kendra J Grubb MD, Irving L Kron MD. Sex and Gender in Thoracic Aortic Aneurysms and Dissection. Seminars in Thoracic and Cardiovascular Surgery. 2011;23(2):124-125. 
58) Christoph A. Nienaber, MD; Rossella Fattori, MD; Rajendra H. Mehta, MD, MS;Barbara M. Richartz, MD; Arturo Evangelista, MD; Michael Petzsch, MD; Jeanna V. Cooper, MS;James L. Januzzi, MD; Hüseyin Ince, MD; Udo Sechtem, MD; Eduardo Bossone, MD;Jianming Fang, MD; Dean E. Smith, PhD; Eric M. Isselbacher, MD; Linda A. Pape, MD;Kim A. Eagle, MD; on Behalf of the International Registry of Acute Aortic Dissection.Gender-Related Differences in Acute Aortic Dissection. Circulation 2004;109;3014-3021

59) Folke Lohse, MD, Nora Lang, MD, Wolfgang Schiller, MD, Wilhelm Roell, MD, Oliver Dewald, MD, Claus-Juergen Preusse, MD, Armin Welz, MD, and Christoph Schmitz, MD.Quality of Life after Replacement of the Ascending Aorta in Patients with True Aneurysms.Tex Heart Inst J. 2009; 36(2): 104-110.

60) A. L. Estrera, C. C. Miller, T. Kaneko, T. Y. Lee, J. C. Walkes, L. R. Kaiser, and H. J. Safi.Outcomes of Acute Type A Aortic Dissection After Previous Cardiac Surgery. Ann. Thorac. Surg. 2010; 89(5): $1467-1474$.

61) Keane M.G., Wingers S.E., Plappert T., et al. Bicuspid aortic valves are associated with aortic dilatation out of proportion to coexistent valvular lesion. Circulation. 2000;102(Suppl III):35-39.

62) Nistri S., Sorbo M.D., Martin M., et al. Aortic root dilatation in young men with normally functioning bicuspid aortic valve. Heart. 1999;82:19-22.

63) Bonderman D, Gharehbaghi-Schnell E, Wolleneck G. Mechanism underlying aortic dilatation in congenital aortic valve malformation. Circulation. 1999;16:2138-43 
64) Prenger K., Pieters F., Cheriex E., et al. Aortic dissection after aortic valve replacement: incidence and consequences for strategy. J Card Surg. 1994;9:495-499

65) Claudio F. Russo, MD, Simone Mazzetti, MD, Andrea Garatti, MD, Elena Ribera, MD, Angela Milazzo, MD, Giuseppe Bruschi, Marco Lanfranconi, MD, Tiziano Colombo, MD, Ettore Vitali, MD.Aortic complications after bicuspid aortic valve replacement: long-term results . Ann Thorac Surg 2002;74:S1773-S1776.

66) C. B. Park, K. L. Greason, R. M. Suri, H. I. Michelena, H. V. Schaff, and T. M. Sundt III.Should the proximal arch be routinely replaced in patients with bicuspid aortic valve disease and ascending aortic aneurysm?J. Thorac. Cardiovasc. Surg., September 1, 2011; 142(3): $602-607$.

67) C. B. Park, K. L. Greason, R. M. Suri, H. I. Michelena, H. V. Schaff, and T. M. Sundt III.Fate of nonreplaced sinuses of Valsalva in bicuspid aortic valve disease. J. Thorac. Cardiovasc. Surg., 2011; 142(2): 278 $-284$.

68) C. D. Etz, S. Zoli, R. Brenner, F. Roder, M. Bischoff, C. A. Bodian, G. DiLuozzo, and R. B. Griepp.When to Operate on the Bicuspid Valve Patient With a Modestly Dilated Ascending Aorta. Ann. Thorac. Surg., 2010; 90(6): 1884 - 1892.

69) Chaturvedi N. Ethnic differences in cardiovascular disease. Heart 2003;89:681-6.

70) Khawaja FJ, Bailey KR, Turner ST, Kardia SL, Mosley TH, Kullo IL. Association of novel risk factors with the ankle brachial index in African American and Non-Hispanic White populations. Mayo Clin Proc 2007;82:709-16. 
71) Hobbs SD, Wilmink $A B$, Bradbury AW. Ethnicity and peripheral arterial disease. Eur J Vasc Surg 2003;25:505-12.

72) Robbs JV. Atherosclerotic peripheral arterial disease in blacks- an established problem. S Afr Med J 1985;67:797-801.

73) Dardik A, Lin JW, Gordon TA, Williams GM, Perler BA. Results of elective abdominal aortic aneurysm repair in the 1990s: a population based analysis of 2335 cases. J Vasc Surg 1999;30:985-95.

74) Julius Alexander Ogeng'o \& Moses Madadi Obimbo \&Beda Otieno Olabu \& Simeon Ranket Sinkeet.Pattern of aneurysms among young black Kenyans. Indian J Thorac Cardiovasc Surg . 2011; 27(2):7075

75) Telly A Meadows, Deepak L Bhatt, Christopher P Cannon, Bernard J Gersh, Joachim Röther, Shinya Goto, Chiau-Suong Liau, Peter W F Wilson, Genevieve Salette, Sidney C Smith, Ph Gabriel Steg and for the REACH Registry Investigators. Ethnic Differences in Cardiovascular Risks and Mortality in Atherothrombotic Disease: Insights From the REduction of Atherothrombosis for Continued Health (REACH) Registry. Mayo Clin Proc 86(10):960-967 (2011).

76) Lane, Deirdre A; Lip, Gregory YH; Beevers, D Gareth.Ethnic differences in cardiovascular and all-cause mortality in Birmingham, England: The Birmingham Factory Screening Project. Journal of Hypertension . 23(7):1347-1353, July 2005.

77) Masanao Nakai, Mitsuomi Shimamoto, Fumio Yamasaki, Shoji Fujita, Hidetoshi Masumoto, Tetsu Yamada, Daisuke Nakajima, Masatsugu Hamaji.Surgical treatment of thoracic aortic aneurysm in patients with concomitant coronary artery disease. The Japanese Journal of Thoracic and Cardiovascular Surgery. 2005;53(2):84-87. 
78) Toshihiko Ueda, Hideyuki Shimizu, Hankei Shin, Ichiro Kashima, Koji Tsutsumi, Yoshimi lino, Ryohei Yozu, Shiaki Kawada.Detection and management of concomitant coronary artery disease in patients undergoing thoracic aortic surgery. The Japanese Journal of Thoracic and Cardiovascular Surgery. 2001; 49(7):424-430.

79) Zhi-Yong Wu, Zhi-Fu Mao, Shang-Zhi Gao, Bang-Chang Cheng, ZhiWei Wang, Jie Huang. The clinical study on the surgical treatment of thoracic aortic aneurysm associated with coronary artery disease.Zhonghua wai ke za zhi Chinese journal of surgery. 2006;44(14):943-945.

80) Carlos Romério Costa Ferro; Dinaldo Cavalcanti de Oliveira; Fábio de Freitas Guimarães Guerra; Alexandre Jorge de Lucena; Fabiana Piech Nunes; Sergio Tranchesi Ortiz; Enilton Sergio Tabosa Egito; Luis Carlos Bento de Sousa; Adib Domingos Jatene; Leopoldo Soares Piegas.Prevalence of and risk factors for combined coronary artery disease and aortic aneurysm. Arq. Bras. Cardiol. 2007;88(1).

81) Kitamura $T$, Kigawa I, Fukuda $S$, Miyairi $T$, Takamoto $S$. Long term results with the Cabrol aortic root replacement. Int Heart J. 2011;52(4):229-32.

82) Sandro Gelsomino, Giorgio Morocutti, Romeo Frassani, Gianluca Masullo, Paolo Da Col, Leonardo Spedicato and Ugolino Livi. Aneurysms and Dissections Root Replacement for Ascending AorticLong-term Results of Bentall Composite Aortic. Chest 2003;124;984-98.

83) Davies RR, Kaple RK, Mandapati D, Gallo A, Botta DM Jr, Elefteriades JA, Coady MA.Natural history of ascending aortic aneurysms in the setting of an unreplaced bicuspid aortic valve. Ann Thorac Surg. 2007 ;83(4):1338-44. 
84) Ioannis E. Kallikazaros, MD; Costas P. Tsioufis, MD; Christodoulos I. Stefanadis, MD; Christos E. Pitsavos, MD; Pavlos K. Toutouzas, MD. Closed Relation Between Carotid and Ascending Aortic Atherosclerosis in Cardiac Patients. Circulation. 2000;102:I/I-263-III268

85) Gavin J. Murphy, Barnaby C. Reeves, Chris A. Rogers, Syed I.A. Rizvi, Lucy Culliford, Gianni D. Angelini.Increased Mortality, Postoperative Morbidity, and Cost After Red Blood Cell Transfusion in Patients Having Cardiac Surgery. Circulation. 2007; 116: 2544-2552.

86) U. Alström, L.-Å. Levin, E. Ståhle, R. Svedjeholm, Ö. Friberg.Cost analysis of re-exploration for bleeding after coronary artery bypass graft surgery. Br. J. Anaesth. (2011) doi: 10.1093/bja/aer391.

87) B Daan Westenbrink, Lennaert Kleijn, Rudolf A de Boer, Jan G Tijssen, Wayne J Warnica, Richard Baillot, Jean L Rouleau, Wiek H van Gilst.Sustained postoperative anaemia Is associated with an impaired outcome after coronary artery bypass graft surgery: insights from the IMAGINE trial. Heart 2011;97:1590-1596 doi:10.1136/heartjnl-2011-300118.

88) Albert H.M. van Straten, Margreet W.A. Bekker, Mohamed A. Soliman Hamad, André A.J. van Zundert, Elisabeth J. Martens, Jacques P.A.M. Schönberger and Andre M. de Wolf.Transfusion of red blood cells: the impact on short-term and long-term survival after coronary artery bypass grafting, a ten-year follow-up. Interact CardioVasc Thorac Surg 2010;10:37-42.

89) Lars G. Svensson, Jianping Sun, Edward Nadolny and Wendy A. Kimmel. Prospective evaluation of minimal blood use for ascending aorta and aortic arch operations Ann Thorac Surg 1995;59:15011508. 
90) K. Shibata, S. Takamoto, Y. Kotsuka, and H. Sato.Effectiveness of combined blood conservation measures in thoracic aortic operations with deep hypothermic circulatory arrest. Ann. Thorac. Surg., March 1, 2002; 73(3): 739 - 743.

91) EM Isselbacher, JE Cigarroa and KA Eagle.Cardiac tamponade complicating proximal aortic dissection. Is pericardiocentesis harmful? Circulation 1994, 90:2375-2378.

92) Motohiko Goda, MD, Kiyotaka Imoto, MD, Shinichi Suzuki, MD, Keiji Uchida, MD, Hiromasa Yanagi, MD, Shota Yasuda, MD, Munetaka Masuda, MD. Risk Analysis for Hospital Mortality in Patients With Acute Type A Aortic Dissection. Ann Thorac Surg 2010;90:12461250.

93) Rajendra H. Mehta, Toru Suzuki, Peter G. Hagan, Eduardo Bossone, Dan Gilon,Armstrong, Christoph A. Nienaber and Kim A. Eagle,Alfredo Llovet, Luis C. Maroto, Jeanna V. Cooper, Dean E. Smith, William F. Armstrong, MD; Christoph A. Nienaber, MD; Kim A. Eagle, MD; on Behalf of the International Registry of Acute Aortic Dissection (IRAD) Investigators. Predicting Death in Patients With Acute Type A Aortic Dissection. Circulation 2002, 105:200-206.

94) Hessel E Ai I I , Edmunds L Hi J r . Extracorporeal Circulation: Perfusion Systems.In: Cohn LH, Edmunds LH Jr, eds. Cardiac Surgery in the Adult. 2003:317-338.

95) A. Parolari, F. Alamanni, M. Naliato, R. Spirito, V. FranzeÁ, G. Pompilio,M. Agrifoglio, P. Biglioli. Adult cardiac surgery outcomes: role of the pump type. European Journal of Cardio-thoracic Surgery 18 (2000) $575 \pm 582$. 
96) Marco Ranucci, MD, Anna Balduini, AHA, Antonio Ditta, CCP, Alessandra Boncilli, CCP, and Simonetta Brozzi, CCP.A Systematic Review of Biocompatible Cardiopulmonary Bypass Circuits and Clinical Outcome. Ann Thorac Surg 2009;87:1311-9.

97) $F$ Biancari, $R$ Rimpiläinen. Meta-analysis of randomised trials comparing the effectiveness of miniaturised versus conventional cardiopulmonary bypass in adult cardiac surgery. Heart 2009;95:964969.

98) John Kokotsakis, MD, PhD, George Lazopoulos, MD, PhD, Michael Milonakis, MD, George Athanasiadis, MD, Konstantina Romana, MD, Elian Skouteli, MD, and Elias Bastounis, MD, PhD.Right Axillary Artery Cannulation for Surgical Management of the Hostile Ascending Aorta. Tex Heart Inst J. 2005; 32(2): 189-193.

99) L. G. Svensson, E. H. Blackstone, J. Rajeswaran, J. F. Sabik III, B. W. Lytle, G. Gonzalez-Stawinski, P. Varvitsiotis, M. K. Banbury, P. M. McCarthy, G. B. Pettersson, et al.Does the Arterial Cannulation Site for Circulatory Arrest Influence Stroke Risk?Ann. Thorac. Surg., October 1, 2004; 78(4): 1274 - 1284.

100) P. P. Urbanski, A. Lenos, P. Bougioukakis, I. Neophytou, M. Zacher, and A. Diegeler.Mild-to-moderate hypothermia in aortic arch surgery using circulatory arrest: a change of paradigm?Eur $\boldsymbol{J}$ Cardiothorac Surg, January 1, 2012; 41(1): 185 - 191.

101) V. Casati, L. Sandrelli, G. Speziali, G. Calori, M. A. Grasso, and S. Spagnolo.Hemostatic effects of tranexamic acid in elective thoracic aortic surgery: A prospective, randomized, double-blind, placebocontrolled studyJ. Thorac. Cardiovasc. Surg., June 1, 2002; 123(6): $1084-1091$. 
102) Souza HJ, Moitinho RF. Estratégias para redução do uso de hemoderivados em cirurgia cardiovascular. Rev Bras Cir Cardiovasc. 2008;23(1):53-9.

103) Brown JR, Birkmeyer NJ, O'Connor GT. Meta-analysis comparing the effectiveness and adverse outcomes of antifibrinolytic agents in cardiac surgery. Circulation. 2007;115(22):2801-13.

104) Glenn M Chertow, Elliott $M$ Levy, Elliott $M$ Levy, Karl E Hammermeister, Frederick Grover, Jennifer Daley. Independent Association between Acute Renal Failure and Mortality following Cardiac Surgery. The American Journal of Medicine Volume 104, Issue 4 , Pages 343-348, April 1998.

105) Charuhasv Thakar, Sarah Worley, Susana Arrigain, Jean-Pierre Yarred and Emil P Paganin. Influence of renal dysfunction on mortality after cardiac surgery: Modifying effect of preoperative renal function.Kidney International (2005) 67, 1112-1119.

106) Keyvan Karkouti,Duminda N. Wijeysundera, Terrence M. Yau, Jeannie L. Callum,Davy C. Cheng,Mark Crowther,Jean-Yves Dupuis, Stephen E. Fremes, Blaine Kent, Claude Laflamme, Andre Lamy, JeanFrancois Legare, C. David Mazer, Stuart A. McCluskey, Fraser D. Rubens, Corey Sawchuk, W. Scott Beattie. Acute Kidney Injury After Cardiac Surgery.Focus on Modifiable Risk Factors. Circulation. 2009; 119: 495-502.

107) Bove $T$, Calabro MG, Landoni $G$, et al. The incidence and risk of acute renal failure after cardiac surgery. J Cardiothorac Vasc Anesthe 2004;18:442-445. 
108) Danny Del Duca, Sameena lqbal, Elham Rahme,Peter Goldberg, Benoit de Varennes.Renal Failure After Cardiac Surgery: Timing of Cardiac Catheterization and Other Perioperative Risk Factors. Ann Thorac Surg 2007;84:1264-1271.

109) Weiland AP, Walker WE. Physiologic principles and clinical sequelae of cardiopulmonary bypass. Heart Lung. 1986;15:34-39.

110) Utley JR. Pathophysiology of cardiopulmonary bypass: a current review. Aust J Card Thorac Surg. 1992;1:46-52.

111) Martin W, Carter R, Tweddel A, et al. Respiratory dysfunction and white cell activation following cardiopulmonary bypass: comparison of membrane and bubble oxygenators. Eur $\boldsymbol{J}$ Cardiothorac Surg. 1996;10:774-783

112) Royston D, Minty BD, Higenbottam TW, Wallwork J, Jones GJ. The effect of surgery with cardiopulmonary bypass on alveolar-capillary barrier function in human beings. Ann Thorac Surg. 1985;40:139-143

113) Reeve WG, Ingram SM, Smith DC. Respiratory function after cardiopulmonary bypass: a comparison of bubble and membrane oxygenators. J Cardiothorac Vasc Anesth. 1994;8:502-508

114) Habib RH, Zacharias A, Schwann TA, Riordan CJ, Durham SJ, Shah A. Adverse effects of low hematocrit during cardiopulmonary bypass in the adult: should current practice be changed? J Thorac Cardiovasc Surg. 2003;125:1438-1450.

115) Utley JR, Wilde EF, Leyland SA, Morgan MS, Johnson HD. Intraoperative blood transfusion is a major risk factor for coronary artery bypass grafting in women. Ann Thorac Surg. 1995;60:570-575 
116) De Feo $M$, Renzulli $A$, Ismeno $G$, et al. Variables predicting adverse outcome in patients with deep sternal wound infection. Ann Thorac Surg. 2001;71:324-331

117) Milot J, Perron J, Lacasse $Y$, Letourneau L, Cartier PC, Maltais F. Incidence and predictors of ARDS after cardiac surgery. Chest. 2001;119:884-888

118) Stiller $K$, Montarello J, Wallace $M$, et al. Are breathing and coughing exercises necessary after coronary artery surgery? Physiother Theory Prac. 1994;10:143-152.

119) O'Donohue WJ Jr. Prevention and treatment of postoperative atelectasis: can it and will it be adequately studied? Chest. 1985;87:1-2.

120) Weiner $P$, Zeidan $F$, Zamir $D$, et al. Prophylactic inspiratory muscle training in patients undergoing coronary artery bypass graft. World $\mathrm{J}$ Surg. 1998;22:427-431.

121) Lederer $D H$, Van-de-Water JM, Indech RB. Which deep breathing device should the postoperative patient use? Chest. 1980;77:610-613

122) Westerdahl E, Lindmark B, Almgren S, Tenling A. Chest physiotherapy after coronary artery bypass graft surgery: a comparison of three different deep breathing techniques. J Rehabil Med. 2001;33:79-84.

123) Crowe JM, Bradley CA. The effectiveness of incentive spirometry with physical therapy for high-risk patients after coronary artery bypass surgery. Phys Ther. 1997;77:260-268. 
124) Rau JL, Thomas $L$, Haynes RL. The effect of method of administering incentive spirometry on postoperative pulmonary complications in coronary artery bypass patients. Respir Care. 1988;33:771-778.

125) Johnson D, Kelm C, Thomson D, Burbridge B, Mayers I. The effect of physical therapy on respiratory complications following cardiac valve surgery. Chest. 1996;109:638-644.

126) Lawrence VA, Hilsenbeck SG, Mulrow CD, Dhanda R, Sapp J, Page $\mathrm{CP}$. Incidence and hospital stay for cardiac and pulmonary complications after abdominal surgery. J Gen Intern Med 1995;10:671-678.Smetana GW. Preoperative pulmonary evaluation. N Engl J Med 1999;340:937-944.

127) Rochelle Wynne and Mari Botti.Posoperative Pulmonary Dysfunction in Adults After Cardiac Surgery With Cardiopulmonary Bypass: Clinical significance and implications for Practice. AMERICAN JOURNAL OF CRITICAL CARE, September 2004, Volume 13, No. 5.

128) Morita $Y$, Mizuno J, Yoshimura $T$, Morita S.Efficacy of amiodarone on refractory ventricular fibrillation resistant to lidocaine and cardioversion during weaning from cardiopulmonary bypass in aortic valve replacement for severe aortic stenosis with left ventricular hypertrophy. J Anesth. 2010 Oct;24(5):761-4. Epub 2010 Jul 28

129) Sansone F, Trichiolo S, Ceresa F, Attisani M, Berardo A, Rinaldi M.Recurrent ventricular fibrillation due to coronary artery spasm immediately after ascending aorta replacement.J Cardiovasc Med (Hagerstown). 2009 Oct;10(10):810-2

130) Bhan A, Choudhary SK, Saikia $M$, Shama R, Venugopal $P$. Surgical experience with dissecting and nondissecting aneurysms of the ascending aorta. Indian Heart J. 2001 May-Jun;53(3):319-22. 
131) PC Bennett, S.Silverman, P.S.Gill and G.Y.H.Lip. QJM (2009) 102 (1): 3-16. doi: 10.1093/qjmed/hcn140

132) Libby $P$,Ridker PM,Maseri $A$. Inflammation and atherosclerosis. Circulation 2002;105:1135-43.

133) Brevetti G, Schiano V, Sirico G, Giugliano G, Laurenzano E, Chiariello M. Metabolic syndrome in peripheral arterial disease: relationship with severity of peripheral circulatory insufficiency, inflammatory status, and cardiovascular comorbidity. J Vasc Surg 2006;44:101-7

134) Joseph F. Sabik MD, Bruce W. Lytle MD, Patrick M. McCarthy MD, Delos M. Cosgrove MD.Axillary artery: An alternative site of arterial cannulation for patients with extensive aortic and peripheral vascular disease. J THORAC CARDIOVASC SURG 1995;109:885-91.

135) Subodh Verma, Paul E. Szmitko, Paul W. M. Fedak, Lee Errett, David A. Latter and Tirone E. David.Can statin therapy alter the natural history of bicuspid aortic valves?Am J Physiol Heart Circ Physiol 288:H2547-H2549, 2005.

136) Kosmas I. Paraskevas.Applications of statins in cardiothoracic surgery: more than just lipid-lowering.Eur J Cardiothorac Surg 2008;33:377-390.

137) Anji T Yetman MD, Renee A Bornemeier MD, Brian W McCrindle MD.Long-term outcome in patients with Marfan syndrome: is aortic dissection the only cause of sudden death? Journal of the American College of Cardiology Volume 41, Issue 2, 15 January 2003, Pages 329-332. 
138) Rebecca Finkbohner, MS; Dennis Johnston, PhD; E. Stanley Crawford, MD; Joseph Coselli, MD; Dianna M. Milewicz, MD, PhD Marfan Syndrome. Long-term Survival and Complications After Aortic Aneurysm Repair. Circulation. 1995; 91: 728-733.

139) Gott VL, Greene PS, Alejo DE, et al: Replacement of the aortic root in patients with Marfan's syndrome. N Engl J Med 1999; 340:1307.

140) Ani C. Anyanwu, MD, FRCS, Farzan Filsoufi, MD, Sacha P. Salzberg, MD, David J. Bronster, MD, David H. Adams, MD.Epidemiology of stroke after cardiac surgery in the current era.J Thorac Cardiovasc Surg 2007;134:1121-1127.

141) Vishnu Patlolla, MD, MPH, Vanajakshi Mogulla, MD, David DeNofrio, MD, Marvin A. Konstam, MD and Rajan Krishnamani, MD.Outcomes in Patients With Symptomatic Cerebrovascular Disease Undergoing Heart Transplantation.J Am Coll Cardiol, 2011; 58:1036-1041, doi:10.1016/j.jacc.2011.04.038.

142) Guy M. McKhann, MD; Maura A. Grega, RN, MSN; Louis M. Borowicz Jr, MS;William A. Baumgartner, MD; Ola A. Selnes, PhD.Stroke and Encephalopathy After Cardiac Surgery An Update. Stroke. 2006;37:562-571.

143) Colleen Gorman Koch, MD, MS, Liang Li, PhD, Andra I. Duncan, MD, Tomislav Mihaljevic, MD, Floyd D. Loop, MD, Norman J. Starr, MD, Eugene H. Blackstone, MD. Transfusion in Coronary Artery Bypass Grafting is Associated with Reduced Long-Term Survival. Ann Thorac Surg 2006;81:1650-1657. 
144) Stephen D. Surgenor, Robert S. Kramer, Elaine M. Olmstead, Cathy S. Ross, Frank W. Sellke, Donald S. Likosky, Charles A. S. Marrin, Robert E. Helm Jr, Bruce J. Leavitt, Jeremy R. Morton, David C. Charlesworth, Robert A. Clough, Felix Hernandez, Carmine Frumiento, Arnold Benak, Christian DioData, Gerald T. O'Connor and For the Northern New England Cardiovascular Disease Study Group.The Association of Perioperative Red Blood Cell Transfusions and Decreased Long-Term Survival After Cardiac Surgery. ANESTHESIA \& ANALGESIA.June 2009 vol. 108 no. 6 1741-1746.

145) Faisal Masud, Karin Larson-Pollock, Christopher Leveque, Daynene Vykoukal.Establishing a Culture of Blood Management Through Education.A Quality Initiative Study of Postoperative Blood Use in CABG Patients at Methodist DeBakey Heart \& Vascular Center.American Journal of Medical Quality September/October 2011 vol. 26 no. 5 349-356. 